\title{
Synthesis of 0-1-0-6 Substituted Positional Isomers of D-Glucose- Thioether Ligands and Their Ruthenium Polypyridyl Conjugates
}

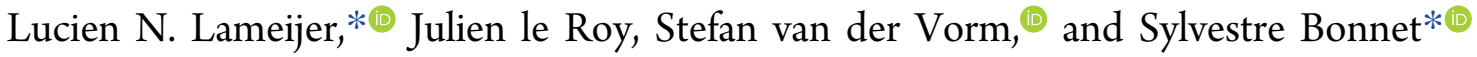 \\ Leiden Institute of Chemistry, Leiden University, Gorlaeus Laboratories, P.O. Box 9502, Leiden 2300 RA, The Netherlands
}

\section{Supporting Information}

ABSTRACT: A library of positional isomers of D-glucose $(\mathrm{O}-1-\mathrm{O}$ 6) as ligands and their 11 light-active ruthenium conjugates has been synthesized. A protecting group strategy without the necessity of using palladium on carbon for the modification for the $2-\mathrm{O}$ and 4-O position allows for the incorporation of sulfur donor atoms as ligands for transition metal complexes.

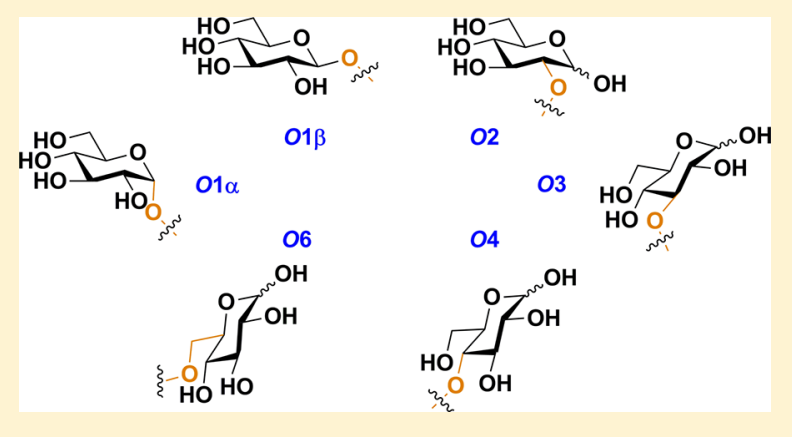

\section{INTRODUCTION}

Carbohydrates are a class of biomolecules ubiquitously present in nature, comprising monosaccharides, oligosaccharides, and polysaccharides, of which monosaccharides cannot be hydrolyzed further into smaller units. These molecules are recognized as important building blocks in the cell wall of bacteria, ${ }^{1,2}$ in plants, ${ }^{3}$ in the exoskeleton of insects, ${ }^{4}$ in cell recognition processes, ${ }^{5}$ and in the backbone of RNA and DNA ${ }^{6}$ and are associated with many different physiological and disease-related processes. $^{7,8}$ Among them, D-glucose is the most well-known monosaccharide as it serves as the primary source of chemical energy in eukaryotic cells for the production of ATP. 9 Otto Warburg found that cancer cells have an increased glycolysis rate for the production of ATP compared to normal cells. ${ }^{10}$ As a consequence, glucose transporters (GLUTs) 1 and 3 are overexpressed in cancer cells. ${ }^{11}$ In recent years, there has been a growing interest in using this effect to selectively deliver molecules of interest to cancer cells. In the field of diagnostic imaging, the well-known radiotracer 2 -deoxy-2-[ $\left.{ }^{18} \mathrm{~F}\right]$ fluoroglucose (2-FDG) selectively accumulates in cancer cells since its metabolic breakdown is hampered by the replacement of a hydroxyl group on the 2-position of D-glucose by fluoride. ${ }^{12}$ This clinically approved agent allows PET imaging of tumors anywhere in the whole body. In the field of medicinal chemistry, glufosfamide has shown some success as a safer alternative for ifosfamide, an alkylating agent used in cancer treatment. The therapeutic efficiency of glufosfamide is thought to be higher due to its increased water solubility and preferred uptake in malignant cells versus normal cells. ${ }^{13}$ Recently, Palay et al. have demonstrated that a series of glucose conjugates of platinum-based medicines are taken up via GLUT1. ${ }^{14,15}$ This result is in contrast to the observation of Schubiger, who found that none of their radiodiagnostic glycoconjugates based on ${ }^{99 \mathrm{~m}} \mathrm{Tc}$ were taken up via glucose transporters. ${ }^{16}$
For ruthenium(II) polypyridyl-based drugs, this effect has not been thoroughly investigated. Our group has been involved in a research program aimed at targeting ruthenium-based lightactivated anticancer prodrugs to GLUT transporters by glucose conjugation. $^{17,18}$ These photoactivated chemotherapeutic prodrugs are typically protected from binding to biomolecules in the dark by thioether ligands, which under visible light irradiation are photosubstituted by water, thereby activating the prodrug. ${ }^{19-21}$ En route to functionalizing such complexes with glucose, it came out that all available synthetic routes toward a series of positional isomers of glucose were incompatible with the presence of thioether groups, which deactivate $\mathrm{Pd} / \mathrm{C}$ catalysts used to deprotect benzyl protecting groups. For that reason, we developed and report here on a series of new synthetic routes toward all positional isomers of glucose that are compatible with the presence of sulfur-based ligands. ${ }^{22}$ As traces of palladium also often interfere with the biological activity of pharmaceuticals, $^{23}$ these new routes do not make use of palladium catalysts. PEGylation of all positional isomers was also realized to vary the spacer between the thioether ligands and the glucose moiety. The coordination of the thioether-glucose ligands to known photoactive ruthenium(II) polypyridyl precursors afford 11 ruthenium-glucose conjugates (Figure 1) as a demonstration that such molecules can be obtained on a synthetical useful scale. Recent publications describe the more photophysical and/or biological properties of these type of complexes. $^{17,18}$

\section{RESULTS AND DISCUSSION}

Five hydroxyl groups are available for modification in D-glucose, of which the 1-O position is modified via chemical glycosylation. ${ }^{24}$ Recently, Patra et al. have demonstrated that

Received: May 27, 2018

Published: October 1, 2018 


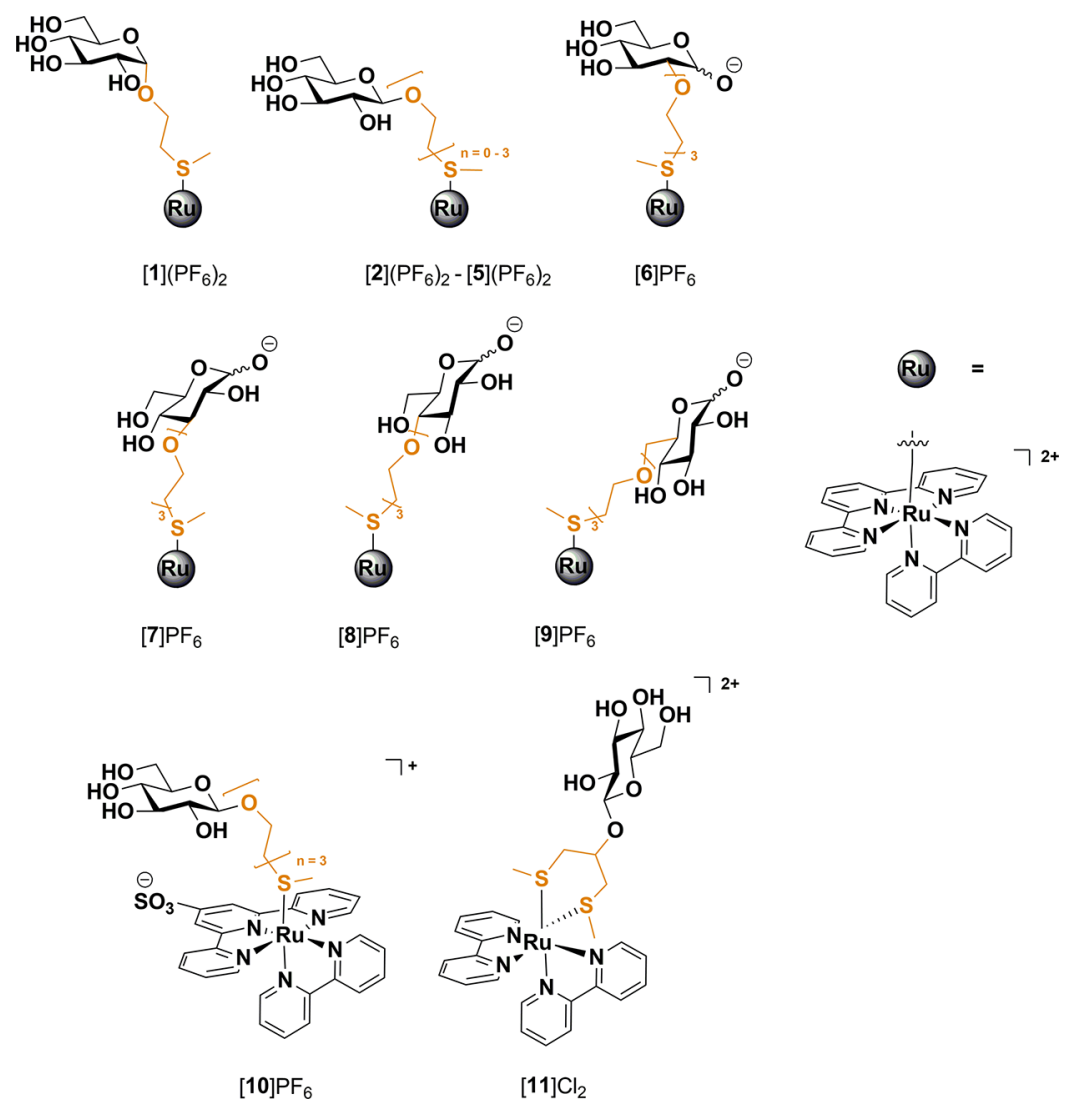

Figure 1. Overview of $O-1$ to $O-6$ positional D-glucose ruthenium(II) polypyridyl conjugates presented in this study.

the spacer length exerts influence over the GLUT-mediated uptake of platinum complexes in cells; ${ }^{14}$ however, there is currently no established understanding of this effect in cationic ruthenium(II) polypyridyl compounds. Therefore, oligoethylene glycol spacers $\left[\mathrm{OCH}_{2} \mathrm{CH}_{2}\right]_{n}$ with varying lengths $(n=0-3)$ were introduced in glycoconjugates $[1]\left(\mathrm{PF}_{6}\right)_{2}-[5]\left(\mathrm{PF}_{6}\right)_{2}$ (Figure 1). The first complex in this series $\left([1]\left(\mathrm{PF}_{6}\right)_{2}\right)$ was synthesized starting from precursor 12 (Scheme 1). ${ }^{25}$ This

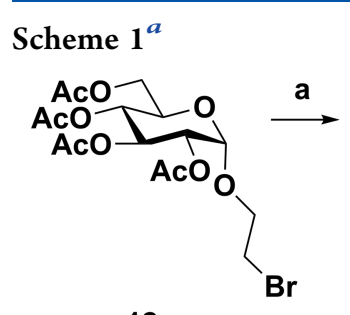

12

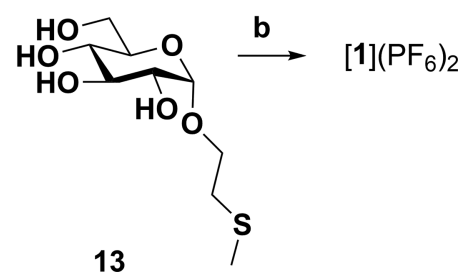

13
Scheme $2^{a}$

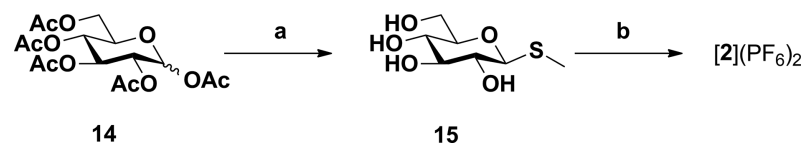

${ }^{a}$ Reaction conditions: (a) (i) $\mathrm{I}_{2}, \mathrm{Et}_{3} \mathrm{SiH}$ in DCM, rt, $10 \mathrm{~min}$, (ii) thiourea in $\mathrm{MeCN}, 80^{\circ} \mathrm{C}, 30 \mathrm{~min}$, (iii) $\mathrm{MeI}, \mathrm{Et}_{3} \mathrm{~N}, \mathrm{rt}, 10 \mathrm{~min}$, (iv) cat. $\mathrm{NaOMe}$ in $\mathrm{MeOH}$, rt, overnight, $57 \%$ over four steps; (b) $[\mathrm{Ru}($ tpy $)($ bpy $) \mathrm{Cl}] \mathrm{Cl}$ in $\mathrm{H}_{2} \mathrm{O}, 80^{\circ} \mathrm{C}, 48 \mathrm{~h}, 28 \%$.

a $55 \%$ overall yield. Subsequent reaction of this ligand with $[\mathrm{Ru}($ tpy $)($ bpy $) \mathrm{Cl}] \mathrm{Cl}$ then gave the orange complex $[2]\left(\mathrm{PF}_{6}\right)$.

A different approach was employed for the installment of the ethylene glycol-based linkers $(n=1-3)$ for complexes $[3]\left(\mathrm{PF}_{6}\right)_{2}-[\mathbf{5}]\left(\mathrm{PF}_{6}\right)_{2}$ and $[\mathbf{1 1}] \mathrm{Cl}_{2}$ (Figure 1). The disarmed Schmidt donor 20 (Scheme 3) was chosen due to its straightforward synthesis and robustness. The benzoyl protecting group in this building block was favored over the more common acetyl group, due to its lower reactivity. ${ }^{27}$ Furthermore, this donor was chosen to reduce the possible formation of orthoesters, a common side reaction when using acetyl-bearing donors. ${ }^{28}$ Commercially available 2 -(methylthio)ethanol was used as an acceptor and condensed with donor $\mathbf{2 0}$ (Scheme 3), affording 21, which after de-O-benzoylation acquired depro-

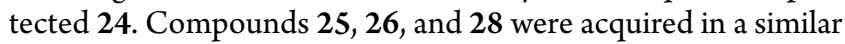
fashion using acceptors 18, 19, and 1,3-bis(methylthio)propan2 -ol, respectively. The synthesis of the corresponding ruthenium complexes was found to be straightforward, by reacting excess ligand with the ruthenium species $[\mathrm{Ru}(\mathrm{tpy})(\mathrm{bpy}) \mathrm{Cl}] \mathrm{Cl}$ or $\left[\mathrm{Ru}(\mathrm{bpy})_{2} \mathrm{Cl}_{2}\right]$. Their purification, however, was found arduous due to the increased water solubility of these compounds. 
Scheme $3^{a}$
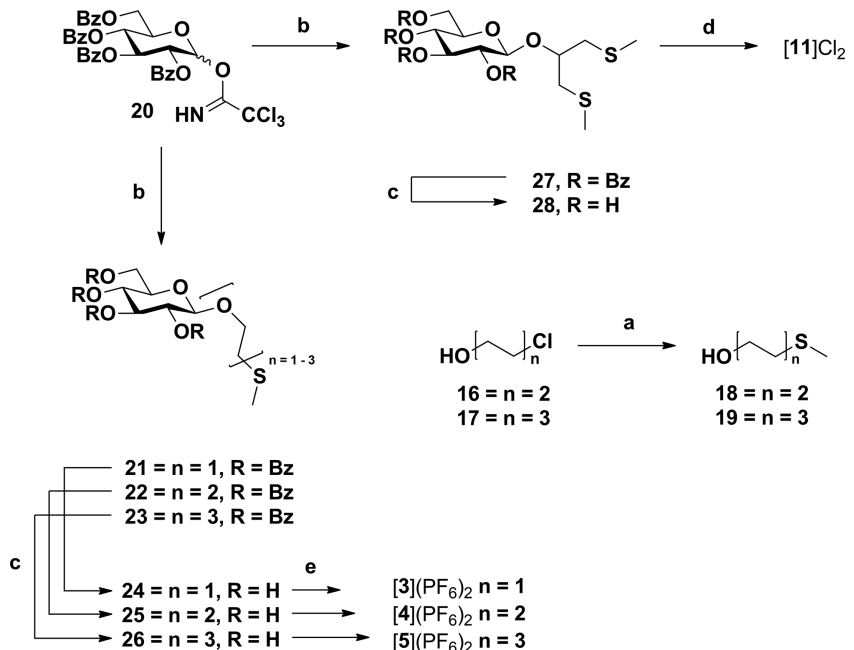

${ }^{a}$ Reaction conditions: (a) 2-(2-chloroethoxy)ethanol or 2-[2-(2chloroethoxy)ethoxy]ethanol, NaSMe in THF, reflux, $6 \mathrm{~h}, 89 \%$ for 18 , $85 \%$ for 19; (b) 2-(methylthio)ethanol, 1,3-bis(methylthio)propanol, 18 or 19, cat. TMSOTf in DCM, 4 A molecular sieves, rt, 4 h, $81 \%$ for 21, $66 \%$ for 22, $85 \%$ for 23, 90\% for 27; (c) $\mathrm{NaOMe}$ in $\mathrm{MeOH}$, rt, $88 \%$ for $24,86 \%$ for $\mathbf{2 5}, 91 \%$ for $\mathbf{2 6}, 70 \%$ for 28 ; (d) $\left[\mathrm{Ru}(\mathrm{bpy})_{2} \mathrm{Cl}_{2}\right]$ in $\mathrm{H}_{2} \mathrm{O}, 80{ }^{\circ} \mathrm{C}, 59 \%$ for $[11] \mathrm{Cl}_{2}$; (e) $\left[\mathrm{Ru}\left(\right.\right.$ tpy) (bpy) Cl] Cl in $\mathrm{H}_{2} \mathrm{O}, 80$ ${ }^{\circ} \mathrm{C}, 39 \%$ for $[3]\left(\mathrm{PF}_{6}\right)_{2}, 66 \%$ for $[4]\left(\mathrm{PF}_{6}\right)_{2}, 65 \%$ for $[5]\left(\mathrm{PF}_{6}\right)_{2}$.

Common workup methods were not applicable, and the lability of these compounds on C-18 columns prevented reverse-phase chromatographic purification. The most reproducible approach was by purification over silica using a mixture of acetone, water, and aqueous $\mathrm{KPF}_{6}$, followed by Sephadex LH-20 size exclusion purification to remove excess salt and minor impurities. This method afforded the orange $\left(\lambda_{\max }=450 \mathrm{~nm}\right)$ ruthenium polypyridyl derivatives $[3]\left(\mathrm{PF}_{6}\right)_{2}-[\mathbf{5}]\left(\mathrm{PF}_{6}\right)_{2}$ and $[\mathbf{1 1}] \mathrm{Cl}_{2}$ in moderate to good yields $(28-66 \%)$.

Park and co-workers have demonstrated that glucose bioprobes with a formal charge of +1 are taken up preferentially over neutral and negatively charged probes. ${ }^{29}$ To allow future study of the effect on the overall charge for ruthenium(II) polypyridyl drugs on uptake and toxicity, a derivative of $[\mathrm{Ru}(\mathrm{tpy})(\mathrm{bpy}) \mathrm{Cl}] \mathrm{Cl}$ bearing a negative charge on the spectator terpyridine ligand was also synthesized. Compound 31 (Scheme 4) was prepared starting from thione $29,{ }^{30}$ which was oxidized using in situ generated peracetic acid followed by hydrogenation using $10 \%$ palladium on carbon to reverse partial overoxidation to its $N$-oxide, affording ligand 30. A one-pot synthesis using ( $p$ cymene)ruthenium(II) chloride dimer $\mathbf{3 0}$ and bpy provided complex 31. Reaction of ligand $\mathbf{2 6}$ (Scheme 3 ) with this complex then gave the ruthenium complex $[10]\left(\mathrm{PF}_{6}\right)_{2}$.

Demonstrations of the covalent modification of the 2-O position of D-glucose with an alkyl-based linker have been given by Dumas et al. and Patray and co-workers. ${ }^{14,31}$ Both groups chose a similar approach starting from methyl 3,5,6-tri-Obenzyl- $\alpha / \beta$-D-glucofuranoside followed by installment of the linker and subsequent deprotection of the protection groups using dihydrogen and palladium on carbon. Sulfur-based linkers, however, poisoned the palladium catalysts, which made removal of the benzyl protecting groups impossible following this approach. ${ }^{22,32}$ Other methods to remove benzyl groups, such as Birch reductions, have been reported to cleave thioethers. ${ }^{33}$ Therefore, all described approaches for the functionalization of
Scheme $4^{a}$

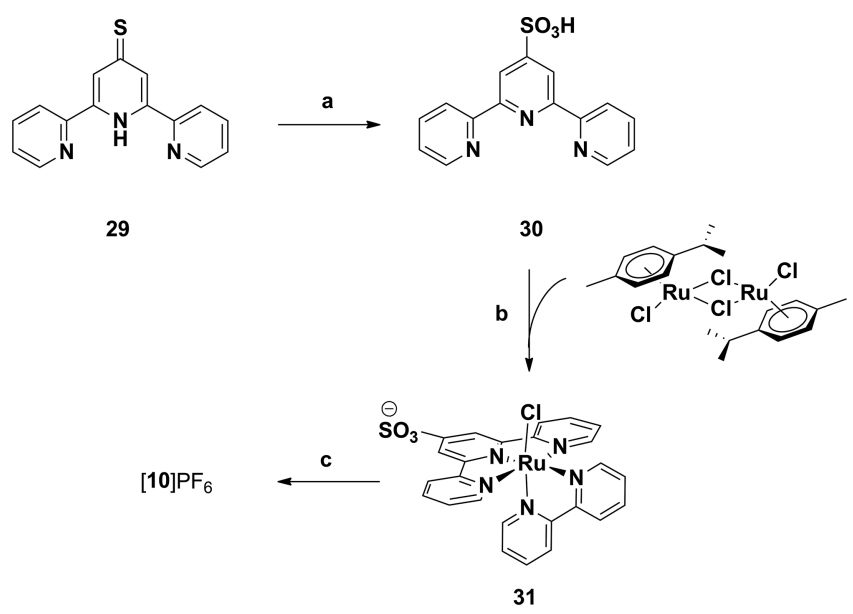

${ }^{a}$ Reaction conditions: (a) (i) $\mathrm{H}_{2} \mathrm{O}_{2}$ in $\mathrm{AcOH}, 70{ }^{\circ} \mathrm{C}, 6 \mathrm{~h}$, (ii) $\mathrm{H}_{2}, \mathrm{Pd} /$ $\mathrm{C}, 40{ }^{\circ} \mathrm{C}$, overnight, $24 \%$ over two steps; (b) bpy in $\mathrm{MeOH}, 60{ }^{\circ} \mathrm{C}$, $72 \%$; (c) 25 , in $\mathrm{H}_{2} \mathrm{O}, 80{ }^{\circ} \mathrm{C}, 16 \mathrm{~h}, 38 \%$.

the $\mathrm{O}-2$ position in $\mathrm{D}$-glucose with a metal-binding moiety, including the glucofuranoside approach described by Schubiger or Lippard, or the approach via a benzylorthoacetate intermediate described by Miao et al. ${ }^{34}$ were found unsuitable for thioether-containing compounds. We therefore devised a new protecting group strategy improving the 10 -step, $5 \%$ yield procedure published by Lippard et al. ${ }^{14}$ and employing the $\alpha$ oxirane method developed by the group of Danishefsky ${ }^{35,36}$ and attempted by Dumas et al. (Scheme 5). ${ }^{31}$ Using this method, D-

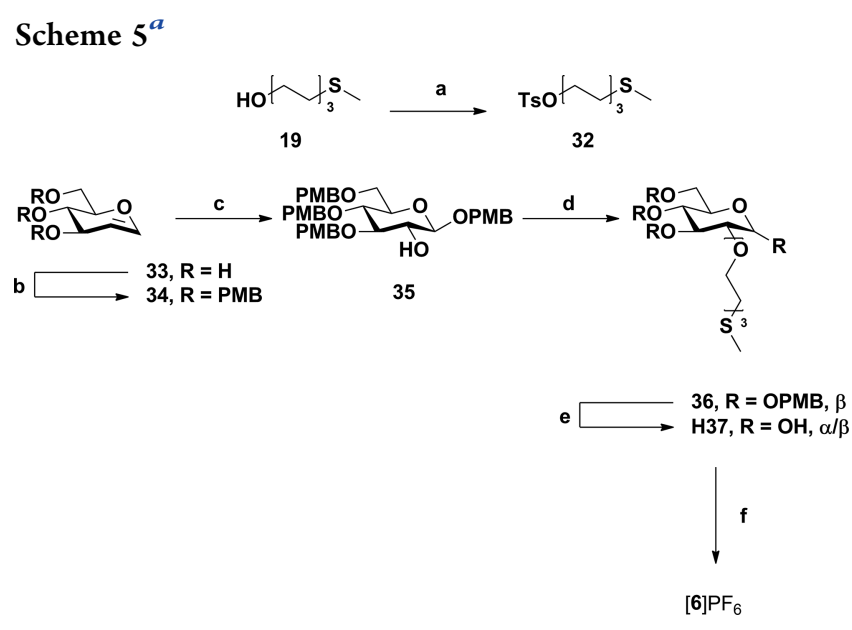

${ }^{a}$ Reaction conditions: (a) 19, TsCl, $\mathrm{Et}_{3} \mathrm{~N}$ in DCM, $0{ }^{\circ} \mathrm{C}$ to rt, $16 \mathrm{~h}$, 92\%; (b) $\mathrm{PMB}-\mathrm{Cl}, \mathrm{NaH}$ in $\mathrm{DMF}, 0{ }^{\circ} \mathrm{C}$ to $\mathrm{rt}, 16 \mathrm{~h}, 84 \%$; (c) (i) DMDO (0.088 $\mathrm{M}$ in acetone) in DCM, $0{ }^{\circ} \mathrm{C}$ to $\mathrm{rt}, 3 \mathrm{~h}$, (ii) PMB$\mathrm{OH}, \mathrm{ZnCl}_{2}$ in THF, $-78{ }^{\circ} \mathrm{C}$ to rt, $16 \mathrm{~h}, 39 \%$ over two steps; (d) 32, $\mathrm{NaH}$ in DMF, $0{ }^{\circ} \mathrm{C}$ to rt, $6 \mathrm{~h}, 80 \%$; (e) (i) cat. $\mathrm{HCl}$ in HFIP/DCM, 5 min, (ii) $\mathrm{MeNH}_{2}$ in $\mathrm{MeOH} / \mathrm{H}_{2} \mathrm{O}, 60{ }^{\circ} \mathrm{C}, 30 \mathrm{~min}, 67 \%$; (f) $\left[\mathrm{Ru}(\right.$ tpy $)($ bpy $\left.)\left(\mathrm{H}_{2} \mathrm{O}\right)\right]\left(\mathrm{PF}_{6}\right)_{2}$ in acetone $/ \mathrm{H}_{2} \mathrm{O}, 80^{\circ} \mathrm{C}, 24 \mathrm{~h}, 36 \%$.

glucal was protected using the $p$-methoxy benzyl (PMB) group, affording 34. Treatment of this compound with freshly prepared dimethyldioxirane (DMDO) afforded its corresponding 1,2anhydrosugar, which was then condensed with $p$-methoxy benzyl alcohol (PMB-OH) in the presence of anhydrous $\mathrm{ZnCl}_{2}$ in THF, affording $\beta$-substituted 35 , while simultaneously liberating the $2-O$ position. This compound was then treated 
with tosylate 32 (Scheme 5) for the installment of the thioether moiety. This conversion proceeded smoothly, which is in contrast to the observation of Schubiger et al., who had to divert to the furanoside approach due to difficulties encountered during the installment of their iminodiacetic acid-based spacer. $^{31}$ With compound 36 in hand, a recently described method $^{37}$ using $37 \%$ hydrochloric acid in hexafluoroisopropanol (HFIP) was used to remove all four PMB groups simultaneously. After the reaction was quenched using $\mathrm{Et}_{3} \mathrm{~N}$, an intermediate species was observed $(\mathrm{m} / z=463.4$ found, 463.2 calcd) corresponding to the desired product $\mathrm{H} 37$ and a PMB group. This same intermediate was also observed in the presence of a mild reducing agent such as $\mathrm{Et}_{3} \mathrm{SiH}$. However, when this intermediate was treated with $\mathrm{MeNH}_{2}$ in $\mathrm{MeOH}^{38}$ the methyl thioether could be liberated, acquiring hemiacetal $\mathbf{H} 37$ in five steps (18\% overall yield). After reaction of this compound with $\left[\mathrm{Ru}(\mathrm{tpy})(\mathrm{bpy})\left(\mathrm{H}_{2} \mathrm{O}\right)\right]\left(\mathrm{PF}_{6}\right)_{2}$ glycoconjugate $[\mathrm{Ru}($ tpy $)($ bpy $)$ (37) $] \mathrm{PF}_{6},\left([6] \mathrm{PF}_{6}\right)$ was acquired instead of $[\mathrm{Ru}(\mathrm{tpy})$ (bpy)$(\mathrm{H} 37)]\left(\mathrm{PF}_{6}\right)_{2}$. This is most likely due to the relatively protic nature of the anomeric proton, resulting in deprotonation during purification on Sephadex and replacement of one of the $\mathrm{PF}_{6}$ counterions by the "charged" deprotonated glucose species as interpreted by elemental analysis. On mass, however, only the $2+$ species is observed, indicating that reprotonation occurs in solution. This behavior was observed for all hemiacetal glucose derivatives.

The most straightforward thioether functionalization in these series of ligands was the modification of the 3-O position of $\mathrm{D}$ glucose. Starting from diacetone glucose 38 (Scheme 6), ${ }^{39-41}$

\section{Scheme $6^{a}$}

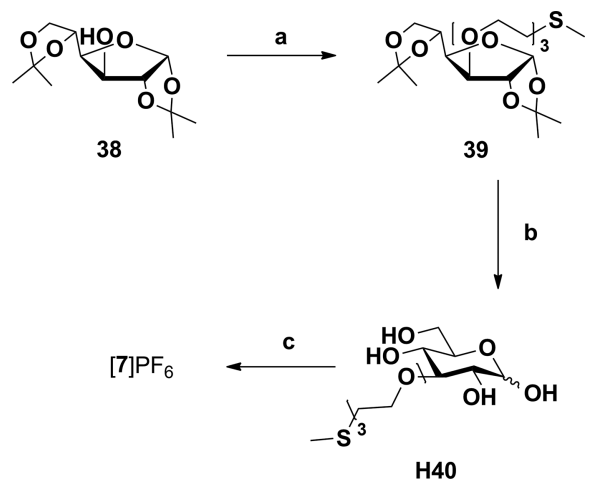

${ }^{a}$ Reaction conditions: (a) 32, $\mathrm{NaH}$ in DMF, $0{ }^{\circ} \mathrm{C}$ to $\mathrm{rt}, 16 \mathrm{~h}, 91 \%$; (b) Amberlite IR-120 $\mathrm{H}^{+}$in $\mathrm{H}_{2} \mathrm{O}, 60{ }^{\circ} \mathrm{C}, 24 \mathrm{~h}, 46 \%$; (c) $[\mathrm{Ru}($ tpy $)(\mathrm{bpy}) \mathrm{Cl}] \mathrm{Cl}$ in $\mathrm{H}_{2} \mathrm{O}, 80^{\circ} \mathrm{C}, 16 \mathrm{~h}, 37 \%$.

the thioether moiety was installed using 32 (Scheme 5), affording compound 39, which was subsequently hydrolyzed using Amberlite IR-120 $\mathrm{H}^{+}$, affording $\mathrm{H} 40$ in $42 \%$ overall yield. Glycoconjugation of $\mathbf{H 4 0}$ with $[\mathrm{Ru}(\mathrm{tpy})(\mathrm{bpy}) \mathrm{Cl}] \mathrm{Cl}$ gave the orange $\left(\lambda_{\max }=450 \mathrm{~nm}\right)$ complex $[\mathrm{Ru}(\mathrm{tpy})(\mathrm{bpy})(40)] \mathrm{PF}_{6}$ $\left([7] \mathrm{PF}_{6}\right)$.

The 4-O position of $\mathrm{D}$-glucose was modified starting from acetobromo- $\alpha$-D-glucose 40 (Scheme 7 ). Using a procedure first described by Kaji et al., this building block was converted in situ to its anomeric iodide, followed by a Koenigs-Knorr-type glycosylation with $p$-methoxy benzyl alcohol as an acceptor and $\mathrm{Ag}_{2} \mathrm{CO}_{3}$ as a base. ${ }^{42} \mathrm{De}-\mathrm{O}$-acetylation furnished intermediate 41, followed by 4,6-O-benzylidenation and installment of PMB groups, affording fully protected 43 . With this building block in
Scheme $7^{a}$

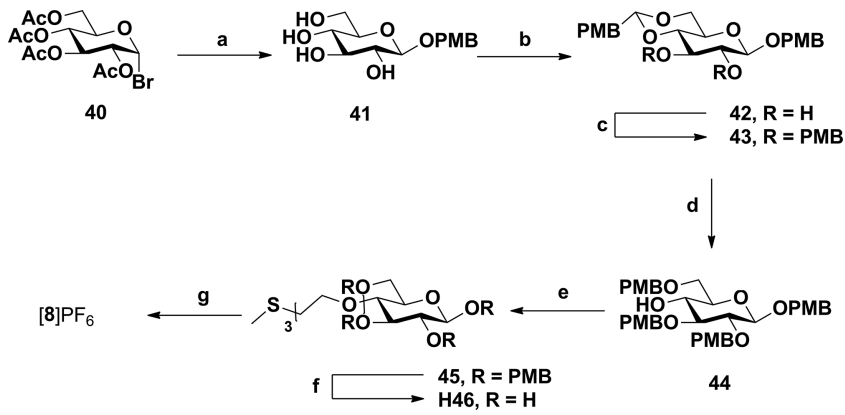

${ }^{a}$ Reaction conditions: (a) (i) PMB-OH, $\mathrm{I}_{2}, \mathrm{Ag}_{2} \mathrm{CO}_{3}$ in $\mathrm{Et}_{2} \mathrm{O}, \mathrm{rt}, 24 \mathrm{~h}$, (ii) $\mathrm{NaOMe}$ in $\mathrm{MeOH}$, rt, $4 \mathrm{~h}, 72 \%$ over two steps; (b) $\alpha, \alpha, 4$ trimethoxytoluene, cat. $p$-TsOH $\cdot \mathrm{H}_{2} \mathrm{O}$ in DMF, $60{ }^{\circ} \mathrm{C}, 16 \mathrm{~h}, 89 \%$; (c) $\mathrm{PMB}-\mathrm{Cl}, \mathrm{NaH}$ in DMF, $0{ }^{\circ} \mathrm{C}$ to rt, $78 \%$; (d) $\mathrm{NaCNBH}_{3}$, TFA in $\mathrm{DMF}, 0{ }^{\circ} \mathrm{C}$ to rt, $48 \mathrm{~h}, 95 \%$; (e) $32, \mathrm{NaH}$ in DMF, $0{ }^{\circ} \mathrm{C}$ to $\mathrm{rt}, 6 \mathrm{~h}$, 78\%; (f) cat. $\mathrm{HCl}$ in HFIP/DCM, $30 \mathrm{~min}, 29 \%$; (g) [Ru(tpy)(bpy)$\mathrm{Cl}] \mathrm{Cl}$ in $\mathrm{H}_{2} \mathrm{O}, 80^{\circ} \mathrm{C}, 64 \%$.

hand, a reductive opening using $\mathrm{NaCNBH}_{3}$ and TFA liberated the 4-O position, which could then be alkylated via a Williamson etherification using 32 described in the previous sections, affording 45. Global deprotection was achieved by treatment with $\mathrm{HFIP} / \mathrm{HCl}$, which gave thioether ligand $\mathbf{H 4 6}$ in an $11 \%$ overall yield. The subsequent reaction of $\mathbf{H 4 6}$ with $[\mathrm{Ru}(\mathrm{tpy})$ (bpy) $\left.\left(\mathrm{H}_{2} \mathrm{O}\right)\right]\left(\mathrm{PF}_{6}\right)_{2}$ afforded glycoconjugate $[\mathrm{Ru}(\mathrm{tpy})(\mathrm{bpy})$ (46) $] \mathrm{PF}_{6}\left([8] \mathrm{PF}_{6}\right)$. The synthesis of $\mathbf{H} 46$ was also attempted via an alternative approach using $\alpha$-methyl glucose following a similar protecting group strategy. However, this proved to be unsuccessful due to the inertness of the anomeric methyl acetal toward acid.

Finally, the 6-O position of D-glucose was easily modified starting from dimethyl glucose 48 (Scheme 8$),{ }^{43}$ which could be

Scheme $8^{a}$

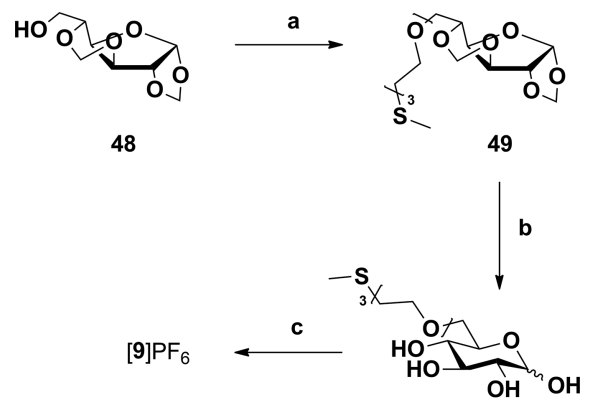

H50

a (a) 32, $\mathrm{NaH}$ in DMF, $0{ }^{\circ} \mathrm{C}$ to rt, $3 \mathrm{~h}, 78 \%$; (b) $2 \mathrm{M} \mathrm{HCl}$ in $\mathrm{H}_{2} \mathrm{O}, 60$ ${ }^{\circ} \mathrm{C}, 1 \mathrm{~h}, 70 \%$; (c) $\left[\mathrm{Ru}\left(\right.\right.$ tpy) (bpy)Cl] Cl in $\mathrm{H}_{2} \mathrm{O}, 80^{\circ} \mathrm{C}, 16 \mathrm{~h}, 17 \%$.

converted to 49 using a Williamson etherification with tosylate 32, followed by acid hydrolysis using dilute hydrochloric acid, affording methyl thioether $\mathbf{H 5 0}$ in $55 \%$ over two steps. Glycoconjugation with $[\mathrm{Ru}(\mathrm{tpy})(\mathrm{bpy}) \mathrm{Cl}] \mathrm{Cl}$ afforded $[\mathrm{Ru}(\mathrm{tpy})$ (bpy) (50) $] \mathrm{PF}_{6}\left([\mathbf{9}] \mathrm{PF}_{6}\right)$.

\section{CONCLUSION}

In this work, we have presented efficient and robust routes to all positional isomers of $\mathrm{D}$-glucose bearing a thioether ligand bound to a light-cleavable ruthenium(II) polypyridyl complex. The 
general protecting-deprotecting group strategy presented in this work is compatible with compounds bearing donor atoms such as sulfur, without the need of palladium catalysts until final coordination to the functional ruthenium compound. These routes might possibly be extended to application with other functionalized ligands, such as carboxylates, amines, or pyridines. The study of this library of ruthenium(II) glycoconjugates might shed light on the influence of the stereochemistry of glucose functionalization on GLUT-mediated uptake and the metabolism of the ruthenium-glucose conjugates by enzymes such as hexokinase II.

\section{EXPERIMENTAL SECTION}

General. Reagents were purchased from Sigma-Aldrich and used without further purification. $2,2^{\prime}: 6^{\prime}, 2^{\prime \prime}$-Terpyridine (tpy) was ordered from $\mathrm{ABCR} \mathrm{GmbH} \& \mathrm{Co}$. Dry solvents were collected from a Pure Solve MD5 solvent dispenser from Demaco. For all inorganic reactions, solvents were deoxygenated by bubbling dinitrogen through the solution for $30 \mathrm{~min}$. All organic reactions were carried out under a diniotrogen atmosphere at rt. Flash chromatography was performed on silica gel (Screening devices B.V.) with a particle size of $40-64 \mu \mathrm{M}$ and a pore size of $60 \AA$. TLC analysis was conducted on TLC aluminum foils with a silica gel matrix (Supelco, silica gel 60,56524) with detection by UV absorption (254 nm), by spraying with $10 \% \mathrm{H}_{2} \mathrm{SO}_{4}$ in ethanol or with a solution of $\mathrm{NH}_{4} \mathrm{Mo}_{7} \mathrm{O}_{24} \cdot 4 \mathrm{H}_{2} \mathrm{O}(25 \mathrm{~g} / \mathrm{L}), \mathrm{NH}_{4} \mathrm{CeSO}_{4} \cdot \mathrm{H}_{2} \mathrm{O}(10$ $\mathrm{g} / \mathrm{L}), 10 \% \mathrm{H}_{2} \mathrm{SO}_{4}$ in $\mathrm{H}_{2} \mathrm{O}$, followed by charring at $\sim 250^{\circ} \mathrm{C}$ on a heating plate. Optical rotation measurements were performed on a Propol automated polarimeter (sodium $\mathrm{D}$ line, $\lambda=589 \mathrm{~nm}$ ) with a concentration of $10 \mathrm{mg} / \mathrm{mL}(c=1)$ unless stated otherwise. Infrared spectra were recorded on a PerkinElmer UATR (Single Reflection Diamond) Spectrum Two device $\left(4000-700 \mathrm{~cm}^{-1}\right.$; resolution $\left.4 \mathrm{~cm}^{-1}\right)$. ${ }^{1} \mathrm{H}$ NMR and ${ }^{13} \mathrm{C}$ NMR were recorded in $\mathrm{CD}_{3} \mathrm{OD}$ and $\mathrm{CDCl}_{3}$ with a chemical shift $(\delta)$ relative to the solvent peak on a Bruker AV 400 or AV 500 unit. High-resolution mass spectra were recorded by direct injection ( $2 \mu \mathrm{L}$ of $2 \mu \mathrm{M}$ solution in water/acetoneitrile; $50 / 50$; $\mathrm{v} / \mathrm{v}$ and $0.1 \%$ formic acid) in a mass spectrometer (Thermo Finnigan LTQ Orbitrap) equipped with an electrospray $\left(250{ }^{\circ} \mathrm{C}\right)$ with a resolution (R) $=60000$ at $\mathrm{m} / z 400$ (mass range $\mathrm{m} / z=150-2000$ ) and dioctylphtalate $(m / z=391.28428)$ as a lock mass. The high-resolution mass spectrometer was calibrated prior to measurements with a calibration mixture (Thermo Finnigan). Melting point ranges were determined on a Stuart SMP30 unit. Elemental analysis for glycoconjugates $[1]\left(\mathrm{PF}_{6}\right)_{2}-[5]\left(\mathrm{PF}_{6}\right)_{2},[6] \mathrm{PF}_{6}-[10] \mathrm{PF}_{6}$, and $[11] \mathrm{Cl}_{2}$ was performed at Mikrolab Kolbe, Germany.

Synthesis. (2-Methylthio)ethyl- $\alpha$-D-glucopyranoside (13). 2,3,4,6-Tetra- $O$-acetyl-(2-bromo)ethyl- $\alpha$-D-glucopyranoside ${ }^{25}$ (135 $\mathrm{mg}, 0.297 \mathrm{mmol}$ ) was dissolved in dry DMF $(3 \mathrm{~mL})$, and to this solution was added fresh $\mathrm{NaSMe}(23 \mathrm{mg}, 0.33 \mathrm{mmol})$. The reaction was stirred overnight, after which it was diluted with EtOAc $(25 \mathrm{~mL})$, washed with water $(2 \times)$ and aq $\mathrm{NaHCO}_{3}(2 \times)$, and dried $\left(\mathrm{Na}_{2} \mathrm{SO}_{4}\right)$. Concentration in vacuo was followed by purification of the residue by silica column chromatography (10\% $\mathrm{MeOH}$ in DCM), affording the title compound $(50.0 \mathrm{mg}, 0.197 \mathrm{mmol}, 66 \%$ over two steps) as a colorless oil: $R_{f}=0.84(20 \% \mathrm{MeOH}$ in DCM); IR (neat) 3350, 2918, $1639,1426,1018 ;{ }^{1} \mathrm{H}$ NMR $\left(400 \mathrm{MHz}, \mathrm{CD}_{3} \mathrm{OD}\right) \delta 4.80(\mathrm{~d}, J=3.8 \mathrm{~Hz}$, $1 \mathrm{H}, \mathrm{H}-1)$, 3.91-3.75 (m, 2H, CHH H-6, $\mathrm{CHH} \mathrm{OCH}$ ), 3.69-3.58 (m, $4 \mathrm{H}, \mathrm{H}-4, \mathrm{H}-5, \mathrm{CHH} \mathrm{H}-6, \mathrm{CHH} \mathrm{OCH})^{2}, 3.37$ (dd, $J=9.7,3.8 \mathrm{~Hz}, 1 \mathrm{H}$, $\mathrm{H}-2$ ), 3.25 (d, $J=9.3 \mathrm{~Hz}, 1 \mathrm{H}, \mathrm{H}-3), 2.73(\mathrm{td}, J=6.9,1.8 \mathrm{~Hz}, 2 \mathrm{H}$, $\left.\mathrm{OCH}_{2} \mathrm{SMe}\right), 2.12$ (s, 3H, OCH $\mathrm{OMe}_{2} ;{ }^{13} \mathrm{C} \mathrm{NMR}\left(101 \mathrm{MHz}, \mathrm{CD}_{3} \mathrm{OD}\right)$ $\delta 100.3$ (C-1), 75.1 (C-4), 73.9 (C-5), 73.5 (C-2), 71.8 (C-3), 68.4 $\left(\mathrm{OCH}_{2}\right), 62.7$ (C-6), $34.3\left(\mathrm{OCH}_{2} \mathrm{SMe}\right), 15.8\left(\mathrm{OCH}_{2} \mathrm{SMe}\right)$; HRMS (ESI) $\mathrm{m} / z[\mathrm{M}+\mathrm{Na}]^{+}$calcd for $\mathrm{C}_{9} \mathrm{H}_{18} \mathrm{O}_{6} \mathrm{SNa} 277.0716$, found 277.0711.

Methylthio- $\beta$-D-glucopyranoside (15). $\alpha / \beta$-D-Glucose pentaacetate $(4.99 \mathrm{~g}, 12.4 \mathrm{mmol})$ was dissolved in anhydrous DCM $(20 \mathrm{~mL})$, and to this solution were added $\mathrm{I}_{2}(4.84 \mathrm{~g}, 19.0 \mathrm{mmol})$ and $\mathrm{Et}_{3} \mathrm{SiH}(2.90 \mathrm{~mL}$, $18.2 \mathrm{mmol}$ ). This mixture was allowed to stir for $10 \mathrm{~min}$, after which it was diluted with DCM $(100 \mathrm{~mL})$ and washed with aqueous saturated
$\mathrm{Na}_{2} \mathrm{~S}_{2} \mathrm{O}_{3}(1 \times)$ and $\mathrm{Na}_{2} \mathrm{CO}_{3}(1 \times)$. Layers were separated, and the organic layer was dried $\left(\mathrm{Na}_{2} \mathrm{SO}_{4}\right)$ and concentrated in vacuo. The crude was coevaporated with toluene $(3 \times)$ and redissolved in dry MeCN $(20$ $\mathrm{mL})$, followed by the addition of thiourea $(1.46 \mathrm{~g}, 19.2 \mathrm{mmol})$. The mixture was then heated for $30 \mathrm{~min}$ at $80^{\circ} \mathrm{C}$, after which it was allowed to cool down to rt, followed by the addition of MeI $(1.60 \mathrm{~mL}, 25.7$ $\mathrm{mmol})$ and $\mathrm{Et}_{3} \mathrm{~N}(7.10 \mathrm{~mL}, 50.9 \mathrm{mmol})$. After an additional stirring for $10 \mathrm{~min}$, the mixture was concentrated in vacuo, followed by purification of the residue over silica ( 0 to $50 \% \mathrm{Et}_{2} \mathrm{O}$ in $\mathrm{PE}$ ), yielding methyl 2,3,4,6tetra- $O$-acetyl-1-thio- $\beta$-D-glucopyranoside as a yellow foam $(2.71 \mathrm{~g}$, $7.24 \mathrm{mmol})$. This compound was then dissolved in dry $\mathrm{MeOH}(70 \mathrm{~mL})$ followed by the addition of a catalytic amount of $\mathrm{NaOMe}$, which after stirring overnight was quenched upon the addition of Amberlite IR-120 $\mathrm{H}^{+}$. Filtration was followed by concentration in vacuo, yielding the title compound as a colorless oil (1.48 g, $7.04 \mathrm{mmol}, 57 \%$ over four steps): $R_{f}$ $=0.63$ (20\% MeOH in DCM); IR (neat) 3336, 2923, 2881, 1425, 1017; ${ }^{1} \mathrm{H} \mathrm{NMR}\left(400 \mathrm{MHz}, \mathrm{CD}_{3} \mathrm{OD}\right) \delta 4.35(\mathrm{~d}, J=9.6 \mathrm{~Hz}, 1 \mathrm{H}, \mathrm{H}-1), 3.93(\mathrm{~d}, J$ $=11.8 \mathrm{~Hz}, 1 \mathrm{H}, \mathrm{CHH} \mathrm{H}-6), 3.77-3.68(\mathrm{~m}, 1 \mathrm{H}, \mathrm{CHH} \mathrm{H}-6), 3.48-3.35$ (m, 3H, H-3, H-4, H-5), $3.31(\mathrm{t}, J=9.1 \mathrm{~Hz}, 1 \mathrm{H}, \mathrm{H}-2), 2.26(\mathrm{~s}, 3 \mathrm{H}$, $\mathrm{SMe}) ;{ }^{13} \mathrm{C}$ NMR (101 MHz, CD $\left.\mathrm{OD}\right) \delta 87.1$ (C-1), 81.8 (C-3), 79.3 (C-4), 73.5 (C-2), 71.3 (C-5), 62.7 (C-6), 12.0 (SMe); HRMS (ESI) $\mathrm{m} / z[\mathrm{M}+\mathrm{Na}]^{+}$calcd for $\mathrm{C}_{7} \mathrm{H}_{14} \mathrm{O}_{5} \mathrm{SNa} 233.0454$, found 233.0444 .

2-(Methylthio)ethoxy)ethanol (18). To a flame-dried roundbottom flask was added freshly prepared $\mathrm{NaSMe}^{44}(1.21 \mathrm{~g}, 15.5$ $\mathrm{mmol})$ under argon. Deoxygenated THF $(50 \mathrm{~mL})$ was added, followed by the addition of 2-chloroethoxy)ethanol ( $1.50 \mathrm{~mL}, 14.2 \mathrm{mmol})$. This solution was heated at $60^{\circ} \mathrm{C}$ for $6 \mathrm{~h}$, after which it was allowed to cool to room temperature. The mixture was diluted with EtOAc $(100 \mathrm{~mL})$ and washed with aqueous $\mathrm{NaHCO}_{3}(2 \times)$ and water $(1 \times)$. The layers were separated, and the organic layer was dried $\left(\mathrm{Na}_{2} \mathrm{SO}_{4}\right)$ and concentrated in vacuo, affording a slightly yellowish oil $(1.89 \mathrm{~g}, 13.9 \mathrm{mmol}, 89 \%)$ : IR (neat) $3480,2907,2866,1611,1512 ;{ }^{1} \mathrm{H} \mathrm{NMR}\left(400 \mathrm{MHz}, \mathrm{CDCl}_{3}\right) \delta$ $3.68\left(\mathrm{~m}, 2 \mathrm{H}, \mathrm{CH}_{2}\right), 3.62\left(\mathrm{t}, J=6.7 \mathrm{~Hz}, 2 \mathrm{H}, \mathrm{CH}_{2}\right), 3.54(\mathrm{~d}, J=5.1 \mathrm{~Hz}$, $\left.2 \mathrm{H}, \mathrm{CH}_{2}\right), 2.94-2.81(\mathrm{~s}, 1 \mathrm{H}, \mathrm{OH}), 2.66\left(\mathrm{t}, J=6.6 \mathrm{~Hz}, 2 \mathrm{H}, S_{\mathrm{CH}}\right), 2.10$ $\left(\mathrm{s}, 3 \mathrm{H}, \mathrm{CH}_{3}\right) ;{ }^{13} \mathrm{C} \mathrm{NMR}\left(100 \mathrm{MHz}, \mathrm{CDCl}_{3}\right) \delta 72.1\left(\mathrm{CH}_{2}\right), 69.9\left(\mathrm{CH}_{2}\right)$, $61.5\left(\mathrm{CH}_{2}\right), 33.6\left(\mathrm{SCH}_{2}\right), 15.8\left(\mathrm{SCH}_{3}\right)$; HRMS (ESI) $\mathrm{m} / z[\mathrm{M}+\mathrm{Na}]^{+}$ calcd for $\mathrm{C}_{5} \mathrm{H}_{12} \mathrm{O}_{2} \mathrm{SNa} 159.0450$, found 159.0457 .

2-[2-(2-(Methylthio)ethoxy)ethoxy]ethanol (19). The procedure was followed as described for 18 using $\mathrm{NaSMe}^{44}(4.23 \mathrm{~g}, 60.4 \mathrm{mmol})$ and 2-[2-(2-chloroethoxy)ethoxy] ethanol ( $10.0 \mathrm{~g}, 59.3 \mathrm{mmol}) .19$ was afforded as a colorless oil $(9.25 \mathrm{~g}, 51.0 \mathrm{mmol}, 85 \%)$ : IR (neat) 3427 , 2915, 2869, 1105, 1063; ${ }^{1} \mathrm{H} \mathrm{NMR}\left(400 \mathrm{MHz}, \mathrm{CDCl}_{3}\right) \delta 3.61-3.42(\mathrm{~m}$, $\left.10 \mathrm{H}, 5 \times \mathrm{CH}_{2}\right), 3.09(\mathrm{~s}, 1 \mathrm{H}, \mathrm{OH}), 2.60-2.50\left(\mathrm{~m}, 2 \mathrm{H}, 1 \times \mathrm{CH}_{2}\right), 2.03-$ $1.94\left(\mathrm{~s}, 3 \mathrm{H}, \mathrm{CH}_{3}\right) ;{ }^{13} \mathrm{C} \mathrm{NMR}\left(100 \mathrm{MHz}, \mathrm{CDCl}_{3}\right) \delta 72.4\left(\mathrm{CH}_{2}\right), 70.2$ $\left(\mathrm{CH}_{2}\right), 70.1\left(\mathrm{CH}_{2}\right), 70.0\left(\mathrm{CH}_{2}\right), 61.3\left(\mathrm{CH}_{2}\right) 33.13\left(\mathrm{SCH}_{2}\right), 15.7$ $\left(\mathrm{SCH}_{3}\right)$; HRMS (ESI) $\mathrm{m} / z[\mathrm{M}+\mathrm{Na}]^{+}$calcd for $\mathrm{C}_{7} \mathrm{H}_{16} \mathrm{O}_{3} \mathrm{SNa}$ 203.0712, found 203.0713.

(2-Methylthio)ethyl 2,3,4,6-tetra-O-benzoyl- $\beta$-D-glucopyranoside (21). 2,3,4,6-Tetra- $O$-benzoyl- $\beta$-D-glucopyranosyl trichloroacetimidate $^{45}(370 \mathrm{mg}, 0.364 \mathrm{mmol}$ ) and 2-(methylthio)ethanol $(100 \mu \mathrm{L}$, $1.15 \mathrm{mmol}$ ) were coevaporated three times with anhydrous toluene, after which they were dissolved in anhydrous DCM $(36 \mathrm{~mL})$. Freshly activated $4 \AA$ molecular sieves were added, and the mixture was allowed to stir for $15 \mathrm{~min}$, after which a catalytic amount of TMSOTf $(20.0 \mu \mathrm{L}$, $111 \mu \mathrm{mol}$ ) was added. After stirring for $4 \mathrm{~h}$ at room temperature, the reaction was quenched upon the addition of $\mathrm{Et}_{3} \mathrm{~N}(100 \mu \mathrm{L}, 0.714$ $\mathrm{mmol}$ ) and concentrated in vacuo followed by purification of the residue over silica ( $10 \%$ to $50 \% \mathrm{EtOAc}$ in $\mathrm{PE}$ ), affording the title compound as a clear oil $(270 \mathrm{mg}, 0.410 \mathrm{mmol}, 81 \%): R_{f}=0.74(30 \%$ EtOAc in PE); IR (neat) 3064, 2922, 2853, 1720, 1258; ${ }^{\mathrm{H}} \mathrm{H}$ NMR (400 $\left.\mathrm{MHz} \mathrm{CDCl}_{3}\right) \delta 8.07-8.02\left(\mathrm{~m}, 2 \mathrm{H}, \mathrm{H}_{\text {arom }}\right), 8.00-7.96\left(\mathrm{~m}, 2 \mathrm{H}, \mathrm{H}_{\text {arom }}\right)$, 7.94-7.90 (m, $\left.2 \mathrm{H}, \mathrm{H}_{\text {arom }}\right), 7.87-7.81\left(\mathrm{~m}, 2 \mathrm{H}, \mathrm{H}_{\text {arom }}\right), 7.60-7.25(\mathrm{~m}$, $\left.12 \mathrm{H}, \mathrm{H}_{\text {arom }}\right), 5.93(\mathrm{t}, J=9.7 \mathrm{~Hz}, 1 \mathrm{H}, \mathrm{H}-3), 5.70(\mathrm{t}, J=9.7 \mathrm{~Hz}, 1 \mathrm{H}, \mathrm{H}-4)$, $5.56(\mathrm{dd}, J=9.8,7.8 \mathrm{~Hz}, 1 \mathrm{H}, \mathrm{H}-2), 4.93(\mathrm{~d}, J=7.8 \mathrm{~Hz}, 1 \mathrm{H}, \mathrm{H}-1), 4.67$ (dd, $J=12.2,3.2 \mathrm{~Hz}, 1 \mathrm{H}, \mathrm{CHH} \mathrm{H}-6), 4.52(\mathrm{dd}, J=12.1,5.4 \mathrm{~Hz}, 1 \mathrm{H}$, CHH H-6), 4.19 (ddd, $J=8.6,5.4,3.2 \mathrm{~Hz}, 1 \mathrm{H}, \mathrm{H}-5), 4.09$ (dt, $J=10.2$, $6.7 \mathrm{~Hz}, 1 \mathrm{H}, \mathrm{CHH} \mathrm{OCH})_{2}, 3.78\left(\mathrm{dt}, J=10.3,7.3 \mathrm{~Hz}, 1 \mathrm{H}, \mathrm{CHH} \mathrm{OCH}{ }_{2}\right)$, $2.67\left(\mathrm{t}, J=6.9 \mathrm{~Hz}, 2 \mathrm{H}, \mathrm{CH}_{2} \mathrm{SMe}\right), 2.01\left(\mathrm{~s}, 3 \mathrm{H}, \mathrm{CH}_{2} \mathrm{SMe}\right) ;{ }^{13} \mathrm{C} \mathrm{NMR}$ $\left(101 \mathrm{MHz}, \mathrm{CDCl}_{3}\right) \delta 166.2(\mathrm{C}=\mathrm{O} \mathrm{Bz}), 165.9(\mathrm{C}=\mathrm{O} \mathrm{Bz}), 165.3(\mathrm{C}=$ $\mathrm{O} \mathrm{Bz}), 165.2(\mathrm{C}=\mathrm{O} \mathrm{Bz}), 133.6\left(\mathrm{C}_{\mathrm{H} \text { arom }}\right), 133.4\left(\mathrm{C}_{\mathrm{H} \text { arom }}\right), 133.3$ 
$\left(\mathrm{C}_{\mathrm{H} \text { arom }}\right), 129.9\left(\mathrm{C}_{\mathrm{H} \text { arom }}\right), 129.9\left(\mathrm{C}_{\mathrm{H} \text { arom }}\right), 129.9\left(\mathrm{C}_{\mathrm{H} \text { arom }}\right), 129.8$ $\left(\mathrm{C}_{\mathrm{H} \text { arom }}\right), 129.7\left(\mathrm{C}_{\mathrm{q} \text { arom }}\right), 129.4\left(\mathrm{C}_{\mathrm{q} \text { arom }}\right), 128.9\left(\mathrm{C}_{\mathrm{q} \text { arom }}\right), 128.8$ $\left(\mathrm{C}_{\mathrm{q} \text { arom }}\right), 128.5$ ( $\left.\mathrm{C}_{\mathrm{H} \text { arom }}\right), 128.5\left(\mathrm{C}_{\mathrm{H} \text { arom }}\right), 128.5\left(\mathrm{C}_{\mathrm{H} \text { arom }}\right), 128.4$ ( $\left.\mathrm{C}_{\mathrm{H} \text { arom }}\right), 101.4$ (C-1), 73.0 (C-3), 72.4 (C-5), 71.9 (C-2), 69.8 (C-4), $69.8\left(\mathrm{OCH}_{2}\right), 63.2(\mathrm{C}-6), 33.4\left(\mathrm{CH}_{2} \mathrm{SMe}\right), 16.1\left(\mathrm{CH}_{2} \mathrm{SMe}\right)$; HRMS (ESI) $\mathrm{m} / z\left[\mathrm{M}+\mathrm{NH}_{4}\right]^{+}$calcd for $\mathrm{C}_{37} \mathrm{H}_{38} \mathrm{O}_{10} \mathrm{SN}$ 688.2211, found 688.2222 .

[2-(2-(Methylthio)ethoxy)]ethyl 2,3,4,6-tetra-O-benzoyl- $\beta$-D-glucopyranoside (22). The general procedure described for 21 was followed, with 2,3,4,6-tetra-O-benzoyl- $\beta$-D-glucopyranosyl trichloroacetimidate $(6.00 \mathrm{~g}, 8.14 \mathrm{mmol})$ and 2-(2-(methylthio)ethoxy)ethanol $(1.24 \mathrm{~g}, 9.10 \mathrm{mmol})$. Purification of the residue by silica column purification (0-25\% EtOAc in PE) afforded the title compound as a clear oil (3.86 g, $5.40 \mathrm{mmol}, 66 \%): R_{f}=0.34$ (33\% EtOAc in PE); IR (neat) $3064,2919,1722,1602,1249 ;{ }^{1} \mathrm{H}$ NMR $\left(400 \mathrm{MHz}, \mathrm{CDCl}_{3}\right) \delta$ 8.05-8.01 (m, $\left.2 \mathrm{H}, \mathrm{H}_{\text {arom }}\right), 8.00-7.96\left(\mathrm{~m}, 2 \mathrm{H}, \mathrm{H}_{\text {arom }}\right), 7.93-7.88(\mathrm{~m}$, $\left.2 \mathrm{H}, \mathrm{H}_{\text {arom }}\right), 7.86-7.81\left(\mathrm{~m}, 2 \mathrm{H}, \mathrm{H}_{\text {arom }}\right), 7.58-7.24\left(\mathrm{~m}, 12 \mathrm{H}, \mathrm{H}_{\text {arom }}\right)$, $5.92(\mathrm{t}, J=9.7 \mathrm{~Hz}, 1 \mathrm{H}, \mathrm{H}-3), 5.69(\mathrm{t}, J=9.7 \mathrm{~Hz}, 1 \mathrm{H}, \mathrm{H}-4), 5.54(\mathrm{dd}, J=$ 9.9, $7.7 \mathrm{~Hz}, 1 \mathrm{H}, \mathrm{H}-2$ ), 4.99 (d, $J=7.8 \mathrm{~Hz}, 1 \mathrm{H}, \mathrm{H}-1$ ), 4.65 (dd, $J=12.1$, $3.2 \mathrm{~Hz}, 1 \mathrm{H}, \mathrm{CHH} \mathrm{H}-6), 4.51$ (dd, $J=12.1,5.1 \mathrm{~Hz}, 1 \mathrm{H}, \mathrm{CHH} \mathrm{H}-6), 4.18$ (ddd, $J=10.1,5.2,3.1 \mathrm{~Hz}, 1 \mathrm{H}, \mathrm{H}-5), 4.00(\mathrm{dt}, J=11.4,4.1 \mathrm{~Hz}, 1 \mathrm{H}$, $\mathrm{CHH} \mathrm{OCH}_{2}$ ), 3.81 (ddd, $\left.\left.J=11.1,6.9,3.8 \mathrm{~Hz}, 1 \mathrm{H}, \mathrm{CHH} \mathrm{OCH}\right)_{2}\right), 3.58$ $\left(\mathrm{dt}, J=6.7,3.7 \mathrm{~Hz}, 2 \mathrm{H}, \mathrm{OCH}_{2}\right), 3.48\left(\mathrm{t}, J=6.7 \mathrm{~Hz}, 2 \mathrm{H}, \mathrm{OCH}_{2}\right), 2.44(\mathrm{t}$, $\left.J=6.7 \mathrm{~Hz}, 2 \mathrm{H}, \mathrm{CH}_{2} \mathrm{SMe}\right), 2.03\left(\mathrm{~s}, 3 \mathrm{H}, \mathrm{CH}_{2} \mathrm{SMe}\right) ;{ }^{13} \mathrm{C} \mathrm{NMR}(101 \mathrm{MHz}$, $\left.\mathrm{CDCl}_{3}\right) \delta 166.3(\mathrm{C}=\mathrm{O} \mathrm{Bz}), 165.9(\mathrm{C}=\mathrm{O} \mathrm{Bz}), 165.3(\mathrm{C}=\mathrm{O} \mathrm{Bz})$, $165.2(\mathrm{C}=\mathrm{O} \mathrm{Bz}), 133.6\left(\mathrm{C}_{\mathrm{H} \text { arom }}\right), 133.4\left(\mathrm{C}_{\mathrm{H} \text { arom }}\right), 133.3\left(\mathrm{C}_{\mathrm{H} \text { arom }}\right)$, $129.9\left(\mathrm{C}_{\mathrm{H} \text { arom }}\right), 129.9\left(\mathrm{C}_{\mathrm{H} \text { arom }}\right), 129.9\left(\mathrm{C}_{\mathrm{H} \text { arom }}\right), 129.9\left(\mathrm{C}_{\mathrm{H} \text { arom }}\right)$, $129.7\left(\mathrm{C}_{\mathrm{q} \text { arom }}\right), 129.4\left(\mathrm{C}_{\mathrm{q} \text { arom }}\right), 128.9\left(\mathrm{C}_{\mathrm{q} \text { arom }}\right), 128.9\left(\mathrm{C}_{\mathrm{q} \text { arom }}\right), 128.5$ $\left(\mathrm{C}_{\mathrm{H} \text { arom }}\right), 128.5\left(\mathrm{C}_{\mathrm{H} \text { arom }}\right), 128.4\left(\mathrm{C}_{\mathrm{H} \text { arom }}\right), 101.4(\mathrm{C}-1), 73.0(\mathrm{C}-3)$, $72.3(\mathrm{C}-5), 72.0(\mathrm{C}-2), 70.6\left(\mathrm{OCH}_{2}\right), 70.2\left(\mathrm{OCH}_{2}\right), 69.8(\mathrm{C}-4), 69.4$ $\left(\mathrm{OCH}_{2}\right), 63.2(\mathrm{C}-6), 33.5\left(\mathrm{CH}_{2} \mathrm{SMe}\right), 16.1\left(\mathrm{CH}_{2} \mathrm{SMe}\right)$; HRMS (ESI) $m / z\left[\mathrm{M}+\mathrm{NH}_{4}\right]^{+}$calcd for $\mathrm{C}_{39} \mathrm{H}_{42} \mathrm{O}_{11} \mathrm{SN} 732.2473$, found 732.2484 .

2-[2-(2-(Methylthio)ethoxy)ethoxy]ethyl 2,3,4,6-tetra-O-benzoyl$\beta$-D-glucopyranoside (23). The general procedure described for $\mathbf{2 1}$ was followed, with 2,3,4,6-tetra-O-benzoyl- $\beta$-D-glucopyranosyl trichloroacetimidate $^{45}(2.65 \mathrm{~g}, 3.58 \mathrm{mmol})$ and $19(792 \mathrm{mg}, 4.39 \mathrm{mmol})$. Purification of the residue over silica ( $10 \%$ to $50 \%$ EtOAc in PE) afforded the title compound as a clear oil $(2.32 \mathrm{~g}, 3.06 \mathrm{mmol}, 85 \%): R_{f}=$ $0.16\left(20 \%\right.$ EtOAc in PE); $[\alpha]_{\mathrm{D}}^{20}\left(\mathrm{CHCl}_{3}\right)+18.0$; IR (neat) 3063, 2918, 2869, 1722, 1451; ${ }^{1} \mathrm{H}$ NMR $\left(400 \mathrm{MHz}, \mathrm{CDCl}_{3}\right) \delta 8.03(\mathrm{~d}, J=8.6 \mathrm{~Hz}$, $\left.2 \mathrm{H}, \mathrm{H}_{\text {arom }}\right), 7.97\left(\mathrm{~d}, J=8.6 \mathrm{~Hz}, 2 \mathrm{H}, \mathrm{H}_{\text {arom }}\right), 7.90(\mathrm{~d}, J=8.7 \mathrm{~Hz}, 2 \mathrm{H}, 2 \mathrm{H}$, $\left.\mathrm{H}_{\text {arom }}\right), 7.83\left(\mathrm{~d}, J=8.6 \mathrm{~Hz}, 2 \mathrm{H}, \mathrm{H}_{\text {arom }}\right), 7.58-7.43\left(\mathrm{~m}, 3 \mathrm{H}, \mathrm{H}_{\text {arom }}\right)$, 7.43-7.29 (m, 7H, $\left.\mathrm{H}_{\text {arom }}\right), 7.29-7.21\left(\mathrm{~m}, 2 \mathrm{H}, \mathrm{H}_{\text {arom }}\right), 5.93(\mathrm{t}, J=9.7$ $\mathrm{Hz}, 1 \mathrm{H}, \mathrm{H}-3), 5.70(\mathrm{t}, J=9.7 \mathrm{~Hz}, 1 \mathrm{H}, \mathrm{H}-4), 5.55(\mathrm{dd}, J=9.7,7.8 \mathrm{~Hz}$, $1 \mathrm{H}, \mathrm{H}-2), 5.01$ (d, $J=7.8 \mathrm{~Hz}, 1 \mathrm{H}, \mathrm{H}-1), 4.66(\mathrm{dd}, J=12.1,3.1 \mathrm{~Hz}, 1 \mathrm{H}$, CHH H-6), 4.51 (dd, $J=12.1,5.1 \mathrm{~Hz}, 1 \mathrm{H}, \mathrm{CHH} \mathrm{H}-6$ ), 4.20 (ddd, $J=$ 9.9, 5.1, 3.1 Hz, 1H, H-5), 4.03-3.95 (m, $\left.1 \mathrm{H}, \mathrm{CH} H-\mathrm{OCH}_{2}\right), 3.83(\mathrm{~m}$, $\left.1 \mathrm{H}, \mathrm{CHH}-\mathrm{OCH}_{2}\right), 3.69-3.56\left(\mathrm{~m}, 2 \mathrm{H}, \mathrm{OCH}_{2}\right), 3.55(\mathrm{t}, J=6.9 \mathrm{~Hz}$, $\left.2 \mathrm{H}, \mathrm{OCH}_{2}\right), 3.50-3.42\left(\mathrm{~m}, 2 \mathrm{H}, \mathrm{OCH}_{2}\right), 3.37(\mathrm{t}, J=4.6 \mathrm{~Hz}, 2 \mathrm{H}$, $\left.\mathrm{OCH}_{2}\right), 2.64\left(\mathrm{t}, J=6.9 \mathrm{~Hz}, 2 \mathrm{H}, \mathrm{CH}_{2} \mathrm{SMe}\right), 2.11\left(\mathrm{~s}, 3 \mathrm{H}, \mathrm{SCH}_{3}\right) ;{ }^{13} \mathrm{C}$ NMR (101 MHz, CD $\left.{ }_{3} \mathrm{OD}\right) \delta 166.1(\mathrm{C}=\mathrm{O} \mathrm{Bz}), 165.8(\mathrm{C}=\mathrm{O} \mathrm{Bz})$, $165.2(\mathrm{C}=\mathrm{O} \mathrm{Bz}), 165.1(\mathrm{C}=\mathrm{O} \mathrm{Bz}), 133.5\left(\mathrm{CH}_{\text {arom }}\right), 133.3\left(\mathrm{CH}_{\text {arom }}\right)$, $133.2\left(\mathrm{CH}_{\text {arom }}\right), 129.8\left(\mathrm{CH}_{\text {arom }}\right), 129.8\left(\mathrm{CH}_{\text {arom }}\right), 129.6\left(\mathrm{C}_{\mathrm{q} \text { arom }}\right)$, $129.4\left(\mathrm{C}_{\mathrm{q} \text { arom }}\right), 128.8\left(\mathrm{C}_{\mathrm{q} \text { arom }}\right), 128.4\left(\mathrm{CH}_{\text {arom }}\right), 128.4\left(\mathrm{CH}_{\text {arom }}\right), 101.3$ (C-1), $73.0(\mathrm{C}-3), 72.2(\mathrm{C}-5) 72.0(\mathrm{C}-2), 70.7\left(\mathrm{OCH}_{2}\right), 70.5\left(\mathrm{OCH}_{2}\right)$, $70.2\left(\mathrm{OCH}_{2}\right), 69.8(\mathrm{C}-4), 69.4\left(\mathrm{OCH}_{2}\right), 63.2\left(\mathrm{OCH}_{2}\right), 33.4$ $\left(\mathrm{CH}_{2} \mathrm{SMe}\right), 16.0\left(\mathrm{CH}_{2} \mathrm{SMe}\right)$; HRMS (ESI) $\mathrm{m} / z[\mathrm{M}+\mathrm{Na}]^{+}$calcd for $\mathrm{C}_{41} \mathrm{H}_{42} \mathrm{O}_{12} \mathrm{SNa} 781.2289$, found 781.2280.

(2-Methylthio)ethyl- $\beta$-D-glucopyranoside (24). The protected glucoside 23 (240 mg, $0.410 \mathrm{mmol}$ ) was dissolved in $\mathrm{MeOH}(6 \mathrm{~mL})$, after which a catalytic amount of $\mathrm{NaOMe}$ was added. The solution was allowed to stir for $16 \mathrm{~h}$, after which Amberlite IR-120 $\mathrm{H}^{+}$was added, until a neutral $\mathrm{pH}$. The resin was filtered off, and the mixture was concentrated in vacuo. Purification of the residue over silica (0 to $10 \%$ $\mathrm{MeOH}$ in DCM) afforded the title compound as a colorless oil (80.0 $\mathrm{mg}, 0.315 \mathrm{mmol}, 88 \%): R_{f}=0.15(5 \% \mathrm{MeOH}$ in DCM); IR (neat) $3351,2919,2881,1072,1016 ;{ }^{1} \mathrm{H}$ NMR $\left(400 \mathrm{MHz}, \mathrm{CD}_{3} \mathrm{OD}\right) \delta 4.30$ (d, $J=7.8 \mathrm{~Hz}, 1 \mathrm{H}, \mathrm{H}-1), 4.03(\mathrm{dt}, J=10.1,7.1 \mathrm{~Hz}, 1 \mathrm{H}, \mathrm{CHH} \mathrm{OCH})_{2}$, $3.87(\mathrm{dd}, J=11.9,1.8 \mathrm{~Hz}, 1 \mathrm{H}, \mathrm{CHH} \mathrm{H}-6), 3.74(\mathrm{dt}, J=10.1,7.1 \mathrm{~Hz}, 1 \mathrm{H}$, CHH OCH$\left.{ }_{2}\right), 3.69-3.64(\mathrm{~m}, 1 \mathrm{H}, \mathrm{CHH} \mathrm{H}-6), 3.39-3.33(\mathrm{~m}, 1 \mathrm{H}, \mathrm{H}-$
4), 3.29-3.26 (m, 2H, H-3, H-5), 3.21-3.15 (m, 1H, H-2), 2.73 (t, $J=$ $7.1 \mathrm{~Hz}, 2 \mathrm{H}, \mathrm{CH}_{2} \mathrm{SMe}$ ), 2.13 (s, $\left.3 \mathrm{H}, \mathrm{CH}_{2} \mathrm{SMe}\right) ;{ }^{13} \mathrm{C} \mathrm{NMR}(101 \mathrm{MHz}$, $\left.\mathrm{CD}_{3} \mathrm{OD}\right) \delta 104.4(\mathrm{C}-1), 77.9(\mathrm{C}-3), 77.9(\mathrm{C}-4), 75.0(\mathrm{C}-2), 71.6(\mathrm{C}-$ 5), $70.0\left(\mathrm{OCH}_{2}\right), 62.7(\mathrm{C}-6), 34.3\left(\mathrm{CH}_{2} \mathrm{SMe}\right), 15.7\left(\mathrm{CH}_{2} \mathrm{SMe}\right)$; HRMS (ESI) $m / z[\mathrm{M}+\mathrm{Na}]^{+}$calcd for $\mathrm{C}_{9} \mathrm{H}_{18} \mathrm{O}_{6} \mathrm{SNa} 277.0714$, found 277.0716 .

[2-(2-(Methylthio)ethoxy)]-ethyl- $\beta$-D-glucopyranoside (25). The procedure as described for $\mathbf{2 4}$ was followed, using protected glycoside 22 (560 mg, $0.780 \mathrm{mmol}$ ) and THF/MeOH (10 mL, 1:1). Purification of the crude over silica ( 0 to $20 \%$ acetone in DCM) afforded the title compound as a white solid (200 mg, $0.670 \mathrm{mmol}, 86 \%): R_{f}=0.19(10 \%$ acetone in DCM); IR (neat) 3304, 2919, 1075, 1354, 1028; ${ }^{1} \mathrm{H}$ NMR $\left(400 \mathrm{MHz}, \mathrm{CD}_{3} \mathrm{OD}\right) \delta 4.31(\mathrm{~d}, J=7.8 \mathrm{~Hz}, 1 \mathrm{H}, \mathrm{H}-1), 4.05-3.96(\mathrm{~m}$, $1 \mathrm{H}, \mathrm{CHH} \mathrm{OCH}$ ), 3.87 (dd, $J=11.9,1.8 \mathrm{~Hz}, 1 \mathrm{H}, \mathrm{CHH} \mathrm{H}-6), 3.78-$ $3.62\left(\mathrm{~m}, 6 \mathrm{H}, \mathrm{CHH} \mathrm{H}-6, \mathrm{CHH} \mathrm{OCH}{ }_{2}, 2 \times \mathrm{OCH}_{2}\right), 3.40-3.25(\mathrm{~m}, 3 \mathrm{H}$, $\mathrm{H}-3, \mathrm{H}-4, \mathrm{H}-5$ ), 3.19 (dd, $J=9.3,7.5 \mathrm{~Hz}, 1 \mathrm{H}, \mathrm{H}-2), 2.68(\mathrm{t}, J=6.8 \mathrm{~Hz}$, $2 \mathrm{H}, \mathrm{CH}_{2} \mathrm{SMe}$ ), 2.13 (s, 3H, $\mathrm{CH}_{2} \mathrm{SMe}$ ); ${ }^{13} \mathrm{C} \mathrm{NMR}\left(101 \mathrm{MHz}, \mathrm{CD}_{3} \mathrm{OD}\right)$ $\delta 104.4$ (C-1), 78.0 (C-3), 78.0 (C-4), 75.1 (C-2), 71.6 (C-5), 71.5 $\left(\mathrm{OCH}_{2}\right), 71.2\left(\mathrm{OCH}_{2}\right), 69.7\left(\mathrm{OCH}_{2}\right), 62.8(\mathrm{C}-6), 34.2\left(\mathrm{CH}_{2} \mathrm{SMe}\right)$, $15.8\left(\mathrm{CH}_{2} \mathrm{SMe}\right) ; \mathrm{mp} 89.9-90.8^{\circ} \mathrm{C}$; HRMS (ESI) $\mathrm{m} / z[\mathrm{M}+\mathrm{Na}]^{+}$calcd for $\mathrm{C}_{11} \mathrm{H}_{22} \mathrm{O}_{7} \mathrm{SNa} 321.0978$, found 321.0976 .

2-[2-(2-(Methylthio)ethoxy)ethoxy]ethyl $\beta$-D-glucopyranoside (26). The protected glucoside 23 (973 $\mathrm{mg}, 1.28 \mathrm{mmol}$ ) was dissolved in $\mathrm{MeOH}(10 \mathrm{~mL})$, after which a catalytic amount of $\mathrm{NaOMe}$ was added. The solution was allowed to stir for $16 \mathrm{~h}$, after which Amberlite IR- $120 \mathrm{H}^{+}$was added, until reaching a neutral $\mathrm{pH}$. The resin was filtered off, and the mixture was concentrated in vacuo. Purification of the residue over silica $(0-10 \% \mathrm{MeOH}$ in $\mathrm{DCM})$ afforded the title compound as a colorless oil $(400 \mathrm{mg}, 1.17 \mathrm{mmol}, 91 \%): R_{f}=0.29(10 \%$ $\mathrm{MeOH}$ in DCM); $[\alpha]_{\mathrm{D}}^{20}(\mathrm{MeOH})-10.0$; IR (neat) 3371, 2915, 2874, 1073, 1031; ${ }^{1} \mathrm{H}$ NMR $\left(400 \mathrm{MHz}, \mathrm{CDCl}_{3}\right) \delta 4.35$ (d, $J=7.8 \mathrm{~Hz}, 1 \mathrm{H}, \mathrm{H}-$ 1), 4.06 (ddd, $\left.J=10.2,5.0,3.0 \mathrm{~Hz}, 1 \mathrm{H}, \mathrm{CHH} \mathrm{OCH}{ }_{2}\right), 3.90$ (dd, $J=11.9$, $\left.1.7 \mathrm{~Hz}, 1 \mathrm{H}, \mathrm{CHH} \mathrm{OCH}{ }_{2}\right), 3.82-3.65\left(\mathrm{~m}, 10 \mathrm{H}, \mathrm{CHH} \mathrm{OCH} \mathrm{CH}_{2}, \mathrm{H}-5, \mathrm{H}-6\right.$, $\left.3 \times \mathrm{CH}_{2} \mathrm{OCH}_{2}\right), 3.45-3.37(\mathrm{~m}, 1 \mathrm{H}, \mathrm{H}-3), 3.37-3.28(\mathrm{~m}, 1 \mathrm{H}, \mathrm{H}-4)$, $3.24(\mathrm{dd}, J=9.1,7.8 \mathrm{~Hz}, 1 \mathrm{H}, \mathrm{H}-2), 2.72\left(\mathrm{t}, J=6.8 \mathrm{~Hz}, 2 \mathrm{H}, \mathrm{OCH}_{2}\right), 2.17$ $\left(\mathrm{s}, 3 \mathrm{H}, \mathrm{SCH}_{3}\right) ;{ }^{13} \mathrm{C} \mathrm{NMR}\left(101 \mathrm{MHz}, \mathrm{CD}_{3} \mathrm{OD}\right) \delta 104.4(\mathrm{C}-1), 77.9(\mathrm{C}-$ 3), $75.0(\mathrm{C}-4), 71.6\left(\mathrm{OCH}_{2}\right), 71.5(\mathrm{C}-5), 71.5\left(2 \times \mathrm{OCH}_{2}\right), 71.1$ $\left(\mathrm{OCH}_{2}\right), 69.6\left(\mathrm{OCH}_{2}\right), 62.7(\mathrm{C}-6), 34.2\left(\mathrm{CH}_{2} \mathrm{SMe}\right), 15.9\left(\mathrm{CH}_{2} \mathrm{SMe}\right)$; HRMS (ESI) $m / z[\mathrm{M}+\mathrm{Na}]^{+}$calcd for $\mathrm{C}_{13} \mathrm{H}_{26} \mathrm{O}_{8} \mathrm{SNa} 365.1241$, found 365.1238

[1,3-Bis(methylthio)]-propyl-2,3,4,6-tetra-O-benzoyl- $\beta$-D-glucopyranoside (27). The general procedure described for 21 was followed, with 2,3,4,6-tetra- $O$-benzoyl- $\beta$-D-glucopyranosyl trichloroacetimidate $(5.00 \mathrm{~g}, 6.75 \mathrm{mmol})$ and 1,3-bis(methylthio)propanol $(830 \mu \mathrm{L}, 6.09$ $\mathrm{mmol})$. Purification of the residue by silica column purification $(0-20 \%$ EtOAc in PE) afforded the title compound as a clear oil (3.95 g, 5.40 mmol, 90\%): $R_{f}=0.55$ (20\% EtOAc in PE); IR (neat) 2919, 2853, 1722, 1601, 1259; ${ }^{1} \mathrm{H}$ NMR $\left(400 \mathrm{MHz}, \mathrm{CDCl}_{3}\right) \delta 8.07-8.00(\mathrm{~m}, 2 \mathrm{H}$, $\left.\mathrm{H}_{\text {arom }}\right), 7.99-7.94\left(\mathrm{~m}, 2 \mathrm{H}, \mathrm{H}_{\text {arom }}\right), 7.91\left(\mathrm{~d}, J=7.8 \mathrm{~Hz}, 2 \mathrm{H}, \mathrm{H}_{\text {arom }}\right)$, $7.85-7.79\left(\mathrm{~m}, 2 \mathrm{H}, \mathrm{H}_{\text {arom }}\right), 7.60-7.24\left(\mathrm{~m}, 12 \mathrm{H}, \mathrm{H}_{\text {arom }}\right), 5.91(\mathrm{t}, J=9.7$ $\mathrm{Hz}, 1 \mathrm{H}, \mathrm{H}-3), 5.65(\mathrm{t}, J=9.7 \mathrm{~Hz}, 1 \mathrm{H}, \mathrm{H}-4), 5.52(\mathrm{dd}, J=10.1,7.7 \mathrm{~Hz}$, $1 \mathrm{H}, \mathrm{H}-2), 5.09(\mathrm{~d}, J=7.9 \mathrm{~Hz}, 1 \mathrm{H}, \mathrm{H}-1), 4.67(\mathrm{dd}, J=12.1,3.1 \mathrm{~Hz}, 1 \mathrm{H}$, CHH H-6), 4.48 (dd, $J=12.2,5.6 \mathrm{~Hz}, 1 \mathrm{H}, \mathrm{CHH} \mathrm{H}-6$ ), 4.18 (ddd, $J=$ 9.3, 5.7, 3.0 Hz, 1H, H-5), 4.04-3.91 (m, $\left.1 \mathrm{H}, \mathrm{CH}\left(\mathrm{CH}_{2} \mathrm{SMe}\right)_{2}\right), 2.86$ (dd, $\left.J=13.8,4.4 \mathrm{~Hz}, 1 \mathrm{H}, \mathrm{CHH} \mathrm{CH}\left(\mathrm{CH}_{2} \mathrm{SMe}\right)_{2}\right), 2.81-2.71(\mathrm{~m}, 2 \mathrm{H}$, $\left.\mathrm{CH}_{2} \mathrm{CH}\left(\mathrm{CH}_{2} \mathrm{SMe}\right)_{2}\right), 2.61(\mathrm{td}, J=13.5,7.4 \mathrm{~Hz}, 1 \mathrm{H}, \mathrm{CHH}$ $\left.\mathrm{CH}\left(\mathrm{CH}_{2} \mathrm{SMe}\right)_{2}\right), 2.06$ (s, 3H, SMe), 1.90 (s, 3H, SMe); ${ }^{13} \mathrm{C} \mathrm{NMR}$ $\left(101 \mathrm{MHz}, \mathrm{CDCl}_{3}\right) \delta 166.2(\mathrm{C}=\mathrm{O} \mathrm{Bz}), 165.9(\mathrm{C}=\mathrm{O} \mathrm{Bz}), 165.4(\mathrm{C}=$ $\mathrm{O} \mathrm{Bz}), 165.3(\mathrm{C}=\mathrm{O} \mathrm{Bz}), 133.6\left(\mathrm{C}_{\mathrm{H} \text { arom }}\right), 133.4\left(\mathrm{C}_{\mathrm{H} \text { arom }}\right), 133.4$ $\left(\mathrm{C}_{\mathrm{H} \text { arom }}\right), 133.3\left(\mathrm{C}_{\mathrm{H} \text { arom }}\right), 130.0\left(\mathrm{C}_{\mathrm{H} \text { arom }}\right), 129.9\left(\mathrm{C}_{\mathrm{H} \text { arom }}\right), 129.9$ $\left(\mathrm{C}_{\mathrm{H} \text { arom }}\right), 129.9\left(\mathrm{C}_{\mathrm{H} \text { arom }}\right), 129.6\left(\mathrm{C}_{\mathrm{q} \text { arom }}\right), 129.5\left(\mathrm{C}_{\mathrm{q} \text { arom }}\right), 128.9$ $\left(\mathrm{C}_{\mathrm{q} \text { arom }}\right), 128.8\left(\mathrm{C}_{\mathrm{q} \text { arom }}\right), 128.6\left(\mathrm{C}_{\mathrm{H} \text { arom }}\right), 128.4\left(\mathrm{C}_{\mathrm{H} \text { arom }}\right), 101.7(\mathrm{C}-$ 1), $80.2\left(\mathrm{CH}\left(\mathrm{CH}_{2} \mathrm{SMe}\right)_{2}\right), 73.0(\mathrm{C}-3), 72.4(\mathrm{C}-5), 72.1$ (C-2), 69.9 (C4), $63.2(\mathrm{C}-6), 38.4\left(\mathrm{CH}_{2} \mathrm{CH}\left(\mathrm{CH}_{2} \mathrm{SMe}\right)_{2}\right), 37.8\left(\mathrm{CH}_{2} \mathrm{CH}-\right.$ $\left.\left(\mathrm{CH}_{2} \mathrm{SMe}\right)_{2}\right), 16.7(2 \times \mathrm{SMe})$; HRMS (ESI) $\mathrm{m} / z\left[\mathrm{M}+\mathrm{NH}_{4}\right]^{+}$calcd for $\mathrm{C}_{39} \mathrm{H}_{42} \mathrm{O}_{10} \mathrm{~S}_{2} \mathrm{~N} 748.2245$, found 748.2254.

[1,3-Bis(methylthio)]-propyl- $\beta$-D-glucopyranoside (28). The procedure as described for $\mathbf{2 2}$ was followed, using protected glycoside $\mathbf{2 7}$ $(3.20 \mathrm{~g}, 4.38 \mathrm{mmol})$ and DCM/MeOH $(50 \mathrm{~mL}, 1: 50)$. Purification of the residue over silica ( 0 to $10 \% \mathrm{MeOH}$ in DCM) afforded 28 as a white 
foam ( $960 \mathrm{mg}, 3.05 \mathrm{mmol}, 70 \%): R_{f}=0.24$ (100\% EtOAc); IR (neat) $3368,2916,1424,1071,1016 ;{ }^{1} \mathrm{H}$ NMR $\left(400 \mathrm{MHz}, \mathrm{CD}_{3} \mathrm{OD}\right) \delta 4.45$ $(\mathrm{d}, J=7.8 \mathrm{~Hz}, 1 \mathrm{H}, \mathrm{H}-1), 4.06\left(\mathrm{p}, J=5.8 \mathrm{~Hz}, 1 \mathrm{H}, \mathrm{CH}\left(\mathrm{CH}_{2} \mathrm{SMe}\right)_{2}\right)$, 3.90-3.83 (m, 1H, CHH H-6), 3.70-3.63 (m, 1H, CHH H-6), 3.41$3.33(\mathrm{~m}, 1 \mathrm{H}, \mathrm{H}-3), 3.33-3.26$ (m, 2H, H-4, H-5), 3.24-3.14 (m, 1H, $\mathrm{H}-2)$, 2.94-2.83 (m, 3H, CHH, $\left.\mathrm{CH}_{2} \mathrm{CH}\left(\mathrm{CH}_{2} \mathrm{SMe}\right)_{2}\right), 2.79$ (dd, $J=$ 13.8, $\left.5.6 \mathrm{~Hz}, 1 \mathrm{H}, \mathrm{CHH} \mathrm{CH}\left(\mathrm{CH}_{2} \mathrm{SMe}\right)_{2}\right), 2.15(\mathrm{~s}, 6 \mathrm{H}, 2 \times \mathrm{SMe}) ;{ }^{13} \mathrm{C}$ NMR $\left(101 \mathrm{MHz}, \mathrm{CD}_{3} \mathrm{OD}\right) \delta 104.1(\mathrm{C}-1), 79.4\left(\mathrm{CH}\left(\mathrm{CH}_{2} \mathrm{SMe}\right)_{2}\right), 77.9$ (C-3), 77.9 (C-4), 75.2 (C-2), 71.5 (C-5), 62.7 (C-6), $39.0\left(\mathrm{CH}_{2}\right.$ $\left.\mathrm{CH}\left(\mathrm{CH}_{2} \mathrm{SMe}\right)_{2}\right) \quad 37.9\left(\mathrm{CH}_{2} \mathrm{CH}\left(\mathrm{CH}_{2} \mathrm{SMe}\right)_{2}\right), 16.6(\mathrm{SMe}), 16.4$ $(\mathrm{SMe})$; HRMS (ESI) $m / z[\mathrm{M}+\mathrm{Na}]^{+}$calcd for $\mathrm{C}_{11} \mathrm{H}_{22} \mathrm{O}_{6} \mathrm{~S}_{2} \mathrm{Na}$ 337.0750, found 337.0752

$\left[2,2^{\prime}: 6^{\prime}, 2^{\prime \prime}-\right.$ Terpyridine]-4'-sulfonic acid (30 (HS-tpy)). [2,2':6', $2^{\prime \prime}$ Terpyridine $]-4^{\prime}\left(1^{\prime} H\right)$-thione ${ }^{46}(534 \mathrm{mg}, 2.01 \mathrm{mmol})$ was suspended in acetic acid $(6 \mathrm{~mL})$. and to this mixture was added $30 \% \mathrm{H}_{2} \mathrm{O}_{2}(1 \mathrm{~mL})$. The resulting purple mixture was heated at $70{ }^{\circ} \mathrm{C}$ for $12 \mathrm{~h}$ and concentrated in vacuo. The crude was then redissolved in $\mathrm{H}_{2} \mathrm{O}$, followed by the addition of $10 \% \mathrm{Pd} / \mathrm{C}(32 \mathrm{mg})$ and purged with $\mathrm{H}_{2}(5$ min). After stirring overnight at $40{ }^{\circ} \mathrm{C}$ under a $\mathrm{H}_{2}$ atmosphere, the reaction was filtered over Celite, concentrated, and purified over silica ( 0 to $10 \% \mathrm{MeOH}$ in $\mathrm{DCM}$ ), affording the title compound as a bright yellow powder (151 mg, $0.428 \mathrm{mmol}, 24 \%): R_{f}=0.37(20 \% \mathrm{MeOH}$ in DCM); IR (neat) 3391, 3064, 1622, 1398, 1189; ${ }^{1} \mathrm{H}$ NMR (400 MHz, $\left.\mathrm{D}_{2} \mathrm{O}\right) \delta 8.09\left(\mathrm{dd}, J=4.9,1.9 \mathrm{~Hz}, 2 \mathrm{H}, \mathrm{T}_{3}, \mathrm{~T}_{3}{ }^{\prime \prime}\right), 7.84\left(\mathrm{~s}, 2 \mathrm{H}, \mathrm{T}_{3}{ }^{\prime}, \mathrm{T}_{5}{ }^{\prime}\right)$, $7.61\left(\mathrm{~d}, J=7.4 \mathrm{~Hz}, 2 \mathrm{H}, \mathrm{T}_{6}, \mathrm{~T}_{6}{ }^{\prime \prime}\right), 7.54\left(\mathrm{td}, J=7.7,1.9 \mathrm{~Hz}, 2 \mathrm{H}, \mathrm{T}_{4}, \mathrm{~T}_{4}^{\prime \prime}\right)$, 7.15 (ddd, $\left.J=7.4,5.0,1.4 \mathrm{~Hz}, 2 \mathrm{H}, \mathrm{T}_{5}, \mathrm{~T}_{5}{ }^{\prime \prime}\right) ;{ }^{13} \mathrm{C} \mathrm{NMR}(101 \mathrm{MHz}$, $\left.\mathrm{D}_{2} \mathrm{O}\right) \delta 154.9\left(\mathrm{C}_{\mathrm{q} \text { arom }}\right), 152.7\left(\mathrm{C}_{\mathrm{q} \text { arom }}\right), 152.7\left(\mathrm{C}_{\mathrm{q} \text { arom }}\right), 148.1\left(\mathrm{~T}_{3}\right.$, $\left.\mathrm{T}_{3}{ }^{\prime \prime}\right), 138.1\left(\mathrm{~T}_{4}, \mathrm{~T}_{4}{ }^{\prime \prime}\right), 124.9\left(\mathrm{~T}_{5}, \mathrm{~T}_{5}{ }^{\prime \prime}\right), 121.8\left(\mathrm{~T}_{6}, \mathrm{~T}_{6}{ }^{\prime \prime}\right), 116.5\left(\mathrm{~T}_{3}\right.$, $\mathrm{T}_{3}{ }^{\prime \prime}$ ); HRMS (ESI) $m / z[\mathrm{M}+\mathrm{H}]^{+}$calcd for $\mathrm{C}_{15} \mathrm{H}_{12} \mathrm{~N}_{3} \mathrm{O}_{3} \mathrm{~S} 314.0594$, found 314.0600 .

[Ru(S-tpy)(bpy)(Cl)] (31). Compound 30 (134 mg, $0.428 \mathrm{mmol})$ was dissolved in $\mathrm{MeOH}(10 \mathrm{~mL})$, and to this solution was added $100 \mathrm{mg}$ of washed Amberlite $\mathrm{Na}^{+}$. After the mixture stirred for $5 \mathrm{~min}$ at $\mathrm{rt}$, the ionexchange resin was filtered off and the filtrate was concentrated in vacuo, affording a pinkish solid. This compound was then together with dichloro( $p$-cymene)ruthenium(II) dimer (130 mg, $0.213 \mathrm{mmol}$ ) redissolved in deoxygenated $\mathrm{MeOH}(5 \mathrm{~mL})$ and heated to $60{ }^{\circ} \mathrm{C}$. A solution of bpy $(69.0 \mathrm{mg}, 0.440 \mathrm{mmol})$ in $\mathrm{MeOH}(2.3 \mathrm{~mL})$ was then added dropwise over $10 \mathrm{~min}$ from which the color of the solution changed from purple to red. After stirring for $2 \mathrm{~h}$ under nitrogen, the solution was allowed to cool to rt, after which $\mathrm{Et}_{2} \mathrm{O}(20 \mathrm{~mL})$ was added. The resulting precipitate was filtered and washed with $\mathrm{Et}_{2} \mathrm{O}(3 \times)$, affording a brown powder $(185 \mathrm{mg}, 0.306 \mathrm{mmol}, 72 \%): R_{f}=0.29(10 \%$ $\mathrm{MeOH}$ in DCM); $\mathrm{mp}>350{ }^{\circ} \mathrm{C}$; HRMS (ESI) $m / z[\mathrm{M}+\mathrm{H}]^{+}$calcd for $\mathrm{C}_{25} \mathrm{H}_{19} \mathrm{ClN}_{5} \mathrm{O}_{3} \mathrm{RuS}$ 605.9935, found 605.9946.

2-(2-(2-(Methylthio)ethoxy)ethoxy)ethyl 4-methylbenzenesulfonate (32). Compound 19 (715 mg, $3.97 \mathrm{mmol})$ was dissolved in dry $\operatorname{DCM}(40 \mathrm{~mL})$, and the mixture was cooled to $0{ }^{\circ} \mathrm{C}$. To this solution were added $\mathrm{Et}_{3} \mathrm{~N}(850 \mathrm{ul}, 6.09 \mathrm{mmol})$ and Ts-Cl $(1.12 \mathrm{~g}, 5.87 \mathrm{mmol})$. The reaction was allowed to stir overnight, after which it was diluted with DCM $(100 \mathrm{~mL})$ and transferred to a separatory funnel. After washing with water $(1 \times)$ and brine $(1 \times)$, the layers were separated, and the organic layer was dried $\left(\mathrm{Na}_{2} \mathrm{SO}_{4}\right)$ and concentrated in vacuo. Purification of the residue by silica column chromatography ( 0 to $50 \%$ EtOAc in PE) afforded the title compound as a colorless oil (1.22 g, $3.64 \mathrm{mmol}, 92 \%): R_{f}=0.78$ (50\% EtOAc in PE); IR (neat) 2917, 2868, 1598, 1353, 1174; ${ }^{1} \mathrm{H}$ NMR (400 MHz, $\left.\mathrm{CDCl}_{3}\right) \delta 7.73(\mathrm{~d}, J=8.3 \mathrm{~Hz}$, $\left.2 \mathrm{H}, \mathrm{H}_{\text {arom }}\right), 7.30$ (d, $\left.J=8.1 \mathrm{~Hz}, 2 \mathrm{H}, \mathrm{H}_{\text {arom }}\right), 4.18-4.02\left(\mathrm{~m}, 2 \mathrm{H}, \mathrm{CH}_{2}\right)$, $3.65-3.61\left(\mathrm{~m}, 2 \mathrm{H}, \mathrm{CH}_{2}\right), 3.57\left(\mathrm{t}, J=6.8 \mathrm{~Hz}, 2 \mathrm{H}, \mathrm{CH}_{2}\right), 3.51(\mathrm{~m}, 4 \mathrm{H}, 2$ $\left.\times \mathrm{CH}_{2}\right), 2.60\left(\mathrm{t}, J=6.8 \mathrm{~Hz}, 2 \mathrm{H}, \mathrm{CH}_{2}\right), 2.39\left(\mathrm{~s}, 3 \mathrm{H}, \mathrm{CH}_{3}\right.$ tosyl), $2.07(\mathrm{~s}$, $\left.3 \mathrm{H}, \mathrm{CH}_{3}\right) ;{ }^{13} \mathrm{C} \mathrm{NMR}\left(100 \mathrm{MHz}, \mathrm{CDCl}_{3}\right) \delta 144.7\left(\mathrm{C}_{\mathrm{q} \text { arom }}\right), 132.7$ $\left(\mathrm{C}_{\mathrm{q} \text { arom }}\right), 129.7\left(\mathrm{C}_{\mathrm{H} \text { arom }}\right), 127.7\left(\mathrm{C}_{\mathrm{H} \text { arom }}\right), 70.5\left(\mathrm{CH}_{2}\right), 70.4\left(\mathrm{CH}_{2}\right)$, 70.0 $\left(\mathrm{CH}_{2}\right), 69.2\left(\mathrm{CH}_{2}\right), 68.5\left(\mathrm{CH}_{2}\right), 33.2\left(\mathrm{SCH}_{2}\right), 21.5\left(\mathrm{CH}_{3}\right.$ tosyl), $15.8\left(\mathrm{SCH}_{3}\right)$; HRMS (ESI) $m / z[\mathrm{M}+\mathrm{Na}]^{+}$calcd for $\mathrm{C}_{14} \mathrm{H}_{22} \mathrm{O}_{5} \mathrm{~S}_{2} \mathrm{Na}$ 357.0801 , found 357.0800 .

3,4,6-Tri-O-(4-methoxybenzyl)-D-glucal (34). To a cooled solution $\left(0{ }^{\circ} \mathrm{C}\right)$ of D-glucal in dry DMF $(230 \mathrm{~mL})$ was slowly added $\mathrm{NaH}(60 \%$ dispersion in mineral oil, $3.10 \mathrm{~g}, 77.5 \mathrm{mmol})$ followed by the addition of 4-methoxybenzyl chloride $(10.1 \mathrm{~mL}, 74.5 \mathrm{mmol})$. After the mixture stirred overnight under a dinitrogen atmosphere, $\mathrm{H}_{2} \mathrm{O}(10 \mathrm{~mL})$ was added and the mixture was allowed to stir for another $10 \mathrm{~min}$. The mixture was further diluted with EtOAc $(200 \mathrm{~mL})$, transferred to a separatory funnel, and washed with water $(3 x)$ and brine $(3 x)$. The organic layer was dried over $\mathrm{Na}_{2} \mathrm{SO}_{4}$ and concentrated in vacuo. Purification by silica column chromatography ( 0 to $15 \%$ EtOAc in PE) afforded 34 (9.82 g, $19.4 \mathrm{mmol}, 84 \%$ ) as a clear oil that solidified upon standing over a longer time: $R_{f}=0.66(10 \%$ EtOAc in PE); IR (neat) 2999, 2863, 2907, 1647, 1512; ${ }^{1} \mathrm{H}$ NMR (400 MHz, $\left.\mathrm{CDCl}_{3}\right) \delta 7.16$ (d, $J$ $\left.=8.3 \mathrm{~Hz}, 4 \mathrm{H}, \mathrm{H}_{\text {arom }}\right), 7.04\left(\mathrm{~d}, J=8.5 \mathrm{~Hz}, 2 \mathrm{H}, \mathrm{H}_{\text {arom }}\right), 6.75(\mathrm{dd}, J=11.9$, $\left.8.1 \mathrm{~Hz}, 6 \mathrm{H}, \mathrm{H}_{\text {arom }}\right), 6.31(\mathrm{~d}, J=6.2 \mathrm{~Hz}, 1 \mathrm{H}, \mathrm{H}-1), 4.74(\mathrm{dd}, J=6.2,3.2$ $\mathrm{Hz}, 1 \mathrm{H}, \mathrm{H}-2), 4.64$ (d, $J=10.9 \mathrm{~Hz}, 1 \mathrm{H}, \mathrm{CHH} \mathrm{PMB}), 4.52-4.35(\mathrm{~m}$, $5 \mathrm{H}, \mathrm{CHH}$ PMB, $\left.2 \times \mathrm{CH}_{2} \mathrm{PMB}\right), 4.07$ (dd, $J=6.5,2.2 \mathrm{~Hz}, 1 \mathrm{H}, \mathrm{H}-3$ ), $3.92(\mathrm{dt}, J=8.6,4.1 \mathrm{~Hz}, 1 \mathrm{H}, \mathrm{H}-5), 3.70\left(\mathrm{~s}, 3 \mathrm{H}, \mathrm{CH}_{3} \mathrm{PMB}\right), 3.69(\mathrm{~s}, 4 \mathrm{H}$, $\left.\mathrm{CH}_{3} \mathrm{PMB}, \mathrm{H}-4\right), 3.69$ (s, $\left.3 \mathrm{H}, \mathrm{CH}_{3} \mathrm{PMB}\right), 3.66-3.58\left(\mathrm{~m}, 2 \mathrm{H}, \mathrm{CH}_{2} \mathrm{H}-\right.$ 6); ${ }^{13} \mathrm{C} \mathrm{NMR}\left(101 \mathrm{MHz}, \mathrm{CDCl}_{3}\right) \delta 159.3\left(\mathrm{C}_{\mathrm{H} \text { arom }}\right), 159.3\left(\mathrm{C}_{\mathrm{H} \text { arom }}\right)$, $159.3\left(\mathrm{C}_{\mathrm{H} \text { arom }}\right), 144.7(\mathrm{C}-1), 130.6\left(\mathrm{C}_{\mathrm{q} \text { arom }}\right), 130.4\left(\mathrm{C}_{\mathrm{q} \text { arom }}\right), 130.1$ $\left(\mathrm{C}_{\mathrm{q} \text { arom }}\right), 129.7\left(\mathrm{C}_{\mathrm{H} \text { arom }}\right), 129.6\left(\mathrm{C}_{\mathrm{H} \text { arom }}\right), 129.5\left(\mathrm{C}_{\mathrm{H} \text { arom }}\right), 113.9$ $\left(\mathrm{C}_{\mathrm{H} \text { arom }}\right), 113.9\left(\mathrm{C}_{\mathrm{H} \text { arom }}\right), 100.2(\mathrm{C}-2), 76.9(\mathrm{C}-5), 75.6(\mathrm{C}-2), 74.2$ (C-4), $73.5\left(\mathrm{CH}_{2} \mathrm{PMB}\right), 73.2\left(\mathrm{CH}_{2} \mathrm{PMB}\right), 70.3\left(\mathrm{CH}_{2} \mathrm{PMB}\right), 68.3$ (C6), $55.4\left(3 \times \mathrm{CH}_{3} \mathrm{PMB}\right)$; HRMS (ESI) $m / z\left[\mathrm{M}+\mathrm{NH}_{4}\right]^{+}$calcd for $\mathrm{C}_{30} \mathrm{H}_{38} \mathrm{O}_{7} \mathrm{~N}$ 524.2643, found 524.2655.

(4-Methoxybenzyl)-3,4,6-Tri-O-(4-methoxybenzyl)- $\beta$-D-glucopyranoside (35). To a solution of protected glycoside $35(821 \mathrm{mg}, 1.62$ $\mathrm{mmol})$ in dry DCM $(8 \mathrm{~mL})$ under a dinitrogen atmosphere were added freshly activated $4 \AA$ molecular sieves. After stirring for $15 \mathrm{~min}$, the mixture was allowed to cool to $0{ }^{\circ} \mathrm{C}$ and freshly prepared dimethyldioxirane in acetone $(20 \mathrm{~mL}, 88 \mathrm{mM})$ was slowly added. The mixture was stirred for $3 \mathrm{~h}$ and allowed to reach $\mathrm{rt}$, after which it was filtered over Celite and concentrated in vacuo. The crude was then, together with 4-methoxyl benzyl alcohol (335 mg, $2.42 \mathrm{mmol}$ ), redissolved in dry THF under a dinitrogen atmosphere, followed by the addition of freshly activated $4 \AA$ molecular sieves. After stirring for 15 min, the mixture was cooled down to $-78{ }^{\circ} \mathrm{C}$ and a cooled solution $(10$ $\left.{ }^{\circ} \mathrm{C}\right)$ of $\mathrm{ZnCl}_{2}$ in dry THF $(2.43 \mathrm{~mL}, 1 \mathrm{M})$ was added dropwise over 10 min. The mixture was allowed to stir overnight at rt, after which it was filtered over Celite, concentrated in vacuo, and purified by silica column chromatography ( 0 to $20 \%$ EtOAc in PE) to afford 35 (413 mg, 0.625 mmol, $39 \%$ over two steps) as a colorless oil: $R_{f}=0.48$ (40\% EtOAc in $\mathrm{PE})$; IR (neat) $3480,3000,2907,1611,1511 ;{ }^{1} \mathrm{H}$ NMR $(400 \mathrm{MHz}$, $\left.\mathrm{CDCl}_{3}\right) \delta 7.30\left(\mathrm{dd}, J=8.5,4.8 \mathrm{~Hz}, 6 \mathrm{H}, \mathrm{H}_{\text {arom }}\right), 7.08(\mathrm{~d}, J=8.6 \mathrm{~Hz}, 2 \mathrm{H}$, $\left.\mathrm{H}_{\text {arom }}\right), 6.98-6.77\left(\mathrm{~m}, 8 \mathrm{H}, \mathrm{H}_{\text {arom }}\right), 4.87$ (dd, $J=15.4,11.2 \mathrm{~Hz}, 2 \mathrm{H}, \mathrm{CH}_{2}$ PMB), 4.76 (dd, $\left.J=10.7,6.4 \mathrm{~Hz}, 2 \mathrm{H}, \mathrm{CH}_{2} \mathrm{PMB}\right), 4.63-4.42(\mathrm{~m}, 4 \mathrm{H}, 2$ $\left.\times \mathrm{CH}_{2} \mathrm{PMB}\right), 4.32(\mathrm{~d}, J=7.3 \mathrm{~Hz}, 1 \mathrm{H}, \mathrm{H}-1), 3.80\left(\mathrm{~s}, 6 \mathrm{H}, 2 \times \mathrm{CH}_{3}\right.$ PMB), 3.79 (s, 3H, $\mathrm{CH}_{3} \mathrm{PMB}$ ), 3.79 (s, $\left.3 \mathrm{H}, \mathrm{CH}_{3} \mathrm{PMB}\right), 3.70(\mathrm{~m}, 2 \mathrm{H}$, H-6), 3.62-3.50 (m, 3H, H-2, H-3, H-4), 3.45 (dd, $J=9.9,4.1 \mathrm{~Hz}, 1 \mathrm{H}$, $\mathrm{H}-5), 2.41(\mathrm{~s}, 1 \mathrm{H}, \mathrm{OH}) ;{ }^{13} \mathrm{C}$ NMR $\left(101 \mathrm{MHz} \mathrm{CDCl}_{3}\right) \delta 159.5$ $\left(\mathrm{C}_{\mathrm{q} \text { arom }}\right), 159.3\left(\mathrm{C}_{\mathrm{q} \text { arom }}\right), 159.3\left(\mathrm{C}_{\mathrm{q} \text { arom }}\right), 130.9\left(\mathrm{C}_{\mathrm{q} \text { arom }}\right), 130.4$ $\left(\mathrm{C}_{\mathrm{q} \text { arom }}\right), 130.3\left(\mathrm{C}_{\mathrm{q} \text { arom }}\right), 130.0\left(\mathrm{C}_{\mathrm{H} \text { arom }}\right), 129.7\left(\mathrm{C}_{\mathrm{H} \text { arom }}\right), 129.7$ $\left(\mathrm{C}_{\mathrm{H} \text { arom }}\right), 129.6\left(\mathrm{C}_{\mathrm{H} \text { arom }}\right), 129.3\left(\mathrm{C}_{\mathrm{q} \text { arom }}\right), 114.0\left(\mathrm{C}_{\mathrm{H} \text { arom }}\right), 113.9$ $\left(\mathrm{C}_{\mathrm{H} \text { arom }}\right), 113.9\left(\mathrm{C}_{\mathrm{H} \text { arom }}\right), 101.5(\mathrm{C}-1), 84.3$ (C-2), $77.4(\mathrm{C}-3), 75.3$ (C-4), 74.9 ( $\left.\mathrm{CH}_{2} \mathrm{PMB}\right), 74.7$ (C-5), $73.2\left(\mathrm{CH}_{2} \mathrm{PMB}\right), 70.8\left(\mathrm{CH}_{2}\right.$ PMB), 68.5 (C-6), $55.4\left(4 \times \mathrm{CH}_{3} \mathrm{PMB}\right) ; \mathrm{HRMS}(\mathrm{ESI}) \mathrm{m} / z[\mathrm{M}+$ $\left.\mathrm{NH}_{4}\right]^{+}$calcd for $\mathrm{C}_{38} \mathrm{H}_{48} \mathrm{O}_{10} \mathrm{~N}$ 678.3273, found 678.3302.

(4-Methoxybenzyl)-2-O-(2-[2-(2-(methylthio)ethoxy)ethoxy]ethyl)-3,4,6-tetra-O-(4-methoxybenzyl)- $\beta$-D-glucopyranoside (36). Glycoside 35 (333 mg, $0.504 \mathrm{mmol})$ was dissolved in dry DMF (5 $\mathrm{mL})$ and cooled to $0{ }^{\circ} \mathrm{C}$. To this solution was added $\mathrm{NaH}(60 \%$ dispersion in mineral oil, $26 \mathrm{mg}, 0.65 \mathrm{mmol}$ ) portionwise followed by the addition of tosylate $32(185 \mathrm{mg}, 0.554 \mathrm{mmol})$. After the mixture stirred for $6 \mathrm{~h}$ at $\mathrm{rt}$ under a dry atmosphere, $\mathrm{MeOH}$ was added $(1 \mathrm{~mL})$. The mixture was then diluted with EtOAc $(50 \mathrm{~mL})$, transferred to a separatory funnel, and washed with water $(3 \times)$ and brine $(3 \times)$. The organic layer was dried $\left(\mathrm{Na}_{2} \mathrm{SO}_{4}\right)$ and concentrated in vacuo. Purification of the residue by column chromatography (0 to $30 \%$ EtOAc in PE) afforded the title compound $\mathbf{3 6}$ as a milky oil (334 mg, $0.405 \mathrm{mmol}, 80 \%): R_{f}=0.39$ (40\% EtOAc in PE); IR (neat) 2999, 2864, 2835, 1612, 1512; ${ }^{1} \mathrm{H}$ NMR $\left(400 \mathrm{MHz}, \mathrm{CDCl}_{3}\right) \delta 7.39-7.18(\mathrm{~m}$, $\left.6 \mathrm{H}, \mathrm{H}_{\text {arom }}\right), 7.07\left(\mathrm{dd}, J=8.7,4.8 \mathrm{~Hz}, 2 \mathrm{H}, \mathrm{H}_{\text {arom }}\right), 6.92-6.75(\mathrm{~m}, 8 \mathrm{H}$, $\left.\mathrm{H}_{\text {arom }}\right)$, 4.96-4.80 (m, $\left.2 \mathrm{H}, \mathrm{CH}_{2} \mathrm{PMB}\right), 4.78-4.66\left(\mathrm{~m}, 2 \mathrm{H}, \mathrm{CH}_{2} \mathrm{PMB}\right)$, $4.62-4.37$ (m, 5H, $\mathrm{CH}_{2}$ PMB, H-1), $4.06(\mathrm{dt}, J=9.9,4.6 \mathrm{~Hz}, 1 \mathrm{H}, \mathrm{CHH}$ 
$\left.\mathrm{OCH}_{2}\right), 3.85\left(\mathrm{q}, J=5.2 \mathrm{~Hz}, 1 \mathrm{H}, \mathrm{CHH} \mathrm{OCH}{ }_{2}\right), 3.81\left(\mathrm{~s}, 3 \mathrm{H}, \mathrm{CH}_{3} \mathrm{PMB}\right)$, 3.80 (s, 3H, $\mathrm{CH}_{3} \mathrm{PMB}$ ), 3.79 (s, 3H, $\mathrm{CH}_{3} \mathrm{PMB}$ ), 3.79 (s, 3H, $\mathrm{CH}_{3}$ PMB), 3.74-3.66 (m, 2H, H-6), 3.66-3.53 (m, 9H, H-3, $\left.4 \times \mathrm{OCH}_{2}\right)$, $3.49(\mathrm{t}, J=9.2 \mathrm{~Hz}, 1 \mathrm{H}, \mathrm{H}-4), 3.40$ (ddd, $J=9.7,5.1,2.2 \mathrm{~Hz}, 1 \mathrm{H}, \mathrm{H}-5)$, $3.29(\mathrm{t}, J=8.3 \mathrm{~Hz}, 1 \mathrm{H}, \mathrm{H}-2), 2.62\left(\mathrm{t}, J=7.0 \mathrm{~Hz}, 2 \mathrm{H}, \mathrm{CH}_{2} \mathrm{SMe}\right), 2.10(\mathrm{~s}$, $\left.3 \mathrm{H}, \mathrm{CH}_{2} \mathrm{SMe}\right) ;{ }^{13} \mathrm{C}$ NMR (101 MHz, $\left.\mathrm{CDCl}_{3}\right) \delta 159.3\left(\mathrm{C}_{\mathrm{q}}\right.$ arom), $159.3\left(\mathrm{C}_{\mathrm{q}}\right.$ arom $), 159.3\left(\mathrm{C}_{\mathrm{q}}\right.$ arom $), 159.3\left(\mathrm{C}_{\mathrm{q}}\right.$ arom $), 131.1\left(\mathrm{C}_{\mathrm{q}}\right.$ arom $)$, $130.5\left(\mathrm{C}_{\mathrm{q}}\right.$ arom $), 130.4\left(\mathrm{C}_{\mathrm{q}}\right.$ arom $), 129.8\left(\mathrm{C}_{\mathrm{H}}\right.$ arom $), 129.7\left(\mathrm{C}_{\mathrm{H}}\right.$ arom $)$, $129.7\left(\mathrm{C}_{\mathrm{H}}\right.$ arom $), 129.6\left(\mathrm{C}_{\mathrm{H}}\right.$ arom $), 113.8\left(\mathrm{C}_{\mathrm{H}}\right.$ arom $), 102.1(\mathrm{C}-1)$, 84.4 (C-4), 83.3 (C-2), 77.6 (C-4), 75.3 ( $\left.\mathrm{CH}_{2} \mathrm{PMB}\right), 74.9$ (C-5), 74.7 $\left(\mathrm{CH}_{2} \mathrm{PMB}\right), 73.2\left(\mathrm{CH}_{2} \mathrm{PMB}\right), 72.1\left(\mathrm{OCH}_{2}\right), 70.9\left(\mathrm{OCH}_{2}\right), 70.9$ $\left(\mathrm{CH}_{2} \mathrm{PMB}\right), 70.6(\mathrm{OCH} 2), 70.5(\mathrm{OCH} 2), 70.4(\mathrm{OCH} 2), 68.7(\mathrm{C}-6)$, $55.4\left(4 \times \mathrm{CH}_{3} \mathrm{PMB}\right), 33.4\left(\mathrm{CH}_{2} \mathrm{SMe}\right), 16.1\left(\mathrm{CH}_{2} \mathrm{SMe}\right) ; \mathrm{HRMS}(\mathrm{ESI})$ $m / z\left[\mathrm{M}+\mathrm{NH}_{4}\right]^{+}$calcd for $\mathrm{C}_{45} \mathrm{H}_{62} \mathrm{O}_{12} \mathrm{SN} 840.3987$, found 840.4002.

2-O-(2-[2-(2-(Methylthio)ethoxy)ethoxy]ethyl)- $\alpha / \beta$-D-glucopyranoside (H37). Compound $36(241 \mathrm{mg}, 0.293 \mathrm{mmol})$ was dissolved in a mixture of DCM/HFIP (1:1, $3 \mathrm{~mL})$, and to this solution were added 5 drops of $37 \% \mathrm{HCl}$ in $\mathrm{H}_{2} \mathrm{O}$. The color immediately changed to dark red, and after stirring for $5 \mathrm{~min}$, the mixture was quenched upon the addition of $\mathrm{Et}_{3} \mathrm{~N}(500 \mu \mathrm{L}, 3.59 \mathrm{mmol})$. The mixture was then concentrated in vacuo and redissolved in $\mathrm{H}_{2} \mathrm{O}(5.8 \mathrm{~mL})$, followed by the addition of a solution of $\mathrm{MeNH}_{2}$ in $\mathrm{MeOH}(145 \mu \mathrm{L}, 2 \mathrm{M}, 0.29 \mathrm{mmol})$. After the reaction mixture was heated for $30 \mathrm{~min}$ at $60{ }^{\circ} \mathrm{C}$, the solvents were removed under reduced pressure and the resulting residue was purified by silica column chromatography ( 0 to $20 \% \mathrm{MeOH}$ in DCM) to afford the fully deprotected hemiacetal $\mathrm{H} 37(67 \mathrm{mg}, 0.196 \mathrm{mmol}, 67 \%)$ as a clear oil: $R_{f}=0.54$ (25\% MeOH in DCM); IR (neat) 3411, 2917, 2865, 1115,$1042 ;{ }^{1} \mathrm{H}$ NMR $\left(400 \mathrm{MHz}, \mathrm{CD}_{3} \mathrm{OD}\right) \delta 5.29(\mathrm{~d}, J=3.5 \mathrm{~Hz}, 1 \mathrm{H}$, $\mathrm{H}-1 \alpha), 4.53(\mathrm{~d}, J=7.8 \mathrm{~Hz}, 1 \mathrm{H}, \mathrm{H}-1 \beta), 4.04(\mathrm{dt}, J=11.3,4.4 \mathrm{~Hz}, 1 \mathrm{H}$, CHH H-6), 3.89-3.70 (m, 8H), 3.70-3.59 (m, 19H), 3.42-3.32 (m, $1 \mathrm{H}, \mathrm{H}-3 \beta), 3.30-3.20(\mathrm{~m}, 2 \mathrm{H}), 3.03-2.86(\mathrm{~m}, 1 \mathrm{H}, \mathrm{H}-2 \beta), 2.68(\mathrm{t}, J=$ $\left.6.8 \mathrm{~Hz}, 4 \mathrm{H}, 2 \times \mathrm{CH}_{2} \mathrm{SMe}\right), 2.13\left(\mathrm{~s}, 6 \mathrm{H}, 2 \times \mathrm{CH}_{2} \mathrm{SMe}\right) ;{ }^{13} \mathrm{C} \mathrm{NMR}(101$ $\left.\mathrm{MHz}, \mathrm{CD}_{3} \mathrm{OD}\right) \delta 98.1(\mathrm{C}-1 \beta), 91.8(\mathrm{C}-1 \alpha), 85.1$ (C-1 $\left.\beta\right), 82.4,77.9$, 77.5, 73.9, 72.8, 72.6, 71.9, 71.9, 71.6, 71.6, 71.5, 71.5, 71.4, 71.2, 71.1, 71.0, 62.8 (C-6 $\alpha), 62.7(\mathrm{C}-6 \beta), 34.2\left(2 \times \mathrm{CH}_{2} \mathrm{SMe}\right), 15.9(2 \times$ $\mathrm{CH}_{2} \mathrm{SMe}$ ); HRMS (ESI) $\mathrm{m} / z[\mathrm{M}+\mathrm{Na}]^{+}$calcd for $\mathrm{C}_{13} \mathrm{H}_{26} \mathrm{O}_{8} \mathrm{SNa}$ 365.1241 , found 365.1251 .

1,2:5,6-Di-O-isopropylidene-3-O-(2-[2-(2-(methylthio)ethoxy)ethoxy]ethyl)- $\alpha$-D-glucofuranose (38). To a cooled solution of diacetone glucose $(200 \mathrm{mg}, 0.768 \mathrm{mmol})$ in dry DMF $(8 \mathrm{~mL})$ was added $60 \% \mathrm{NaH}$ in mineral oil $(80.0 \mathrm{mg}, 2.00 \mathrm{mmol})$. After the mixture stirred for $5 \mathrm{~min}$, tosylate 32 was added and the mixture was left overnight. After the reaction was quenched with $\mathrm{MeOH}(1 \mathrm{~mL}), \mathrm{Et}_{2} \mathrm{O}$ $(50 \mathrm{~mL})$ was added and the reaction was transferred to a separatory funnel. After the mixture was washed with water $(1 \times)$, aq $\mathrm{NaHCO}_{3}$ $(1 \times)$, and brine $(1 \times)$, the layers were separated and the organic layer was dried $\left(\mathrm{Na}_{2} \mathrm{SO}_{4}\right)$ and concentrated in vacuo. Purification of the residue over silica (0-50\% EtOAc in PE) gave 38 as a clear oil. (294 $\mathrm{mg}, 0.700 \mathrm{mmol}, 91 \%): R_{f}=0.73$ (50\% EtOAc in PE); IR (neat) 2985, 2871, 1456, 1371, 1058; $\left.{ }^{1} \mathrm{H} \mathrm{NMR} \mathrm{(400} \mathrm{MHz,} \mathrm{CDCl}_{3}\right) \delta 5.87(\mathrm{~d}, J=3.8$ $\mathrm{Hz}, 1 \mathrm{H}, \mathrm{H}-1), 4.57$ (d, $J=3.6 \mathrm{~Hz}, 1 \mathrm{H}, \mathrm{H}-2), 4.31(\mathrm{dt}, J=7.8,5.9 \mathrm{~Hz}$, $1 \mathrm{H}, \mathrm{H}-5), 4.14-4.10(\mathrm{~m}, 1 \mathrm{H}, \mathrm{H}-3), 4.09-4.05$ (m, 1H, CHH H-6), $3.99(\mathrm{dd}, J=8.6,5.8 \mathrm{~Hz}, 1 \mathrm{H}, \mathrm{CHH} \mathrm{H}-6), 3.92(\mathrm{~d}, J=3.1 \mathrm{~Hz}, 1 \mathrm{H}, \mathrm{H}-4)$, $3.79-3.71\left(\mathrm{~m}, 2 \mathrm{H}, \mathrm{OCH}_{2}\right), 3.68-3.60\left(\mathrm{~m}, 8 \mathrm{H}, 4 \times \mathrm{OCH}_{2}\right), 2.69(\mathrm{t}, J=$ $\left.6.9 \mathrm{~Hz}, 2 \mathrm{H}, \mathrm{CH}_{2} \mathrm{SMe}\right), 2.14\left(\mathrm{~s}, 3 \mathrm{H}, \mathrm{CH}_{2} \mathrm{SMe}\right), 1.49$ (d, J = 2.7 Hz, 3H, $\mathrm{CH}_{3}$ isopropylidene), 1.42 (s, $3 \mathrm{H}, \mathrm{CH}_{3}$ isopropylidene), $1.34(\mathrm{~s}, 3 \mathrm{H}$, $\mathrm{CH}_{3}$ isopropylidene), $1.31\left(\mathrm{~d}, \mathrm{~J}=3.6 \mathrm{~Hz}, 3 \mathrm{H}, \mathrm{CH}_{3}\right.$ isopropylidene); ${ }^{13} \mathrm{C}$ NMR (101 MHz, $\left.\mathrm{CDCl}_{3}\right) \delta 111.9\left(\mathrm{C}_{\mathrm{q}}\right.$ isopropylidene $), 109.0\left(\mathrm{C}_{\mathrm{q}}\right.$ isopropylidene), 105.4 (C-1), 82.8 (C-2), 82.7 (C-4), 81.2 (C-3), 72.7 (C-5), $70.8\left(\mathrm{OCH}_{2}\right), 70.7\left(\mathrm{OCH}_{2}\right), 70.6\left(\mathrm{OCH}_{2}\right), 70.5\left(\mathrm{OCH}_{2}\right), 70.28$, 67.3 (C-6), $33.5\left(\mathrm{CH}_{2} \mathrm{SMe}\right), 27.0\left(\mathrm{CH}_{3}\right.$ isopropylidene $), 27.0\left(\mathrm{CH}_{3}\right.$ isopropylidene $), 26.4\left(\mathrm{CH}_{3}\right.$ isopropylidene $), 25.6\left(\mathrm{CH}_{3}\right.$ isopropylidene), $16.2\left(\mathrm{CH}_{2} \mathrm{SMe}\right)$; HRMS (ESI) $m / z\left[\mathrm{M}+\mathrm{NH}_{4}\right]^{+}$calcd for $\mathrm{C}_{19} \mathrm{H}_{38} \mathrm{O}_{8} \mathrm{SN} 440.2313$, found 440.2320 .

3-O-(2-[2-(2-(Methylthio)ethoxy)ethoxy]ethyl)- $\alpha / \beta$-D-glucopyranoside (H40). To a suspension of compound 38 in $\mathrm{H}_{2} \mathrm{O}$ was added Amberlite IR- $120 \mathrm{H}^{+}$, and this mixture was stirred for $24 \mathrm{~h}$ at $60{ }^{\circ} \mathrm{C}$, after which it was filtered and concentrated in vacuo. Purification of the residue over silica ( 0 to $10 \% \mathrm{MeOH}$ in $\mathrm{DCM}$ ) afforded the title compound $\mathrm{H} 40$ as a clear oil $(\alpha / \beta=1: 1,81 \mathrm{mg}, 0.24 \mathrm{mmol}, 46 \%): R_{f}=$
0.32 (10\% MeOH in DCM); IR (neat) 3369, 2918, 2873, 1104, 1077; ${ }^{1} \mathrm{H}$ NMR $\left(400 \mathrm{MHz}, \mathrm{CD}_{3} \mathrm{OD}\right) \delta 5.08(\mathrm{~d}, J=3.6 \mathrm{~Hz}, 1 \mathrm{H}, \mathrm{H}-1 \alpha), 4.47$ $(\mathrm{d}, J=7.7 \mathrm{~Hz}, 1 \mathrm{H}, \mathrm{H}-1 \beta), 4.24-3.13(\mathrm{~m}, 40 \mathrm{H}), 2.67(\mathrm{t}, J=6.9 \mathrm{~Hz}, 4 \mathrm{H}$, $\left.2 \times \mathrm{CH}_{2} \mathrm{SMe}\right), 2.11\left(\mathrm{~s}, 6 \mathrm{H}, 2 \times \mathrm{CH}_{2} \mathrm{SMe}\right) ;{ }^{13} \mathrm{C}$ NMR $(101 \mathrm{MHz}$, $\left.\mathrm{CD}_{3} \mathrm{OD}\right) \delta 98.1(\mathrm{C}-1 \beta), 94.0(\mathrm{C}-1 \alpha), 87.6,84.5,77.8,76.1,73.7,73.1$,

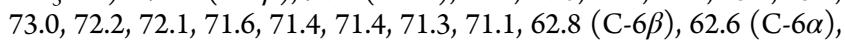
$34.2\left(2 \times \mathrm{OCH}_{2} \mathrm{SMe}\right), 15.9\left(2 \times \mathrm{OCH}_{2} \mathrm{SMe}\right) ; \mathrm{HRMS}(\mathrm{ESI}) \mathrm{m} / z[\mathrm{M}+$ $\mathrm{Na}]^{+}$calcd for $\mathrm{C}_{13} \mathrm{H}_{26} \mathrm{O}_{8} \mathrm{SNa} 365.1241$, found 365.1243.

(4-Methoxybenzyl)- $\beta$-D-glucopyranoside (41). To a solution of 2,3,4,6-tetra- $O$-acetyl- $\alpha$-D-glucopyranosyl bromide $(3.00 \mathrm{~g}, 7.30 \mathrm{mmol})$ and 4-methoxybenzyl alcohol $(5.04 \mathrm{~g}, 36.5 \mathrm{mmol})$ in dry $\mathrm{Et}_{2} \mathrm{O}(75 \mathrm{~mL})$ were added freshly activated $4 \AA$ molecular sieves. The resulting mixture was allowed to stir for $10 \mathrm{~min}$, after which $\mathrm{Ag}_{2} \mathrm{CO}_{3}(6.00 \mathrm{~g}, 21.8 \mathrm{mmol})$ and $\mathrm{I}_{2}(1.85 \mathrm{~g}, 7.30 \mathrm{mmol})$ were added. After the mixture stirred an additional $24 \mathrm{~h}$ under a dinitrogen atmosphere at $\mathrm{rt}$ in the dark, the reaction mixture was filtered over Celite, diluted with EtOAc $(200 \mathrm{~mL})$, and washed with $1 \mathrm{M} \mathrm{Na}_{2} \mathrm{~S}_{2} \mathrm{O}_{3}(3 \times)$, aq $\mathrm{NaHCO}_{3}(3 \times)$, and brine $(3 \times)$. The organic layer was dried $\left(\mathrm{Na}_{2} \mathrm{SO}_{4}\right)$ and concentrated in vacuo. Purification of the residue by silica column chromatography $(20 \%$ EtOAc in DCM) afforded (4-methoxybenzyl)-2,3,4,6-tetra- $O$-acetyl- $\beta$ D-glucopyranoside $(2.39 \mathrm{~g})$, which was then redissolved in dry $\mathrm{MeOH}$ $(70 \mathrm{~mL})$ followed by the addition of a catalytic amount of $\mathrm{NaOMe}$. The resulting mixture was allowed to stir for $4 \mathrm{~h}$, after which Amberlite IR$120 \mathrm{H}^{+}$was added until a neutral $\mathrm{pH}$, filtered, and concentrated in vacuo, affording the title compound 41 as a clear oil $(1.57 \mathrm{~g}, 5.23 \mathrm{mmol}$, $72 \%$ over two steps): $R_{f}=0.57$ (20\% MeOH in DCM); IR (neat) 3335, 2924, 1612, 1027, 819; ${ }^{1} \mathrm{H}$ NMR (400 MHz, CD $\left.{ }_{3} \mathrm{OD}\right) \delta 7.32$ (d, $J=8.6$ $\left.\mathrm{Hz}, 2 \mathrm{H}, \mathrm{H}_{\text {arom }}\right), 6.95-6.71\left(\mathrm{~m}, 2 \mathrm{H}, \mathrm{H}_{\text {arom }}\right), 4.85(\mathrm{~d}, J=18.0 \mathrm{~Hz}, 1 \mathrm{H}$, CHH PMB), 4.58 (d, $J=11.3 \mathrm{~Hz}, 1 \mathrm{H}, \mathrm{CHH} \mathrm{PMB}), 4.31(\mathrm{~d}, J=7.8 \mathrm{~Hz}$, $1 \mathrm{H}, \mathrm{H}-1$ ), 3.89 (dd, $J=12.0,2.2 \mathrm{~Hz}, 1 \mathrm{H}, \mathrm{CHH} \mathrm{H}-6$ ), 3.68 (dd, $J=12.0$, $5.5 \mathrm{~Hz}, 1 \mathrm{H}, \mathrm{CHH} \mathrm{H}-6), 3.42-3.14$ (m, 4H, H-2, H-3, H-4, H-5); ${ }^{13} \mathrm{C}$ NMR (101 MHz, CD 3 OD) $\delta 160.8\left(\mathrm{C}_{\mathrm{q} \text { arom }}\right), 130.9\left(\mathrm{C}_{\mathrm{H} \text { arom }}\right), 130.9$ $\left(\mathrm{C}_{\mathrm{q} \text { arom }}\right), 114.6\left(\mathrm{C}_{\mathrm{H} \text { arom }}\right), 102.9(\mathrm{C}-1), 78.0(\mathrm{C}-3), 78.0(\mathrm{C}-4), 75.1$ (C-2), 71.7 (C-5), $71.4\left(\mathrm{CH}_{2} \mathrm{PMB}\right), 62.8$ (C-6), $55.7\left(\mathrm{CH}_{3} \mathrm{PMB}\right)$; HRMS (ESI) $m / z[\mathrm{M}+\mathrm{Na}]^{+}$calcd for $\mathrm{C}_{14} \mathrm{H}_{20} \mathrm{O}_{7} \mathrm{Na} 323.1107$, found 323.1088 .

(4-Methoxybenzyl)-4,6-O-(4-methoxybenzylidene)- $\beta$-D-glucopyranoside (42). To a solution of 41 (309 $\mathrm{mg}, 1.03 \mathrm{mmol})$ in dry DMF (5 $\mathrm{mL})$ were added 4-methoxybenzaldehyde dimethyl acetal $(135 \mu \mathrm{L}$, $0.793 \mathrm{mmol})$ and $p-\mathrm{TsOH} \cdot \mathrm{H}_{2} \mathrm{O}(10 \mathrm{mg}, 0.05 \mathrm{mmol})$. The resulting reaction mixture was heated at $60{ }^{\circ} \mathrm{C}$ for $16 \mathrm{~h}$, after which it was concentrated in vacuo. Saturated aqueous $\mathrm{NaHCO}_{3}(50 \mathrm{~mL})$ was added, and the mixture was further diluted with EtOAc $(200 \mathrm{~mL})$ and transferred to a separatory funnel. After the mixture was washed with aq $\mathrm{NaHCO}_{3}(3 x)$, water $(3 x)$ and brine $(3 x)$, the layers were separated, and the organic layer was dried $\left(\mathrm{Na}_{2} \mathrm{SO}_{4}\right)$ and concentrated in vacuo. Compound 43 (382 mg, $0.910 \mathrm{mmol}, 89 \%)$ was obtained after silica column chromatography ( 0 to $10 \% \mathrm{MeOH}$ in DCM) as a white powder: $R_{f}=0.48(10 \% \mathrm{MeOH}$ in DCM); IR (neat) 3480, 2869, 1612, 1516,$1244 ;{ }^{1} \mathrm{H}$ NMR $\left(400 \mathrm{MHz}, \mathrm{CD}_{3} \mathrm{CN}\right) \delta 7.39(\mathrm{~d}, J=8.8 \mathrm{~Hz}, 2 \mathrm{H}$, $\left.\mathrm{H}_{\text {arom }}\right), 7.31\left(\mathrm{~d}, J=8.7 \mathrm{~Hz}, 2 \mathrm{H}, \mathrm{H}_{\text {arom }}\right), 7.00-6.86\left(\mathrm{~m}, 4 \mathrm{H}, \mathrm{H}_{\text {arom }}\right), 5.50$ (s, 1H, CH PMB acetal), $4.76(\mathrm{~d}, J=11.5 \mathrm{~Hz}, 1 \mathrm{H}, \mathrm{CHH}$ PMB $), 4.55(\mathrm{~d}$, $J=11.5 \mathrm{~Hz}, 1 \mathrm{H}, \mathrm{CHH}$ PMB), $4.43(\mathrm{~d}, J=7.8 \mathrm{~Hz}, 1 \mathrm{H}, \mathrm{H}-1), 4.24$ (dd, $J$ $=10.3,4.6 \mathrm{~Hz}, 1 \mathrm{H}, \mathrm{CHH} \mathrm{H}-6), 3.78\left(\mathrm{~s}, 6 \mathrm{H}, 2 \times \mathrm{CH}_{3} \mathrm{OMe}\right), 3.72(\mathrm{t}, J=$ $9.9 \mathrm{~Hz}, 1 \mathrm{H}, \mathrm{CHH} \mathrm{H}-6), 3.62-3.50(\mathrm{~m}, 1 \mathrm{H}, \mathrm{H}-3), 3.49-3.33(\mathrm{~m}, 2 \mathrm{H}$, $\mathrm{H}-4, \mathrm{H}-5), 3.26(\mathrm{td}, J=8.1,3.7 \mathrm{~Hz}, 1 \mathrm{H}, \mathrm{H}-2) ;{ }^{13} \mathrm{C}$ NMR $(101 \mathrm{MHz}$, $\left.\mathrm{CD}_{3} \mathrm{CN}\right) \delta 161.1\left(\mathrm{C}_{\mathrm{q} \text { arom }}\right), 160.4\left(\mathrm{C}_{\mathrm{q} \text { arom }}\right), 131.3\left(\mathrm{C}_{\mathrm{q} \text { arom }}\right), 130.7$ $\left(\mathrm{C}_{\mathrm{H} \text { arom }}\right), 128.6\left(\mathrm{C}_{\mathrm{H} \text { arom }}\right), 114.6\left(\mathrm{C}_{\mathrm{H} \text { arom }}\right), 114.4\left(\mathrm{C}_{\mathrm{H} \text { arom }}\right), 103.4(\mathrm{C}-$ 1), 102.1 (CH PMB acetal), 81.6 (C-4), 75.6 (C-2), 74.3 (C-3), 71.4 ( $\mathrm{CH}_{2}$ PMB), 69.3 (C-6), 67.2 (C-5), $55.9\left(2 \times \mathrm{CH}_{3} \mathrm{PMB}\right)$; HRMS (ESI) $m / z[\mathrm{M}+\mathrm{H}]^{+}$calcd for $\mathrm{C}_{22} \mathrm{H}_{27} \mathrm{O}_{8} 419.1700$, found 419.1710 .

(4-Methoxybenzyl)-2,3-di-O-(4-methoxybenzyl)-4,6-O-(4-methoxybenzylidene)- $\beta$-D-glucopyranoside (43). To a cooled solution $\left(0{ }^{\circ} \mathrm{C}\right)$ of $p$-methoxy benzylidene protected $42(377 \mathrm{mg}, 0.900 \mathrm{mmol})$ in dry DMF $(9 \mathrm{~mL})$ was slowly added $\mathrm{NaH}(60 \%$ dispersion in mineral oil, $80.0 \mathrm{mg}, 2.00 \mathrm{mmol}$ ) followed by the addition of 4-methoxybenzyl chloride $(255 \mu \mathrm{L}, 1.89 \mathrm{mmol})$. After stirring for $5 \mathrm{~h}$ under a dinitrogen atmosphere, the reaction was quenched upon the addition of $\mathrm{MeOH}$ ( 3 $\mathrm{mL})$. The mixture was further diluted with $\mathrm{Et}_{2} \mathrm{O}(200 \mathrm{~mL})$, transferred to a separatory funnel, and washed with water $(1 \times), \mathrm{aq} \mathrm{NaHCO}_{3}(1 \times)$, 
and brine $(1 \times)$. The organic layer was dried over $\mathrm{Na}_{2} \mathrm{SO}_{4}$ and concentrated in vacuo. Purification by silica column chromatography $(0$ to $20 \%$ EtOAc in PE) yielded the title compound $\mathbf{4 3}$ as a clear oil ( 447 $\mathrm{mg}, 0.680 \mathrm{mmol}, 76 \%): R_{f}=0.74$ (40\% EtOAc in PE); IR (neat) 3480 , $2869,1612,1516,1244 ;{ }^{1} \mathrm{H}$ NMR $\left(400 \mathrm{MHz}, \mathrm{CDCl}_{3}\right) \delta 7.43(\mathrm{~d}, J=8.9$ $\left.\mathrm{Hz}, 2 \mathrm{H}, \mathrm{H}_{\text {arom }}\right), 7.36-7.18\left(\mathrm{~m}, 5 \mathrm{H}, \mathrm{H}_{\text {arom }}\right), 7.00-6.78\left(\mathrm{~m}, 6 \mathrm{H}, \mathrm{H}_{\text {arom }}\right)$, 5.54 (s, $1 \mathrm{H}, \mathrm{CH}$ benzylidene), 4.89 (d, $J=11.4 \mathrm{~Hz}, 1 \mathrm{H}, \mathrm{CH} \mathrm{H}$ PMB), $4.82\left(\mathrm{dd}, J=10.8,5.6 \mathrm{~Hz}, 2 \mathrm{H}, \mathrm{CH}_{2} \mathrm{PMB}\right), 4.71(\mathrm{dd}, J=16.0,10.7 \mathrm{~Hz}$, $2 \mathrm{H}, \mathrm{CH}_{2} \mathrm{PMB}$ ), $4.65-4.57(\mathrm{~m}, 2 \mathrm{H}, \mathrm{CHH} \mathrm{PMB}, \mathrm{H}-1), 4.37$ (dd, $J=$ $10.5,5.0 \mathrm{~Hz}, 1 \mathrm{H}, \mathrm{CHH} \mathrm{H}-6), 3.82\left(\mathrm{~s}, 6 \mathrm{H}, 2 \times \mathrm{CH}_{3} \mathrm{PMB}\right), 3.82(\mathrm{~s}, 3 \mathrm{H}$, $\mathrm{CH}_{3} \mathrm{PMB}$ ), 3.80 (s, 3H, $\mathrm{CH}_{3} \mathrm{PMB}$ ), 3.69 (p, $\left.J=9.1 \mathrm{~Hz}, 2 \mathrm{H}, \mathrm{H}-3, \mathrm{H}-4\right)$, $3.49(\mathrm{t}, J=7.9 \mathrm{~Hz}, 1 \mathrm{H}, \mathrm{H}-2), 3.40(\mathrm{td}, J=9.5,5.0 \mathrm{~Hz}, 1 \mathrm{H}, \mathrm{H}-5) ;{ }^{13} \mathrm{C}$ NMR $\left(101 \mathrm{MHz}, \mathrm{CDCl}_{3}\right) \delta 160.1$ ( $\left.\mathrm{C}_{\mathrm{q} \text { arom }}\right), 159.5\left(\mathrm{C}_{\mathrm{q} \text { arom }}\right), 159.3$ $\left(\mathrm{C}_{\mathrm{q} \text { arom }}\right), 159.3\left(\mathrm{C}_{\mathrm{q} \text { arom }}\right), 130.8\left(\mathrm{C}_{\mathrm{q} \text { arom }}\right), 130.6\left(\mathrm{C}_{\mathrm{q} \text { arom }}\right), 129.9$ $\left(\mathrm{C}_{\mathrm{H} \text { arom }}\right), 129.8\left(\mathrm{C}_{\mathrm{H} \text { arom }}\right), 129.8\left(\mathrm{C}_{\mathrm{H} \text { arom }}\right), 129.3\left(\mathrm{C}_{\mathrm{q} \text { arom }}\right), 127.4$ $\left(\mathrm{C}_{\mathrm{H} \text { arom }}\right), 113.9\left(\mathrm{C}_{\mathrm{H} \text { arom }}\right), 113.8\left(\mathrm{C}_{\mathrm{H} \text { arom }}\right), 113.7\left(\mathrm{C}_{\mathrm{H} \text { arom }}\right), 103.0(\mathrm{C}-$ 1), 101.2 (CH PMB acetal), 81.9 (C-2), 81.5 (C-3), 80.7 (C-4), 75.1 ( $\left.\mathrm{CH}_{2} \mathrm{PMB}\right), 74.9$ ( $\left.\mathrm{CH}_{2} \mathrm{PMB}\right), 71.4\left(\mathrm{CH}_{2} \mathrm{PMB}\right), 68.9$ (C-6), 66.2 (C5), $55.4\left(3 \times \mathrm{CH}_{3} \mathrm{PMB}\right), 55.3\left(\mathrm{CH}_{3} \mathrm{PMB}\right.$ acetal); HRMS (ESI) $\mathrm{m} / z$ $[\mathrm{M}+\mathrm{Na}]^{+}$calcd for $\mathrm{C}_{38} \mathrm{H}_{42} \mathrm{O}_{10} \mathrm{Na}$ 681.2670, found 681.2671.

(4-Methoxybenzyl)-2,3,6-tri-O-(4-methoxybenzyl)- $\beta$-D-glucopyranoside (44). Fully protected glycoside $43(400 \mathrm{mg}, 0.610 \mathrm{mmol})$ was dissolved in DMF $(12 \mathrm{~mL})$, and to this solution were added freshly activated $4 \AA$ molecular sieves and fresh $\mathrm{NaCNBH}_{3}(385 \mathrm{mg}, 6.13$ $\mathrm{mmol}$ ). After the mixture stirred for $15 \mathrm{~min}$, the solution was cooled to $0^{\circ} \mathrm{C}$, and a precooled solution $\left(0^{\circ} \mathrm{C}\right)$ of trifluoroacetic acid $(1.2 \mathrm{~mL})$ in dry DMF $(3 \mathrm{~mL})$ on $4 \AA$ molecular sieves was then added dropwise over $15 \mathrm{~min}$. The reaction mixture was maintained at $\mathrm{rt}$ for $48 \mathrm{~h}$ and filtered over Celite, diluted with EtOAc $(100 \mathrm{~mL})$, and transferred to a separatory funnel. After washing with water $(1 \times)$, aq $\mathrm{NaHCO}_{3}(1 \times)$, and brine $(1 \times)$, the organic layer was dried $\left(\mathrm{Na}_{2} \mathrm{SO}_{4}\right)$ and concentrated in vacuo. Purification of the residue by column chromatography over silica (0 to 30\% EtOAc in PE) afforded 44 ( $385 \mathrm{mg}, 0.580 \mathrm{mmol}, 95 \%)$ as a clear oil: $R_{f}=0.48$ (40\% EtOAc in PE); IR (neat) 3480, 3000, 2907, 1612,$1512 ;{ }^{1} \mathrm{H}$ NMR $\left(400 \mathrm{MHz}, \mathrm{CD}_{3} \mathrm{Cl}_{3}\right) \delta 7.42-7.16\left(\mathrm{~m}, 8 \mathrm{H}, \mathrm{H}_{\text {arom }}\right)$, 6.87 (tdd, $\left.J=8.9,4.7,2.6 \mathrm{~Hz}, 8 \mathrm{H}, \mathrm{H}_{\text {arom }}\right), 4.92-4.82(\mathrm{~m}, 3 \mathrm{H}, \mathrm{CHH}$ PMB, $\mathrm{CH}_{2} \mathrm{PMB}$ ), 4.67-4.53 (m, 5H, CHH PMB, $\left.2 \times \mathrm{CH}_{2} \mathrm{PMB}\right), 4.49$ (d, $J=7.2 \mathrm{~Hz}, 1 \mathrm{H}, \mathrm{H}-1), 3.82$ (s, $\left.3 \mathrm{H}, \mathrm{CH}_{3} \mathrm{PMB}\right), 3.81$ (s, $3 \mathrm{H}, \mathrm{CH}_{3}$ PMB), 3.81 (s, 3H, $\left.\mathrm{CH}_{3} \mathrm{PMB}\right), 3.80\left(\mathrm{~s}, 3 \mathrm{H}, \mathrm{CH}_{3} \mathrm{PMB}\right), 3.79-3.66(\mathrm{~m}$, 2H, H-6), 3.59-3.51 (m, 1H, H-5), 3.48-3.36 (m, 3H, H-2, H-3, H-4); ${ }^{13} \mathrm{C}$ NMR $\left(101 \mathrm{MHz}, \mathrm{CDCl}_{3}\right) \delta 159.4\left(\mathrm{C}_{\mathrm{q} \text { arom }}\right), 152.7\left(\mathrm{C}_{\mathrm{q} \text { arom }}\right), 152.5$ $\left(\mathrm{C}_{\mathrm{q} \text { arom }}\right), 130.7\left(\mathrm{C}_{\mathrm{H} \text { arom }}\right), 130.0\left(\mathrm{C}_{\mathrm{H} \text { arom }}\right), 129.9\left(\mathrm{C}_{\mathrm{H} \text { arom }}\right), 129.8$ $\left(\mathrm{C}_{\mathrm{H} \text { arom }}\right), 129.5\left(\mathrm{C}_{\mathrm{H} \text { arom }}\right), 114.1\left(\mathrm{C}_{\mathrm{H} \text { arom }}\right), 113.9\left(\mathrm{C}_{\mathrm{H} \text { arom }}\right), 102.5(\mathrm{C}-$ 1), 83.8 (C-4), 81.6 (C-2), $75.0\left(\mathrm{CH}_{2} \mathrm{PMB}\right), 74.5\left(\mathrm{CH}_{2} \mathrm{PMB}\right), 74.2$ (C-3), $73.4\left(\mathrm{CH}_{2} \mathrm{PMB}\right), 71.7$ (C-5), $71.1\left(\mathrm{CH}_{2} \mathrm{PMB}\right), 70.2$ (C-6), $55.4\left(4 \times \mathrm{CH}_{3} \mathrm{PMB}\right)$; HRMS (ESI) $m / z\left[\mathrm{M}+\mathrm{NH}_{4}\right]^{+}$calcd for $\mathrm{C}_{38} \mathrm{H}_{48} \mathrm{O}_{10} \mathrm{~N}$ 678.3273, found 678.3321 .

(4-Methoxybenzyl)-2-O-(2-[2-(2-(methylthio)ethoxy)ethoxy]ethyl)-3,6-tri-O-(4-methoxybenzyl)- $\beta$-D-glucopyranoside (45). Compound $44(300 \mathrm{mg}, 0.454 \mathrm{mmol})$ was dissolved in dry DMF $(5 \mathrm{~mL})$, and the mixture was cooled to $0{ }^{\circ} \mathrm{C}$, after which $60 \% \mathrm{NaH}$ in mineral oil ( $31 \mathrm{mg}, 0.77 \mathrm{mmol}$ ) was added. This mixture was allowed to stir for 5 min, after which tosylate $32(177 \mathrm{mg}, 0.530 \mathrm{mmol})$ was added dropwise. The reaction was allowed to stir for $6 \mathrm{~h}$, after which it was quenched upon the addition of $\mathrm{MeOH}(2 \mathrm{~mL})$, diluted with $\mathrm{Et}_{2} \mathrm{O}(20$ $\mathrm{mL}$ ), and transferred to a separatory funnel. After washing with aq $\mathrm{NaHCO}_{3}(1 \times)$, water $(1 \times)$, and brine $(1 \times)$, the layers were separated, and the organic layer was dried $\left(\mathrm{Na}_{2} \mathrm{SO}_{4}\right)$ and concentrated in vacuo. Purification of the residue by column chromatography (0 to $40 \%$ EtOAc in PE) afforded the title compound 45 as a clear oil $(291 \mathrm{mg}$, $0.354 \mathrm{mmol}, 78 \%): R_{f}=0.38$ (40\% EtOAc in PE); IR (neat) 2998, 2907, 2836, 1612, 1513; ${ }^{1} \mathrm{H} \mathrm{NMR}\left(400 \mathrm{MHz}, \mathrm{CDCl}_{3}\right) \delta 7.36-7.18(\mathrm{~m}$, $\left.8 \mathrm{H}, \mathrm{H}_{\text {arom }}\right), 6.94-6.79\left(\mathrm{~m}, 8 \mathrm{H}, \mathrm{H}_{\text {arom }}\right), 4.97-4.50\left(\mathrm{~m}, 8 \mathrm{H}, 4 \times \mathrm{CH}_{2}\right.$ PMB), $4.46(\mathrm{~d}, J=7.8 \mathrm{~Hz}, 1 \mathrm{H}, \mathrm{H}-1), 3.95(\mathrm{dt}, J=9.8,4.5 \mathrm{~Hz}, 1 \mathrm{H}, \mathrm{CHH}$ $\left.\mathrm{OCH}_{2}\right), 3.81-3.74(\mathrm{~m}, 1 \mathrm{H}, \mathrm{CHH} \mathrm{H}-6), 3.76-3.63(\mathrm{~m}, 3 \mathrm{H}, \mathrm{CHH} \mathrm{H}-6$, $\left.2 \times \mathrm{CHH} \mathrm{OCH}_{2}\right), 3.65-3.50\left(\mathrm{~m}, 8 \mathrm{H}, \mathrm{H}-5, \mathrm{CHH} \mathrm{OCH} \mathrm{OH}_{2}, 3 \times \mathrm{OCH}_{2}\right)$, $3.46-3.38(\mathrm{~m}, 3 \mathrm{H}, \mathrm{H}-2, \mathrm{H}-3, \mathrm{H}-4), 2.66\left(\mathrm{t}, J=6.9 \mathrm{~Hz}, 2 \mathrm{H}, \mathrm{CH}_{2} \mathrm{SMe}\right)$, $2.12\left(\mathrm{~s}, 3 \mathrm{H}, \mathrm{CH}_{2} \mathrm{SMe}\right) ;{ }^{13} \mathrm{C} \mathrm{NMR}\left(101 \mathrm{MHz}, \mathrm{CDCl}_{3}\right) \delta 159.7\left(\mathrm{C}_{\mathrm{q}}\right.$ arom $)$, $159.4\left(\mathrm{C}_{\mathrm{q} \text { arom }}\right), 131.1\left(\mathrm{C}_{\mathrm{q} \text { arom }}\right), 130.8\left(\mathrm{C}_{\mathrm{q} \text { arom }}\right), 130.6\left(\mathrm{C}_{\mathrm{q} \text { arom }}\right), 130.0$ $\left(\mathrm{C}_{\mathrm{H} \text { arom }}\right), 129.8\left(\mathrm{C}_{\mathrm{H} \text { arom }}\right), 129.5\left(\mathrm{C}_{\mathrm{H} \text { arom }}\right), 113.9\left(\mathrm{C}_{\mathrm{H} \text { arom }}\right), 113.8$
$\left(\mathrm{C}_{\mathrm{H} \text { arom }}\right), 102.5$ (C-1), 84.3 (C-5), 82.0 (C-2), 78.7 (C-3), $75.4\left(\mathrm{CH}_{2}\right.$ PMB), 75.0 (C-4), $74.6\left(\mathrm{CH}_{2} \mathrm{PMB}\right), 73.2\left(\mathrm{CH}_{2} \mathrm{PMB}\right), 72.2\left(\mathrm{OCH}_{2}\right)$, $71.0\left(\mathrm{CH}_{2} \mathrm{PMB}\right), 70.9\left(\mathrm{OCH}_{2}\right), 70.7\left(\mathrm{OCH}_{2}\right), 70.6\left(\mathrm{OCH}_{2}\right), 70.4$ $\left(\mathrm{CH}_{2} \mathrm{SMe}\right), 68.8$ (C-6), 33.5 (4× $\left.\mathrm{CH}_{3} \mathrm{PMB}\right), 16.2\left(\mathrm{CH}_{2} \mathrm{SMe}\right)$; HRMS

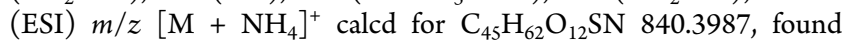
840.4028 .

4-O-(2-[2-(2-(Methylthio)ethoxy)ethoxy]ethyl)- $\alpha / \beta$-D-glucopyranoside (H46). Compound $45(108 \mathrm{mg}, 0.131 \mathrm{mmol})$ was dissolved in a mixture of DCM/HFIP (1:1, $2 \mathrm{~mL})$, and to this solution were added 4 drops of $37 \% \mathrm{HCl}$. The mixture slowly turned red to deep purple in 30 min, after which it was quenched with $\mathrm{Et}_{3} \mathrm{~N}(0.5 \mathrm{~mL})$ and concentrated in vacuo. The crude was redissolved in $\mathrm{MeOH}(5 \mathrm{~mL})$; Amberlite IR$120 \mathrm{H}^{+}$was added, and the mixture was stirred for $5 \mathrm{~min}$, filtered, and concentrated. Purification of the resulting residue over silica ( 0 to $15 \%$ $\mathrm{MeOH}$ in DCM) afforded the title compound $\mathbf{H} 46$ as a clear oil ( $13 \mathrm{mg}$, $0.038 \mathrm{mmol}, 29 \%): R_{f}=0.57(20 \% \mathrm{MeOH}$ in DCM); IR (neat) 3370, $2918,2873,1104,1077 ;{ }^{1} \mathrm{H}$ NMR $\left(400 \mathrm{MHz}, \mathrm{CD}_{3} \mathrm{OD}\right) \delta 5.09$ (d, $J=$ $3.7 \mathrm{~Hz}, 1 \mathrm{H}, \mathrm{H}-1 \alpha), 4.45(\mathrm{~d}, J=7.7 \mathrm{~Hz}, 1 \mathrm{H}, \mathrm{H}-1 \beta), 4.02-3.58(\mathrm{~m}$, $28 \mathrm{H}), 3.47(\mathrm{t}, J=8.9 \mathrm{~Hz}, 1 \mathrm{H}, \mathrm{H}-3 \beta), 3.29-3.19(\mathrm{~m}, 2 \mathrm{H}), 3.13(\mathrm{dd}, J=$ 9.2, $7.9 \mathrm{~Hz}, 1 \mathrm{H}, \mathrm{H}-2 \beta), 2.68\left(\mathrm{t}, J=6.8 \mathrm{~Hz}, 4 \mathrm{H}, 2 \times \mathrm{OCH}_{2} \mathrm{SMe}\right), 2.13(\mathrm{~s}$, $\left.6 \mathrm{H}, 2 \times \mathrm{OCH}_{2} \mathrm{SMe}\right) ;{ }^{13} \mathrm{C} \mathrm{NMR}\left(100 \mathrm{MHz}, \mathrm{CD}_{3} \mathrm{OD}\right) \delta 98.2(\mathrm{C}-1 \beta)$, $93.9(\mathrm{C}-1 \alpha), 80.5,80.3,78.2,77.0,76.3,75.0,73.9,72.9,72.0,71.7$, 71.5, 71.2, $62.5(\mathrm{C}-1 \beta), 62.4(\mathrm{C}-1 \alpha), 34.3\left(2 \times \mathrm{OCH}_{2} \mathrm{SMe}\right), 15.9$ $\left(\mathrm{OCH}_{2} \mathrm{SMe}\right)$; HRMS (ESI) $\mathrm{m} / z[\mathrm{M}+\mathrm{Na}]^{+}$calcd for $\mathrm{C}_{13} \mathrm{H}_{26} \mathrm{O}_{8} \mathrm{SNa}$ 365.1241 , found 365.1251 .

1,2:3,5-Bis(O-methylidene)-6-O-(2-[2-(2-(methylthio)ethoxy)ethoxy]ethyl) $\alpha$-D-glucofuranose (49). To a cooled $\left(0{ }^{\circ} \mathrm{C}\right)$ solution of 1,2:3,5-bis( $O$-methylidene $)-\alpha$-D-glucofuranose $(206 \mathrm{mg}, 1.00 \mathrm{mmol})$ in dry DMF $(10 \mathrm{~mL})$ was added $60 \% \mathrm{NaH}$ in mineral oil $(57 \mathrm{mg}, 1.42$ $\mathrm{mmol}$ ). After $10 \mathrm{~min}, 19$ (385 mg, $1.15 \mathrm{mmol})$ was added dropwise, and the resulting mixture was stirred for $3 \mathrm{~h}$ at $\mathrm{rt}$, after which it was quenched upon the addition of $\mathrm{MeOH}(2 \mathrm{~mL})$. The reaction mixture was extracted with $\mathrm{Et}_{2} \mathrm{O}(50 \mathrm{~mL})$ and washed with aq $\mathrm{NaHCO}_{3}(2 \times)$, water $(2 \times)$, and brine $(2 \times)$. The layers were separated, and the organic layer was dried $\left(\mathrm{Na}_{2} \mathrm{SO}_{4}\right)$ and concentrated in vacuo. The resulting residue was then purified by silica column chromatography ( 0 to $60 \%$ EtOAc in PE) affording 49 as a colorless oil ( $286 \mathrm{mg}, 0.78 \mathrm{mmol}, 78 \%)$ : $R_{f}=0.57$ (50\% EtOAc in PE); IR (neat) 2867, 1455, 1082, 1184, 1058; ${ }^{1} \mathrm{H}$ NMR (400 MHz, $\left.\mathrm{CDCl}_{3}\right) \delta 6.03(\mathrm{~d}, J=3.8 \mathrm{~Hz}, 1 \mathrm{H}, \mathrm{H}-1), 5.12(\mathrm{~d}, J$ $=5.9 \mathrm{~Hz}, 1 \mathrm{H}, \mathrm{CHH}$ methylene $), 5.08\left(\mathrm{~s}, 1 \mathrm{H}, \mathrm{CH}_{2}\right.$ methylene $), 5.03(\mathrm{~s}$, $1 \mathrm{H}, \mathrm{CH}_{2}$ methylene), $4.78(\mathrm{~d}, J=6.0 \mathrm{~Hz}, 1 \mathrm{H}, \mathrm{CHH}$ methylene), 4.46 $(\mathrm{d}, J=3.9 \mathrm{~Hz}, 1 \mathrm{H}, \mathrm{H}-2), 4.37(\mathrm{~d}, J=3.0 \mathrm{~Hz}, 1 \mathrm{H}, \mathrm{H}-3), 4.14(\mathrm{t}, J=4.4$ $\mathrm{Hz}, 1 \mathrm{H}, \mathrm{H}-5$ ), 4.03 (d, $J=2.7 \mathrm{~Hz}, 1 \mathrm{H}, \mathrm{H}-4), 3.85$ (dd, $J=10.5,3.9 \mathrm{~Hz}$, $1 \mathrm{H}, \mathrm{CHH} \mathrm{H}-6), 3.75$ (dd, $J=10.5,4.8 \mathrm{~Hz}, 1 \mathrm{H}, \mathrm{CHH} \mathrm{H}-6), 3.64$ (dd, $J=$ $\left.11.8,5.6 \mathrm{~Hz}, 10 \mathrm{H}, 4 \times \mathrm{OCH}_{2}\right), 2.69\left(\mathrm{t}, J=6.9 \mathrm{~Hz}, 2 \mathrm{H}, \mathrm{CH}_{2} \mathrm{SMe}\right), 2.14$ (s, 3H, $\left.\mathrm{CH}_{2} \mathrm{SMe}\right) ;{ }^{13} \mathrm{C}$ NMR $\left(101 \mathrm{MHz}, \mathrm{CDCl}_{3}\right) \delta 104.4(\mathrm{C}-1), 96.6$ ( $\mathrm{CH}_{2}$ methylene), $88.2\left(\mathrm{CH}_{2}\right.$ methylene $), 83.9$ (C-2), 76.8 (C-3), 76.1 (C-4), 72.5 (C-6), $71.6(\mathrm{C}-5), 71.0\left(\mathrm{OCH}_{2}\right), 70.7\left(\mathrm{OCH}_{2}\right), 70.7$ $\left(\mathrm{OCH}_{2}\right), 70.7\left(\mathrm{OCH}_{2}\right), 70.4\left(\mathrm{OCH}_{2}\right), 33.5\left(\mathrm{OCH}_{2} \mathrm{SMe}\right), 16.2$ $\left(\mathrm{OCH}_{2} \mathrm{SMe}\right)$; HRMS (ESI) $\mathrm{m} / z[\mathrm{M}+\mathrm{H}]^{+}$calcd for $\mathrm{C}_{15} \mathrm{H}_{27} \mathrm{O}_{8} \mathrm{~S}$ 367.1421 , found 367.1430 .

6-O-(2-[2-(2-(Methylthio)ethoxy)ethoxy]ethyl)- $\alpha / \beta$-D-glucopyranoside (H50). Compound 49 was dissolved in $2 \mathrm{M} \mathrm{HCl}(5 \mathrm{~mL})$, and this mixture was heated at $100{ }^{\circ} \mathrm{C}$ for $1 \mathrm{~h}$, after which the reaction was neutralized with $1 \mathrm{M} \mathrm{NaOH}(10 \mathrm{~mL})$ and concentrated in vacuo. Purification of the residue by silica column chromatography ( 0 to $20 \%$ MeOH in DCM) afforded $\mathbf{H 5 0}$ as a colorless oil (101 mg, $0.295 \mathrm{mmol}$, $70 \%): R_{f}=0.50$ (20\% MeOH in DCM); IR (neat) 3368, 2917, 2874, 1427,$1078 ;{ }^{1} \mathrm{H}$ NMR $\left(500 \mathrm{MHz}, \mathrm{CD}_{3} \mathrm{OD}\right) \delta 5.13(\mathrm{~d}, J=3.7 \mathrm{~Hz}, 1 \mathrm{H}$, $\mathrm{H}-1 \alpha), 4.52(\mathrm{~d}, J=7.7 \mathrm{~Hz}, 1 \mathrm{H}, \mathrm{H}-1 \beta), 4.06-3.94(\mathrm{~m}, 4 \mathrm{H}), 3.91-3.87$ $(\mathrm{m}, 1 \mathrm{H}, \mathrm{CHH} \mathrm{H}-6 \alpha / \beta), 3.86-3.77(\mathrm{~m}, 2 \mathrm{H}), 3.75-3.64(\mathrm{~m}, 20 \mathrm{H}, 10 \times$ $\left.\mathrm{OCH}_{2}\right), 3.49-3.38(\mathrm{~m}, 3 \mathrm{H}), 3.41$ (ddd, $\left.J=9.8,8.8,6.0 \mathrm{~Hz}, 2 \mathrm{H}\right), 3.34-$ $3.30(\mathrm{~m}, 1 \mathrm{H}), 3.25-3.22(\mathrm{~m}, 2 \mathrm{H}), 2.72(\mathrm{t}, J=6.8 \mathrm{~Hz}, 4 \mathrm{H}, 2 \times$ $\left.\mathrm{CH}_{2} \mathrm{SMe}\right), 2.16\left(\mathrm{~s}, 6 \mathrm{H}, 2 \times \mathrm{CH}_{2} \mathrm{SMe}\right) ;{ }^{13} \mathrm{C} \mathrm{NMR}\left(126 \mathrm{MHz}, \mathrm{CD}_{3} \mathrm{OD}\right)$ $\delta 98.1(\mathrm{C}-1 \beta), 94.0(\mathrm{C}-1 \alpha), 87.6,84.4,77.8,76.1,73.6,73.0\left(\mathrm{OCH}_{2}\right)$, 73.0 $\left(\mathrm{OCH}_{2}\right), 73.0,72.1\left(\mathrm{OCH}_{2}\right), 72.1\left(\mathrm{OCH}_{2}\right), 71.6\left(\mathrm{OCH}_{2}\right), 71.6$ $\left(\mathrm{OCH}_{2}\right), 71.4\left(\mathrm{OCH}_{2}\right), 71.4\left(\mathrm{OCH}_{2}\right), 71.3,71.1\left(\mathrm{OCH}_{2}\right), 71.1$ $\left(\mathrm{OCH}_{2}\right), 62.8(\mathrm{C}-6 \alpha / \beta), 62.7(\mathrm{C}-6 \alpha / \beta), 34.2\left(2 \times \mathrm{CH}_{2} \mathrm{SMe}\right), 15.9(2$ $\times \mathrm{CH}_{2} \mathrm{SMe}$ ); HRMS (ESI) $m / z[\mathrm{M}+\mathrm{Na}]^{+}$calcd for $\mathrm{C}_{13} \mathrm{H}_{26} \mathrm{O}_{8} \mathrm{SNa}$ 365.1241 , found 365.1252 . 
$[R u(t p y)(b p y)(13)]\left(P F_{6}\right)_{2}\left([1]\left(P F_{6}\right)_{2}\right) .[\mathrm{Ru}(\mathrm{tpy})(\mathrm{bpy}) \mathrm{Cl}] \mathrm{Cl}(63 \mathrm{mg}$, $0.112 \mathrm{mmol}$ ) and $13(93 \mathrm{mg}, 0.366 \mathrm{mmol})$ were dissolved in deoxygenated $\mathrm{H}_{2} \mathrm{O}(18 \mathrm{~mL})$, and this mixture was heated at $80{ }^{\circ} \mathrm{C}$ for $16 \mathrm{~h}$, after which it was concentrated in vacuo. Purification of the residue by silica column chromatography (100/0/0 to $100 / 80 / 20$ acetone/water/aq $\mathrm{KPF}_{6}$ ), followed by purification over Sephadex LH$20(\mathrm{MeOH})$, afforded the title compound as a red solid (44 mg, 42.4 $\mu$ mol, $39 \%): R_{f}=0.69\left(100 / 80 / 20\right.$ acetone/water/aq $\left.\mathrm{KPF}_{6}\right) ;{ }^{1} \mathrm{H}$ NMR $\left(400 \mathrm{MHz}, \mathrm{CD}_{3} \mathrm{OD}\right) \delta 9.85(\mathrm{~d}, J=5.7 \mathrm{~Hz}, 1 \mathrm{H}, 1), 8.81(\mathrm{~d}, J=8.0 \mathrm{~Hz}$, $1 \mathrm{H}, 4), 8.77\left(\mathrm{~d}, J=8.2 \mathrm{~Hz}, 2 \mathrm{H}, \mathrm{T}_{3}{ }^{\prime}, \mathrm{T}_{5}{ }^{\prime}\right), 8.62\left(\mathrm{~d}, J=8.1 \mathrm{~Hz}, 2 \mathrm{H}, \mathrm{T}_{6}\right.$, $\left.\mathrm{T}_{6}{ }^{\prime \prime}\right), 8.58(\mathrm{~d}, J=7.8 \mathrm{~Hz}, 1 \mathrm{H}, 10), 8.44-8.34\left(\mathrm{~m}, 2 \mathrm{H}, \mathrm{T}_{4}{ }^{\prime}, 3\right), 8.18-8.04$ $\left(\mathrm{m}, 3 \mathrm{H}, \mathrm{T}_{5}, \mathrm{~T}_{5}{ }^{\prime \prime}, 2\right), 7.92(\mathrm{td}, J=7.8,1.6 \mathrm{~Hz}, 1 \mathrm{H}, 9), 7.79(\mathrm{~d}, J=5.6 \mathrm{~Hz}$, $2 \mathrm{H}, \mathrm{T}_{3}, \mathrm{~T}_{3}^{\prime \prime}$ ), 7.45 (ddd, $J=7.3,5.6,1.4 \mathrm{~Hz}, 2 \mathrm{H}, \mathrm{T}_{4}, \mathrm{~T}_{4}{ }^{\prime \prime}$ ), 7.34-7.26 $(\mathrm{m}, 1 \mathrm{H}, 7), 7.23$ (ddd, $J=7.3,5.7,1.3 \mathrm{~Hz}, 1 \mathrm{H}, 8), 4.69(\mathrm{~d}, J=3.7 \mathrm{~Hz}$, $1 \mathrm{H}, \mathrm{H}-1)$, 3.79-3.68 (m, 2H, CHH H-6, CHH OCH${ }_{2}$ ), 3.64-3.34 (m, $5 \mathrm{H}, \mathrm{CHH} \mathrm{H}-6, \mathrm{CHH} \mathrm{OCH}, \mathrm{H}-2, \mathrm{H}-3, \mathrm{H}-5), 3.29-3.20$ (m, $1 \mathrm{H}, \mathrm{H}-4)$, 2.12-1.91 (m, $\left.2 \mathrm{H}, \mathrm{CH}_{2} \mathrm{SMe}\right), 1.39\left(\mathrm{~s}, 3 \mathrm{H}, \mathrm{CH}_{2} \mathrm{SMe}\right) ;{ }^{13} \mathrm{C}$ NMR (101 $\left.\mathrm{MHz}, \mathrm{CD}_{3} \mathrm{OD}\right) \delta 159.3\left(\mathrm{C}_{\mathrm{q} \text { arom }}\right), 158.7\left(\mathrm{C}_{\mathrm{q} \text { arom }}\right), 158.1\left(\mathrm{C}_{\mathrm{q} \text { arom }}\right)$, $157.9\left(\mathrm{C}_{\mathrm{q} \text { arom }}\right), 154.3\left(\mathrm{C}_{\mathrm{H}} \mathrm{T}_{3}, \mathrm{~T}_{3}{ }^{\prime \prime}\right), 153.5\left(\mathrm{C}_{\mathrm{H}} 1\right), 150.8\left(\mathrm{C}_{\mathrm{H}} 7\right), 140.1$ $\left(\mathrm{C}_{\mathrm{H}} \mathrm{T}_{5}, \mathrm{~T}_{5}{ }^{\prime \prime}\right), 139.4\left(\mathrm{C}_{\mathrm{H}} \mathrm{T}_{4}{ }^{\prime}\right), 139.3\left(\mathrm{C}_{\mathrm{H}} 9\right), 138.3\left(\mathrm{C}_{\mathrm{H}} 3\right), 129.8\left(\mathrm{C}_{\mathrm{H}}\right.$ $\left.\mathrm{T}_{4}, \mathrm{~T}_{4}{ }^{\prime \prime}\right), 129.4\left(\mathrm{C}_{\mathrm{H}} 2\right), 128.4\left(\mathrm{C}_{\mathrm{H}} 8\right), 126.2\left(\mathrm{C}_{\mathrm{H}} \mathrm{T}_{6}\right), 126.2\left(\mathrm{C}_{\mathrm{H}} \mathrm{T}_{6}{ }^{\prime \prime}\right)$, $125.9\left(\mathrm{C}_{\mathrm{H}} 4\right), 125.5\left(\mathrm{C}_{\mathrm{H}} \mathrm{T}_{3}{ }^{\prime}, \mathrm{T}_{5}{ }^{\prime}\right), 125.1\left(\mathrm{C}_{\mathrm{H}} 10\right), 100.2(\mathrm{C}-1), 75.1$ (C-5), 74.3 (C-3), 73.1 (C-2), 71.7 (C-4), $64.8\left(\mathrm{OCH}_{2}\right), 62.8$ (C-6), $35.9\left(\mathrm{CH}_{2} \mathrm{SMe}\right), 14.8\left(\mathrm{CH}_{2} \mathrm{SMe}\right)$; HRMS (ESI) $\mathrm{m} / z[\mathrm{M}]^{2+}$ calcd for $\mathrm{C}_{34} \mathrm{H}_{37} \mathrm{~N}_{5} \mathrm{O}_{6} \mathrm{RuS} 372.5749$, found 372.5756 . Elemental analysis calcd (\%) for $[1]\left(\mathrm{PF}_{6}\right)_{2} \cdot 2 \mathrm{MeOH}$ : C, 39.35; $\mathrm{H}, 4.13 ; \mathrm{N}, 6.37$. Found: 41.45; $\mathrm{H}, 4.18 ; \mathrm{N}, 6.35$.

$[R u(t p y)(b p y)(15)]\left(P F_{6}\right)_{2} \quad\left([2]\left(P F_{6}\right)_{2}\right)$. The title compound was synthesized analogous according to the procedure described for $[\mathbf{1}]\left(\mathrm{PF}_{6}\right)_{2}$ using $[\mathrm{Ru}($ tpy $\left.)(\mathrm{bpy}) \mathrm{Cl})\right] \mathrm{Cl}(200 \mathrm{mg}, 0.357 \mathrm{mmol})$ and $\mathbf{1 5}$ (100 mg, $0.476 \mathrm{mmol})$ in $\mathrm{H}_{2} \mathrm{O}(60 \mathrm{~mL})$, affording $[2]\left(\mathrm{PF}_{6}\right)_{2}$ as an orange powder $(98.4 \mathrm{mg}, 99.3 \mu \mathrm{mol}, 28 \%): R_{f}=0.15(100 / 80 / 20$ acetone/water/aq $\left.\mathrm{KPF}_{6}\right) ;{ }^{1} \mathrm{H} \mathrm{NMR}\left(400 \mathrm{MHz}, \mathrm{CD}_{3} \mathrm{OD}\right) \delta 10.01$ (d, J $=4.1 \mathrm{~Hz}, 1 \mathrm{H}, 1), 8.82(\mathrm{dt}, J=8.2,1.1 \mathrm{~Hz}, 1 \mathrm{H}, 4), 8.76(\mathrm{ddd}, J=8.2,4.3$, $\left.0.9 \mathrm{~Hz}, 2 \mathrm{H}, \mathrm{T}_{3}{ }^{\prime}, \mathrm{T}_{5}{ }^{\prime}\right), 8.66-8.56\left(\mathrm{~m}, 3 \mathrm{H}, \mathrm{T}_{6}, \mathrm{~T}_{6}{ }^{\prime \prime}, 10\right), 8.43-8.36(\mathrm{~m}$, $2 \mathrm{H}, \mathrm{T}_{4}{ }^{\prime}, 3$ ), 8.13-8.02 (m, 3H, $\left.\mathrm{T}_{5}, \mathrm{~T}_{5}{ }^{\prime \prime}, 2\right)$ ), 7.93 (ddd, $J=8.2,7.0,2.1$ $\mathrm{Hz}, 1 \mathrm{H}, 9), 7.86$ (ddd $\left.J=5.5,1.5,0.7 \mathrm{~Hz}, 1 \mathrm{H}, \mathrm{T}_{3}\right), 7.80$ (ddd, $J=5.5$, $\left.1.5,0.7 \mathrm{~Hz}, 1 \mathrm{H}, \mathrm{T}_{3}{ }^{\prime \prime}\right), 7.44\left(\mathrm{ddt}, J=7.8,5.5,1.3 \mathrm{~Hz}, 2 \mathrm{H}, \mathrm{T}_{4}, \mathrm{~T}_{4}{ }^{\prime \prime}\right), 7.27-$ $7.18(\mathrm{~m}, 2 \mathrm{H}, 7,8), 3.52(\mathrm{~d}, J=9.1 \mathrm{~Hz}, 1 \mathrm{H}, \mathrm{H}-1), 3.43(\mathrm{t}, J=3.6 \mathrm{~Hz}, 2 \mathrm{H}$, H-6), 3.02-2.90 (m, 3H, H-2, H-3, H-4), 2.48 (d, J = 8.7 Hz, 1H, H-5), $1.39(\mathrm{~s}, 3 \mathrm{H}, \mathrm{SMe}) ;{ }^{13} \mathrm{C} \mathrm{NMR}\left(101 \mathrm{MHz}, \mathrm{CD}_{3} \mathrm{OD}\right) \delta 163.4\left(\mathrm{C}_{\mathrm{q} \text { arom }}\right)$, $160.7\left(\mathrm{C}_{\mathrm{q} \text { arom }}\right), 160.0\left(\mathrm{C}_{\mathrm{q} \text { arom }}\right), 159.8\left(\mathrm{C}_{\mathrm{q} \text { arom }}\right), 158.9\left(\mathrm{C}_{\mathrm{q} \text { arom }}\right), 158.2$ $\left(\mathrm{C}_{\mathrm{q} \text { arom }}\right), 158.0\left(\mathrm{C}_{\mathrm{q} \text { arom }}\right), 154.5\left(\mathrm{C}_{\mathrm{H}} \mathrm{T}_{3}\right), 154.3\left(\mathrm{C}_{\mathrm{H}} \mathrm{T}_{3}{ }^{\prime \prime}\right), 153.8\left(\mathrm{C}_{\mathrm{H}}\right.$ 1), $150.4\left(\mathrm{C}_{\mathrm{H}} 7\right), 140.2\left(\mathrm{C}_{\mathrm{H}} \mathrm{T}_{5}\right), 140.1\left(\mathrm{C}_{\mathrm{H}} \mathrm{T}_{5}{ }^{\prime \prime}\right), 139.6\left(\mathrm{C}_{\mathrm{H}} \mathrm{T}_{4}{ }^{\prime}\right), 139.5$ $\left(\mathrm{C}_{\mathrm{H}} 9\right), 138.2\left(\mathrm{C}_{\mathrm{H}} 3\right), 129.7\left(\mathrm{C}_{\mathrm{H}} \mathrm{T}_{4}\right), 129.6\left(\mathrm{C}_{\mathrm{H}} \mathrm{T}_{4}{ }^{\prime \prime}\right), 129.0\left(\mathrm{C}_{\mathrm{H}} 2\right)$, $128.5\left(\mathrm{C}_{\mathrm{H}} 8\right), 126.1\left(\mathrm{C}_{\mathrm{H}} 4\right), 126.0\left(\mathrm{C}_{\mathrm{H}} \mathrm{T}_{6}\right), 125.9\left(\mathrm{C}_{\mathrm{H}} \mathrm{T}_{6}{ }^{\prime \prime}\right) 125.3\left(\mathrm{C}_{\mathrm{H}}\right.$ $\left.\mathrm{T}_{3}{ }^{\prime}, \mathrm{T}_{5}{ }^{\prime}\right), 125.1\left(\mathrm{C}_{\mathrm{H}} 10\right), 85.7(\mathrm{C}-1), 82.7(\mathrm{C}-5), 78.6(\mathrm{C}-2), 71.3(\mathrm{C}-$ 3), 70.0 (C-4), 61.8 (C-6), 9.0 (SMe); HRMS (ESI) $\mathrm{m} / z[\mathrm{M}]^{2+}$ calcd for $\mathrm{C}_{32} \mathrm{H}_{33} \mathrm{~N}_{5} \mathrm{O}_{5} \mathrm{RuS} 350.5618$, found 350.5629 . Elemental analysis calcd (\%) for $[2]\left(\mathrm{PF}_{6}\right)_{2}: \mathrm{C}, 38.18 ; \mathrm{H}, 3.30 ; \mathrm{N}, 6.96$. Found: 38.93; H, $3.39 ; \mathrm{N}, 7.19$.

$[R u(t p y)(b p y)(24)]\left(P F_{6}\right)_{2} \quad\left([3]\left(P F_{6}\right)_{2}\right)$. The title compound was synthesized analogous according to the procedure described for $[\mathbf{1}]\left(\mathrm{PF}_{6}\right)_{2}$ using $[\mathrm{Ru}($ tpy $\left.)(\mathrm{bpy}) \mathrm{Cl})\right] \mathrm{Cl}(101 \mathrm{mg}, 0.180 \mathrm{mmol})$ and 24 (75.7 $\mathrm{mg}, 0.298 \mathrm{mmol})$ in $\mathrm{H}_{2} \mathrm{O}(30 \mathrm{~mL})$, affording the title compound as a hygroscopic orange powder (73.3 $\mathrm{mg}, 70.7 \mu \mathrm{mol}, 39 \%): R_{f}=0.36$ (100/10/20 acetone/water/aq $\left.\mathrm{KPF}_{6}\right) ;{ }^{1} \mathrm{H} \mathrm{NMR}$ (500 MHz, $\left.\mathrm{CD}_{3} \mathrm{OD}\right)$ $\delta 9.85(\mathrm{dd}, J=5.6,0.7 \mathrm{~Hz}, 1 \mathrm{H}, 1), 8.81\left(\mathrm{dd}, J=17.9,8.2 \mathrm{~Hz}, 3 \mathrm{H}, 4, \mathrm{~T}_{3}{ }^{\prime}\right.$, $\left.\mathrm{T}_{5}{ }^{\prime}\right), 8.63\left(\mathrm{~d}, J=8.1 \mathrm{~Hz}, 2 \mathrm{H}, \mathrm{T}_{6}, \mathrm{~T}_{6}{ }^{\prime \prime}\right), 8.59(\mathrm{~d}, J=8.2 \mathrm{~Hz}, 1 \mathrm{H}, 10)$, $8.45-8.36\left(\mathrm{~m}, 2 \mathrm{H}, \mathrm{T}_{4}{ }^{\prime}, 3\right), 8.14-8.04\left(\mathrm{~m}, 3 \mathrm{H}, \mathrm{T}_{5}, \mathrm{~T}_{5}{ }^{\prime \prime}, 2\right), 7.93(\mathrm{td}, J=$ $7.8,1.5 \mathrm{~Hz}, 1 \mathrm{H}, 9), 7.80\left(\mathrm{td}, J=5.4,0.8 \mathrm{~Hz}, 2 \mathrm{H}, \mathrm{T}_{3}, \mathrm{~T}_{3}{ }^{\prime \prime}\right), 7.45$ (ddd, $J=$ 7.6, 5.5, $\left.1.3 \mathrm{~Hz}, 2 \mathrm{H}, \mathrm{T}_{4}, \mathrm{~T}_{4}{ }^{\prime \prime}\right), 7.30$ (ddd, $J=5.7,1.5,0.7 \mathrm{~Hz}, 1 \mathrm{H}, 7$ ), 7.23 (ddd, $J=7.2,5.7,1.3 \mathrm{~Hz}, 1 \mathrm{H}, 8), 4.15$ (d, $J=7.8 \mathrm{~Hz}, 1 \mathrm{H}, \mathrm{H}-1$ ), $3.88-$ $3.76\left(\mathrm{~m}, 2 \mathrm{H}, \mathrm{CHH} \mathrm{H}-6, \mathrm{CHH} \mathrm{OCH}_{2}\right), 3.57$ (ddd, $J=12.7,11.5,5.6 \mathrm{~Hz}$, $\left.2 \mathrm{H}, \mathrm{CHH} \mathrm{H}-6, \mathrm{CHH} \mathrm{OCH}{ }_{2}\right), 3.26(\mathrm{~m}, 1 \mathrm{H}, \mathrm{H}-3), 3.23-3.17(\mathrm{~m}, 2 \mathrm{H}$, $\mathrm{H}-2, \mathrm{H}-4), 3.09$ (dd, $J=9.2,7.8 \mathrm{~Hz}, 1 \mathrm{H}, \mathrm{H}-5), 1.98(\mathrm{t}, J=5.6 \mathrm{~Hz}, 2 \mathrm{H}$, $\mathrm{CH}_{2} \mathrm{SMe}$ ), 1.39 (s, $3 \mathrm{H}, \mathrm{CH}_{2} \mathrm{SMe}$ ); ${ }^{13} \mathrm{C}$ NMR (126 MHz, $\left.\mathrm{CD}_{3} \mathrm{OD}\right) \delta$ $159.3\left(\mathrm{C}_{\mathrm{q} \text { arom }}\right), 159.3\left(\mathrm{C}_{\mathrm{q} \text { arom }}\right), 158.8\left(\mathrm{C}_{\mathrm{q} \text { arom }}\right), 158.2\left(\mathrm{C}_{\mathrm{q} \text { arom }}\right), 158.0$ $\left(\mathrm{C}_{\mathrm{q} \text { arom }}\right)$, 154.4 $\left(\mathrm{C}_{\mathrm{H}} \mathrm{T}_{3}\right), 154.4\left(\mathrm{C}_{\mathrm{H}} \mathrm{T}_{3}{ }^{\prime \prime}\right), 153.6\left(\mathrm{C}_{\mathrm{H}} 1\right), 150.8\left(\mathrm{C}_{\mathrm{H}} 7\right)$, $140.1\left(\mathrm{C}_{\mathrm{H}} \mathrm{T}_{5}, \mathrm{~T}_{5}{ }^{\prime \prime}\right), 139.5\left(\mathrm{~T}_{4}{ }^{\prime}\right), 139.4\left(\mathrm{C}_{\mathrm{H}} 9\right), 138.3\left(\mathrm{C}_{\mathrm{H}} 3\right), 129.8\left(\mathrm{C}_{\mathrm{H}}\right.$
$\left.\mathrm{T}_{4}, \mathrm{~T}_{4}{ }^{\prime \prime}\right), 129.2\left(\mathrm{C}_{\mathrm{H}} 2\right), 128.4\left(\mathrm{C}_{\mathrm{H}} 8\right), 126.2\left(\mathrm{~T}_{6}, \mathrm{~T}_{6}{ }^{\prime \prime}\right), 125.9\left(\mathrm{C}_{\mathrm{H}} 4\right)$, $125.5\left(\mathrm{~T}_{3}{ }^{\prime}, \mathrm{T}_{5}{ }^{\prime}\right), 125.1\left(\mathrm{C}_{\mathrm{H}} 10\right), 104.2(\mathrm{C}-1), 78.2(\mathrm{C}-3), 78.1(\mathrm{C}-4)$, 74.9 (C-2), 71.5 (C-5), $66.6\left(\mathrm{OCH}_{2}\right), 62.6$ (C-6), $35.8\left(\mathrm{CH}_{2} \mathrm{SMe}\right)$, $14.8\left(\mathrm{CH}_{2} \mathrm{SMe}\right)$; HRMS (ESI) $m / z[\mathrm{M}]^{2+}$ calcd for $\mathrm{C}_{34} \mathrm{H}_{37} \mathrm{~N}_{5} \mathrm{O}_{6} \mathrm{RuS}$ 372.5749, found 372.5758. Elemental analysis calcd $(\%)$ for $[3]\left(\mathrm{PF}_{6}\right)_{2}$ : C, 39.47; H, 3.60; N, 6.77. Found: 40.57; H, 3.53; N, 7.00.

$[R u(t p y)(b p y)(25)]\left(P F_{6}\right)_{2} \quad\left([4]\left(P F_{6}\right)_{2}\right)$. The title compound was synthesized analogous according to the procedure described for $[1]\left(\mathrm{PF}_{6}\right)_{2}$ using $[\mathrm{Ru}($ tpy $)($ bpy $\left.) \mathrm{Cl})\right] \mathrm{Cl}(94.2 \mathrm{mg}, 0.168 \mathrm{mmol})$ and $25(71.0 \mathrm{mg}, 0.238 \mathrm{mmol})$ in $\mathrm{H}_{2} \mathrm{O}(28 \mathrm{~mL})$, affording the title compound as a hygroscopic orange powder $(120 \mathrm{mg}, 111 \mu \mathrm{mol}, 66 \%)$ : $R_{f}=0.56\left(50 / 30 / 20\right.$ acetone/water/aq $\left.\mathrm{KPF}_{6}\right) ;{ }^{1} \mathrm{H}$ NMR $(400 \mathrm{MHz}$, $\left.\mathrm{CD}_{3} \mathrm{OD}\right) \delta 9.83(\mathrm{~d}, J=5.7 \mathrm{~Hz}, 1 \mathrm{H}, 1), 8.79(\mathrm{dd}, J=14.9,8.1 \mathrm{~Hz}, 3 \mathrm{H}, 4$, $\left.\mathrm{T}_{3}{ }^{\prime}, \mathrm{T}_{5}{ }^{\prime}\right), 8.60\left(\mathrm{dd}, J=16.6,8.1 \mathrm{~Hz}, 2 \mathrm{H}, \mathrm{T}_{6}, \mathrm{~T}_{6}{ }^{\prime \prime}\right), 8.43-8.34(\mathrm{~m}, 2 \mathrm{H}$, $\left.\mathrm{T}_{4}{ }^{\prime}, 3\right), 8.10\left(\mathrm{~m}, 3 \mathrm{H}, \mathrm{T}_{5}, \mathrm{~T}_{5}{ }^{\prime \prime}, 2\right), 7.91(\mathrm{td}, J=7.8,1.5 \mathrm{~Hz}, 1 \mathrm{H}, 9), 7.80$ $\left(\mathrm{d}, J=4.7 \mathrm{~Hz}, 1 \mathrm{H}, \mathrm{T}_{3}, \mathrm{~T}_{3}{ }^{\prime \prime}\right), 7.51-7.41\left(\mathrm{~m}, 2 \mathrm{H}, \mathrm{T}_{4}, \mathrm{~T}_{4}{ }^{\prime \prime}\right), 7.32-7.27(\mathrm{~m}$, $1 \mathrm{H}, 7), 7.23$ (ddd, $J=7.2,5.7,1.3 \mathrm{~Hz}, 1 \mathrm{H}, 8), 4.27(\mathrm{~d}, J=7.8 \mathrm{~Hz}, 1 \mathrm{H}, \mathrm{H}-$ 1), 3.97-3.89 (m, $\left.1 \mathrm{H}, \mathrm{CHH} \mathrm{OCH}{ }_{2}\right), 3.85(\mathrm{dd}, J=11.8,1.7 \mathrm{~Hz}, 1 \mathrm{H}$, CHH H-6), 3.71-3.58 (m, 2H, CHH H-6, CHH OCH${ }_{2}$ ), 3.54 (dd, $J=$ $\left.5.4,3.8 \mathrm{~Hz}, 2 \mathrm{H}, \mathrm{OCH}_{2}\right), 3.46\left(\mathrm{t}, J=5.5 \mathrm{~Hz}, 2 \mathrm{H}, \mathrm{OCH}_{2}\right), 3.35(\mathrm{~m}, J=2.4$ $\mathrm{Hz}, 1 \mathrm{H}, \mathrm{H}-3$ ), $3.28-3.22$ (m, 3H, H-4, H-5), 3.12 (dd, $J=9.0,7.8 \mathrm{~Hz}$, $1 \mathrm{H},), 1.96-1.88\left(\mathrm{~m}, 2 \mathrm{H}, \mathrm{CH}_{2} \mathrm{SMe}\right), 1.40\left(\mathrm{~s}, 3 \mathrm{H}, \mathrm{CH}_{2} \mathrm{SMe}\right) ;{ }^{13} \mathrm{C} \mathrm{NMR}$ $\left(101 \mathrm{MHz}, \mathrm{CD}_{3} \mathrm{OD}\right) \delta 159.3\left(\mathrm{C}_{\mathrm{q} \text { arom }}\right), 158.7\left(\mathrm{C}_{\mathrm{q} \text { arom }}\right), 158.1\left(\mathrm{C}_{\mathrm{q} \text { arom }}\right)$, $157.9\left(\mathrm{C}_{\mathrm{q} \text { arom }}\right), 154.4\left(\mathrm{C}_{\mathrm{H}} \mathrm{T}_{3}, \mathrm{~T}_{3}^{\prime \prime}\right), 153.4\left(\mathrm{C}_{\mathrm{H}} \mathrm{l}\right), 150.8\left(\mathrm{C}_{\mathrm{H}} 7\right), 140.1$ $\left(\mathrm{T}_{5}, \mathrm{~T}_{5}{ }^{\prime \prime}\right), 139.5\left(\mathrm{C}_{\mathrm{H}} \mathrm{T}_{4}{ }^{\prime}\right), 139.3\left(\mathrm{C}_{\mathrm{H}} 9\right), 138.3\left(\mathrm{C}_{\mathrm{H}} 3\right), 129.8\left(\mathrm{C}_{\mathrm{H}} \mathrm{T}_{4}\right.$, $\left.\mathrm{T}_{4}{ }^{\prime \prime}\right), 129.3\left(\mathrm{C}_{\mathrm{H}} 2\right), 128.4\left(\mathrm{C}_{\mathrm{H}} 8\right), 126.2\left(\mathrm{C}_{\mathrm{H}} \mathrm{T}_{6}\right), 125.9\left(\mathrm{C}_{\mathrm{H}} \mathrm{T}_{6}{ }^{\prime \prime}\right)$, $125.5\left(\mathrm{C}_{\mathrm{H}} 4\right), 125.1\left(\mathrm{C}_{\mathrm{H}} \mathrm{T}_{3}{ }^{\prime}, \mathrm{T}_{5}{ }^{\prime}\right), 104.4(\mathrm{C}-1), 78.1(\mathrm{C}-3), 78.0(\mathrm{C}-4)$, $75.1(\mathrm{C}-2), 71.6(\mathrm{C}-5), 71.4\left(\mathrm{OCH}_{2}\right), 69.7\left(\mathrm{OCH}_{2}\right), 68.2\left(\mathrm{OCH}_{2}\right)$, 62.7 (C-6), $35.6\left(\mathrm{CH}_{2} \mathrm{SMe}\right), 15.2\left(\mathrm{CH}_{2} \mathrm{SMe}\right)$; HRMS (ESI) $\mathrm{m} / z[\mathrm{M}]^{2+}$ calcd for $\mathrm{C}_{36} \mathrm{H}_{41} \mathrm{~N}_{5} \mathrm{O}_{7} \mathrm{RuS} 394.5880$, found 394.5887. Elemental analysis calcd (\%) for $[4]\left(\mathrm{PF}_{6}\right)_{2}: \mathrm{C}, 40.08 ; \mathrm{H}, 3.83 ; \mathrm{N}, 6.49$. Found: 40.78; H, 3.97; N, 6.34 .

$[R u(t p y)(b p y)(26)]\left(P F_{6}\right)_{2} \quad\left([5]\left(P F_{6}\right)_{2}\right)$. The title compound was synthesized analogous according to the procedure described for $[\mathbf{1}]\left(\mathrm{PF}_{6}\right)_{2}$ using $\left.[\mathrm{Ru}(\mathrm{tpy})(\mathrm{bpy}) \mathrm{Cl})\right] \mathrm{Cl}(102 \mathrm{mg}, 0.182 \mathrm{mmol})$ and 26 ( $100 \mathrm{mg}, 0.292 \mathrm{mmol})$ in $\mathrm{H}_{2} \mathrm{O}(30 \mathrm{~mL})$, affording the title compound as a red solid (130 mg, $116 \mu \mathrm{mol}, 65 \%): R_{f}=0.35(100 / 80 / 20$ acetone/ water/aq $\left.\mathrm{KPF}_{6}\right) ;{ }^{1} \mathrm{H}$ NMR $\left(400 \mathrm{MHz}, \mathrm{CD}_{3} \mathrm{OD}\right) \delta 9.83(\mathrm{~d}, J=5.8 \mathrm{~Hz}$, $1 \mathrm{H}, 1), 8.81\left(\mathrm{dd}, J=12.6,7.9 \mathrm{~Hz}, 3 \mathrm{H}, 4, \mathrm{~T}_{3}{ }^{\prime}, \mathrm{T}_{5}{ }^{\prime}\right), 8.62(\mathrm{dd}, J=17.9,8.1$ $\left.\mathrm{Hz}, 3 \mathrm{H}, \mathrm{T}_{6}, \mathrm{~T}_{6}{ }^{\prime \prime}, 10\right), 8.46-8.35\left(\mathrm{~m}, 2 \mathrm{H}, \mathrm{T}_{4}{ }^{\prime}, 3\right), 8.10(\mathrm{t}, J=8.3 \mathrm{~Hz}, 3 \mathrm{H}$, $\left.\mathrm{T}_{5}, \mathrm{~T}_{5}{ }^{\prime \prime}, 2\right), 7.93(\mathrm{t}, J=7.9 \mathrm{~Hz}, 1 \mathrm{H}, 9), 7.80\left(\mathrm{~d}, J=5.8 \mathrm{~Hz}, 2 \mathrm{H}, \mathrm{T}_{3}, \mathrm{~T}_{3}{ }^{\prime \prime}\right)$, $7.47\left(\mathrm{t}, J=6.6 \mathrm{~Hz}, 2 \mathrm{H}, \mathrm{T}_{4}, \mathrm{~T}_{4}{ }^{\prime \prime}\right), 7.30(\mathrm{~d}, J=5.8 \mathrm{~Hz}, 1 \mathrm{H}, 7), 7.23(\mathrm{t}, J=$ $6.6 \mathrm{~Hz}, 1 \mathrm{H}, 8), 4.26(\mathrm{~d}, J=7.8 \mathrm{~Hz}, 1 \mathrm{H}, \mathrm{H}-1), 4.06-3.91(\mathrm{~m}, 1 \mathrm{H}, \mathrm{CHH}$ $\left.\mathrm{OCH}_{2}\right), 3.86(\mathrm{~d}, J=11.8 \mathrm{~Hz}, 1 \mathrm{H}, \mathrm{CHH} \mathrm{H}-6), 3.73-3.39(\mathrm{~m}, 10 \mathrm{H}$, $\left.\mathrm{CHH} \mathrm{H}-6, \mathrm{CHH} \mathrm{OCH} 2,4 \times \mathrm{OCH}_{2}\right), 3.35(\mathrm{~m}, 1 \mathrm{H}, \mathrm{H}-5), 3.26$ (d, $J=6.3$ $\mathrm{Hz}, 2 \mathrm{H}, \mathrm{H}-3, \mathrm{H} 4), 3.10$ (t, $J=8.5 \mathrm{~Hz}, 1 \mathrm{H}, \mathrm{H}-2), 1.90(\mathrm{~d}, J=5.6 \mathrm{~Hz}, 2 \mathrm{H}$, $\left.\mathrm{OCH}_{2} \mathrm{SMe}\right), 1.41\left(\mathrm{~s}, 3 \mathrm{H}, \mathrm{OCH}_{2} \mathrm{SMe}\right) ;{ }^{13} \mathrm{C} \mathrm{NMR}\left(101 \mathrm{MHz}, \mathrm{CD}_{3} \mathrm{OD}\right)$ $\delta 157.9\left(\mathrm{C}_{\mathrm{q} \text { arom }}\right), 157.4\left(\mathrm{C}_{\mathrm{q} \text { arom }}\right), 156.8\left(\mathrm{C}_{\mathrm{q} \text { arom }}\right), 156.6\left(\mathrm{C}_{\mathrm{q} \text { arom }}\right)$, 153.1 $\left(\mathrm{C}_{\mathrm{H}} \mathrm{T}_{3}, \mathrm{~T}_{3}{ }^{\prime \prime}\right), 152.1\left(\mathrm{C}_{\mathrm{H}} 1\right), 149.5\left(\mathrm{C}_{\mathrm{H}} 7\right), 138.8\left(\mathrm{C}_{\mathrm{H}} \mathrm{T}_{5}, \mathrm{~T}_{5}{ }^{\prime \prime}\right)$, $138.2\left(\mathrm{C}_{\mathrm{H}} 9\right), 138.0\left(\mathrm{C}_{\mathrm{H}} \mathrm{T}_{4}{ }^{\prime}\right), 136.9\left(\mathrm{C}_{\mathrm{H}} 3\right), 128.5\left(\mathrm{C}_{\mathrm{H}} \mathrm{T}_{4}, \mathrm{~T}_{4}{ }^{\prime \prime}\right), 127.9$ $\left(\mathrm{C}_{\mathrm{H}} 8\right), 127.1\left(\mathrm{C}_{\mathrm{H}} 2\right), 124.9\left(\mathrm{C}_{\mathrm{H}} \mathrm{T}_{6}, \mathrm{~T}_{6}{ }^{\prime \prime}\right), 124.6\left(\mathrm{C}_{\mathrm{H}} 4\right), 124.1\left(\mathrm{C}_{\mathrm{H}} \mathrm{T}_{3}\right.$, $\left.\mathrm{T}_{5}{ }^{\prime}\right), 123.8\left(\mathrm{C}_{\mathrm{H}} 10\right), 103.1(\mathrm{C}-1), 76.6(\mathrm{C}-3, \mathrm{C}-5), 73.7(\mathrm{C}-2), 70.3(\mathrm{C}-$ 4), $70.0\left(\mathrm{OCH}_{2}\right), 69.9\left(\mathrm{OCH}_{2}\right), 69.8\left(\mathrm{OCH}_{2}\right), 68.3\left(\mathrm{OCH}_{2}\right), 67.0$ $\left(\mathrm{OCH}_{2}\right), 61.3(\mathrm{C}-6), 34.1\left(\mathrm{OCH}_{2} \mathrm{SMe}\right), 14.00\left(\mathrm{OCH}_{2} \mathrm{SMe}\right)$; HRMS (ESI) $\mathrm{m} / z[\mathrm{M}]^{2+}$ calcd for $\mathrm{C}_{38} \mathrm{H}_{45} \mathrm{~N}_{5} \mathrm{O}_{8} \mathrm{RuS} 416.6011$, found 416.6025 . Elemental analysis calcd (\%) for $[5]\left(\mathrm{PF}_{6}\right)_{2} \cdot 3 \mathrm{H}_{2} \mathrm{O}: \mathrm{C}, 38.78 ; \mathrm{H}, 4.37 ; \mathrm{N}$, 5.95. Found: $39.27 ; \mathrm{H}, 4.68 ; \mathrm{N}, 5.95$.

$\left[R u\left(\right.\right.$ tpy) $\left(\right.$ bpy)(37)]PF $6\left([6] P F_{6}\right) \cdot\left[\mathrm{Ru}(\right.$ tpy $)($ bpy $\left.)\left(\mathrm{H}_{2} \mathrm{O}\right)\right]\left(\mathrm{PF}_{6}\right)_{2}(35.9$ $\mathrm{mg}, 45.0 \mu \mathrm{mol})$ and $\mathrm{H} 37(30.3 \mathrm{mg}, 44.7 \mu \mathrm{mol})$ were dissolved in a deoxygenated mixture of acetone $/ \mathrm{H}_{2} \mathrm{O}(4: 1,8 \mathrm{~mL})$ and heated at $50{ }^{\circ} \mathrm{C}$ for $16 \mathrm{~h}$, after which the reaction mixture was concentrated in vacuo and purified over Sephadex $\mathrm{LH}-20(\mathrm{MeOH})$, affording the title compound as a red solid (18 mg, $18.4 \mu \mathrm{mol}, 41 \%): R_{f}=0.52$ (acetone/water/aq $\left.\mathrm{KPF}_{6} 100 / 80 / 20\right) ;{ }^{1} \mathrm{H} \mathrm{NMR}\left(500 \mathrm{MHz}, \mathrm{CD}_{3} \mathrm{OD}\right) \delta 9.84(\mathrm{~d}, J=5.6 \mathrm{~Hz}$, $1 \mathrm{H}, 1), 8.88-8.80\left(\mathrm{~m}, 3 \mathrm{H}, 4, \mathrm{~T}_{3}{ }^{\prime}, \mathrm{T}_{5}{ }^{\prime}\right), 8.67\left(\mathrm{~d}, J=7.1 \mathrm{~Hz}, 2 \mathrm{H}, \mathrm{T}_{6}, \mathrm{~T}_{6}{ }^{\prime \prime}\right)$, $8.62(\mathrm{~d}, J=7.5 \mathrm{~Hz}, 1 \mathrm{H}, 10), 8.43\left(\mathrm{q}, J=7.9 \mathrm{~Hz}, 2 \mathrm{H}, \mathrm{T}_{4}{ }^{\prime}, 3\right), 8.17-8.08$ $\left(\mathrm{m}, 3 \mathrm{H}, \mathrm{T}_{5}, \mathrm{~T}_{5}{ }^{\prime \prime}, 2\right), 7.95(\mathrm{td}, J=7.8,1.5 \mathrm{~Hz}, 1 \mathrm{H}, 9), 7.81(\mathrm{~d}, J=5.5 \mathrm{~Hz}$, $\left.2 \mathrm{H}, \mathrm{T}_{3}, \mathrm{~T}_{3}{ }^{\prime \prime}\right), 7.48\left(\mathrm{ddd}, J=7.2,5.5,1.3 \mathrm{~Hz}, 2 \mathrm{H}, \mathrm{T}_{4}, \mathrm{~T}_{4}{ }^{\prime \prime}\right), 7.36-7.28$ $(\mathrm{m}, 1 \mathrm{H}, 7), 7.24$ (ddd, $J=7.2,5.7,1.3 \mathrm{~Hz}, 1 \mathrm{H}, 8), 5.23(\mathrm{~d}, J=3.5 \mathrm{~Hz}$, $0.5 \mathrm{H}, \mathrm{H}-1 \alpha), 4.45(\mathrm{~d}, J=7.8 \mathrm{~Hz}, 0.5 \mathrm{H}, \mathrm{H}-1 \beta), 3.99(\mathrm{dt}, J=11.1,4.6 \mathrm{~Hz}$, 
$\left.0.5 \mathrm{H} \mathrm{CHH} \mathrm{OCH} \mathrm{CH}_{2} \alpha / \beta\right), 3.86(\mathrm{dd}, J=11.8,2.3 \mathrm{~Hz}, 0.5 \mathrm{H}, \mathrm{CHH} \mathrm{H}-6 \alpha$ ), $3.81-3.55\left(\mathrm{~m}, 7.5 \mathrm{H}, \mathrm{CH} \mathrm{H} \mathrm{H}-6 \alpha, \mathrm{CH}_{2} \mathrm{H}-6 \beta, \mathrm{H}-3 \alpha, \mathrm{H}-5 \alpha, \mathrm{H}-5 \beta, \mathrm{CH}\right.$ $\left.\mathrm{OCH}_{2} \alpha / \beta, 1 \times \mathrm{OCH}_{2} \alpha / \beta, 2 \times \mathrm{OCH}_{2} \alpha+\beta\right), 3.51-3.47(\mathrm{~m}, 2 \mathrm{H}$, $\left.\mathrm{OCH}_{2}\right), 3.45\left(\mathrm{ddd}, J=6.4,5.2,1.6 \mathrm{~Hz}, 2 \mathrm{H}, \mathrm{OCH}_{2}\right), 3.30-3.20(\mathrm{~m}$, $1.5 \mathrm{H}, \mathrm{H}-3 \beta, \mathrm{H}-4 \beta, \mathrm{H}-4 \alpha), 3.16(\mathrm{dd}, J=9.6,3.5 \mathrm{~Hz}, 0.5 \mathrm{H}, \mathrm{H}-2 \alpha), 2.91$ (dd, $J=8.9,7.8 \mathrm{~Hz}, 0.5 \mathrm{H}, \mathrm{H}-2 \beta), 1.97-1.89\left(\mathrm{~m}, 2 \mathrm{H}, \mathrm{CH}_{2} \mathrm{SMe}\right), 1.43$ (s, $1.5 \mathrm{H}, \mathrm{CH}_{2} \mathrm{SMe} \alpha$ ), 1.42 (s, $1.5 \mathrm{H}, \mathrm{CH}_{2} \mathrm{SMe} \beta$ ); ${ }^{13} \mathrm{C}$ NMR $(126 \mathrm{MHz}$, $\left.\mathrm{CD}_{3} \mathrm{OD}\right) \delta 159.3\left(\mathrm{C}_{\mathrm{q} \text { arom }}\right), 158.8\left(\mathrm{C}_{\mathrm{q} \text { arom }}\right), 158.2\left(\mathrm{C}_{\mathrm{q} \text { arom }}\right), 158.0$ $\left(\mathrm{C}_{\mathrm{q} \text { arom }}\right), 154.4\left(\mathrm{C}_{\mathrm{H}} \mathrm{T}_{3}, \mathrm{~T}_{3}{ }^{\prime \prime}\right), 153.4\left(\mathrm{C}_{\mathrm{H}} 1\right), 150.8\left(\mathrm{C}_{\mathrm{H}} 7\right), 140.2\left(\mathrm{C}_{\mathrm{H}}\right.$ $\left.\mathrm{T}_{5}, \mathrm{~T}_{5}{ }^{\prime \prime}\right), 139.6\left(\mathrm{C}_{\mathrm{H}} \mathrm{T}_{5}, \mathrm{~T}_{5}{ }^{\prime \prime}\right), 139.4\left(\mathrm{C}_{\mathrm{H}} \mathrm{T}_{4}{ }^{\prime}, 9\right), 138.4\left(\mathrm{C}_{\mathrm{H}} 3\right), 129.9$ $\left(\mathrm{C}_{\mathrm{H}} \mathrm{T}_{4}, \mathrm{~T}_{4}{ }^{\prime \prime}\right), 129.3\left(\mathrm{C}_{\mathrm{H}} 2\right), 128.4\left(\mathrm{C}_{\mathrm{H}} 8\right), 126.3\left(\mathrm{C}_{\mathrm{H}} \mathrm{T}_{6}, \mathrm{~T}_{6}{ }^{\prime \prime}\right), 126.0$ $\left(\mathrm{C}_{\mathrm{H}} 4\right), 125.5\left(\mathrm{C}_{\mathrm{H}} \mathrm{T}_{3}{ }^{\prime}, \mathrm{T}_{5}{ }^{\prime}\right), 125.2\left(\mathrm{C}_{\mathrm{H}} 10\right), 98.1(\mathrm{C}-1 \beta), 91.8(\mathrm{C}-1 \alpha)$,

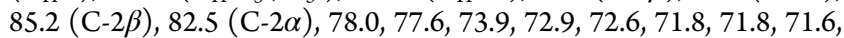
71.3, 71.3, 71.2, 70.9, 68.4, 68.3, $62.8(\mathrm{C}-6 \alpha / \beta), 62.7(\mathrm{C}-6 \alpha / \beta), 35.7$ $\left(\mathrm{CH}_{2} \mathrm{SMe}\right), 35.6\left(\mathrm{CH}_{2} \mathrm{SMe}\right), 15.4\left(\mathrm{CH}_{2} \mathrm{SMe}\right), 15.4\left(\mathrm{CH}_{2} \mathrm{SMe}\right)$; HRMS (ESI) $\mathrm{m} / z[\mathrm{M}+\mathrm{H}]^{2+}$ calcd for $\mathrm{C}_{38} \mathrm{H}_{45} \mathrm{~N}_{5} \mathrm{O}_{8} \mathrm{RuS} 416.6011$, found 416.6028. Elemental analysis calcd (\%) for $[6] \mathrm{PF}_{6} \cdot 3 \mathrm{H}_{2} \mathrm{O}: \mathrm{C}, 44.27 ; \mathrm{H}$, 4.89; N, 6.79. Found: 44.70; H, 4.73; N, 6.49.

$[R u(t p y)(b p y)(40)] P F_{6}\left([7] P F_{6}\right)$. The title compound was synthesized analogous according to the procedure described for $[1]\left(\mathrm{PF}_{6}\right)_{2}$ using $[\mathrm{Ru}(\mathrm{tpy})(\mathrm{bpy}) \mathrm{Cl})] \mathrm{Cl}(59.1 \mathrm{mg}, 0.105 \mathrm{mmol})$ and $\mathbf{H} 40(40.0 \mathrm{mg}$, $0.117 \mathrm{mmol})$ in $\mathrm{H}_{2} \mathrm{O}(18 \mathrm{~mL})$, affording the title compound as a red solid (44.2 mg, $39.3 \mu \mathrm{mol}, 37 \%): R_{f}=0.55$ (100/80/20 acetone/water/ aq $\left.\mathrm{KPF}_{6}\right) ;{ }^{1} \mathrm{H} \mathrm{NMR}\left(500 \mathrm{MHz}, \mathrm{CD}_{3} \mathrm{OD}\right) \delta 9.86(\mathrm{~d}, J=5.9 \mathrm{~Hz}, 1 \mathrm{H}, 1)$, 8.96-8.80 (m, 3H, 4, $\left.\mathrm{T}_{3}{ }^{\prime}, \mathrm{T}_{5}{ }^{\prime}\right), 8.74-8.69\left(\mathrm{~m}, 2 \mathrm{H}, \mathrm{T}_{6}, \mathrm{~T}_{6}{ }^{\prime \prime}\right), 8.67-8.62$ $(\mathrm{m}, 1 \mathrm{H}, 10), 8.51-8.40\left(\mathrm{~m}, 2 \mathrm{H}, \mathrm{T}_{4}{ }^{\prime}, 3\right), 8.15(\mathrm{dtd}, J=9.6,4.4,2.4 \mathrm{~Hz}$, $\left.3 \mathrm{H}, \mathrm{T}_{5}, \mathrm{~T}_{5}{ }^{\prime \prime}, 2\right), 8.01-7.93(\mathrm{~m}, 1 \mathrm{H}, 9), 7.87-7.79\left(\mathrm{~m}, 2 \mathrm{H}, \mathrm{T}_{3}, \mathrm{~T}_{3}{ }^{\prime \prime}\right)$, 7.55-7.46 (m, 2H, $\left.\mathrm{T}_{4}, \mathrm{~T}_{4}{ }^{\prime \prime}\right), 7.36-7.32(\mathrm{~m}, 1 \mathrm{H}, 7), 7.27$ (ddt, $J=7.3$, $5.7,1.5 \mathrm{~Hz}, 1 \mathrm{H}, 8), 5.10(\mathrm{~d}, J=3.6 \mathrm{~Hz}, 0.5 \mathrm{H}, \mathrm{H}-1 \alpha), 4.51(\mathrm{~d}, J=7.6 \mathrm{~Hz}$, $0.5 \mathrm{H}, \mathrm{H}-1 \beta), 4.29-3.08(\mathrm{~m}, 15 \mathrm{H}), 1.96(\mathrm{t}, J=5.4 \mathrm{~Hz}, 2 \mathrm{H}, 2 \times$ $\left.\mathrm{CH}_{2} \mathrm{SMe}\right), 1.45$ (s, $\left.3 \mathrm{H}, 2 \times \mathrm{CH}_{2} \mathrm{SMe}\right) ;{ }^{13} \mathrm{C} \mathrm{NMR}\left(126 \mathrm{MHz}, \mathrm{CD}_{3} \mathrm{OD}\right)$ $\delta 159.3\left(\mathrm{C}_{\mathrm{q} \text { arom }}\right), 158.8\left(\mathrm{C}_{\mathrm{q} \text { arom }}\right), 158.2\left(\mathrm{C}_{\mathrm{q}}\right.$ arom $), 158.0\left(\mathrm{C}_{\mathrm{q} \text { arom }}\right)$, 154.4 $\left(\mathrm{C}_{\mathrm{H}} \mathrm{T}_{3}, \mathrm{~T}_{3}{ }^{\prime \prime}\right), 153.4\left(\mathrm{C}_{\mathrm{H}} 1\right), 150.8\left(\mathrm{C}_{\mathrm{H}} 7\right), 140.2\left(\mathrm{C}_{\mathrm{H}} \mathrm{T}_{5}, \mathrm{~T}_{5}^{\prime \prime}\right)$, 139.6 $\left(\mathrm{C}_{\mathrm{H}} \mathrm{T}_{4}{ }^{\prime}\right), 139.4\left(\mathrm{C}_{\mathrm{H}} 9\right), 138.3\left(\mathrm{C}_{\mathrm{H}} 3\right), 129.9\left(\mathrm{C}_{\mathrm{H}} \mathrm{T}_{4}, \mathrm{~T}_{4}{ }^{\prime \prime}\right), 129.3$ $\left(\mathrm{C}_{\mathrm{H}} 2\right), 128.4\left(\mathrm{C}_{\mathrm{H}} 8\right), 126.3\left(\mathrm{C}_{\mathrm{H}} \mathrm{T}_{6}, \mathrm{~T}_{6}{ }^{\prime \prime}\right), 126.0\left(\mathrm{C}_{\mathrm{H}} 4\right), 125.5\left(\mathrm{C}_{\mathrm{H}} \mathrm{T}_{3}{ }^{\prime}\right.$, $\left.\mathrm{T}_{5}{ }^{\prime}\right)$, $125.2\left(\mathrm{C}_{\mathrm{H}} 10\right)$, $98.2(\mathrm{C}-1 \beta), 94.0(\mathrm{C}-1 \alpha), 87.6,84.4,77.8,76.1$, 73.7, 73.0, 73.0, 72.0, 72.0, 71.6, 71.4, 71.3, 71.2, 71.2, 71.1, 71.1, 68.4, 68.3, $62.6(\mathrm{C}-6 \alpha / \beta), 62.5(\mathrm{C}-6 \alpha / \beta), 35.7\left(2 \times \mathrm{CH}_{2} \mathrm{SMe}\right), 15.4(2 \times$ $\mathrm{CH}_{2} \mathrm{SMe}$ ); HRMS (ESI) $\mathrm{m} / z[\mathrm{M}+\mathrm{H}]^{2+}$ calcd for $\mathrm{C}_{38} \mathrm{H}_{45} \mathrm{~N}_{5} \mathrm{O}_{8} \mathrm{RuS}$ 416.6011, found 416.6024. Elemental analysis calcd (\%) for [7] $\mathrm{PF}_{6}$. $2 \mathrm{H}_{2} \mathrm{O}: \mathrm{C}, 45.02 ; \mathrm{H}, 4.87$; N, 6.91. Found: C, 44.82; H, 4.61; N, 6.79.

$[R u(t p y)(b p y)(46)] P F_{6}\left([8] P F_{6}\right) \cdot\left[\mathrm{Ru}(\right.$ tpy $)($ bpy $\left.)\left(\mathrm{H}_{2} \mathrm{O}\right)\right]\left(\mathrm{PF}_{6}\right)_{2}(25.8$ $\mathrm{mg}, 32.0 \mu \mathrm{mol})$ and $\mathbf{H} 46(11.0 \mathrm{mg}, 32.1 \mu \mathrm{mol})$ were dissolved in a deoxygenated mixture of acetone $/ \mathrm{H}_{2} \mathrm{O}(4: 1,6 \mathrm{~mL})$ and heated at $50{ }^{\circ} \mathrm{C}$ for $48 \mathrm{~h}$, after which the reaction mixture was concentrated in vacuo and purified over Sephadex LH-20 $(\mathrm{MeOH})$, affording the title compound as a red solid $(23 \mathrm{mg}, 23.5 \mu \mathrm{mol}, 73 \%): R_{f}=0.61(100 / 80 / 20$ acetone/ water/aq $\mathrm{KPF}_{6}$ ); ${ }^{1} \mathrm{H} \mathrm{NMR}\left(500 \mathrm{MHz}, \mathrm{CD}_{3} \mathrm{OD}\right) \delta 9.85$ (dd, $J=5.5,1.1$ $\mathrm{Hz}, 1 \mathrm{H}, 1), 8.86(\mathrm{~d}, J=8.3 \mathrm{~Hz}, 1 \mathrm{H}, 4), 8.83\left(\mathrm{~d}, J=8.1 \mathrm{~Hz}, 2 \mathrm{H}, \mathrm{T}_{3}{ }^{\prime}, \mathrm{T}_{5}{ }^{\prime}\right)$, 8.69-8.66 (m, $\left.2 \mathrm{H}, \mathrm{T}_{6}, \mathrm{~T}_{6}{ }^{\prime \prime}\right), 8.63(\mathrm{dt}, J=8.2,1.1 \mathrm{~Hz}, 1 \mathrm{H}, 10), 8.47-$ $8.41\left(\mathrm{~m}, 2 \mathrm{H}, \mathrm{T}_{4}{ }^{\prime}, 3\right), 8.13\left(\mathrm{td}, J=7.8,1.5 \mathrm{~Hz}, 3 \mathrm{H}, \mathrm{T}_{5}, \mathrm{~T}_{5}{ }^{\prime \prime}, 2\right), 7.96(\mathrm{td}, J$ $=7.9,1.5 \mathrm{~Hz}, 1 \mathrm{H}, 9), 7.82\left(\mathrm{dd}, J=5.7,1.6 \mathrm{~Hz}, 2 \mathrm{H}, \mathrm{T}_{3}, \mathrm{~T}_{3}{ }^{\prime \prime}\right), 7.49(\mathrm{ddt}, J$ $\left.=7.3,5.4,1.8 \mathrm{~Hz}, 2 \mathrm{H}, \mathrm{T}_{4}, \mathrm{~T}_{4}{ }^{\prime \prime}\right), 7.31$ (ddd, $J=5.7,1.6,0.8 \mathrm{~Hz}, 1 \mathrm{H}, 7$ ), $7.25(\mathrm{ddd}, J=7.2,5.7,1.3 \mathrm{~Hz}, 1 \mathrm{H}, 8), 5.11(\mathrm{~d}, J=3.7 \mathrm{~Hz}, 0.5 \mathrm{H}, \mathrm{H}-1 \alpha)$, $4.44(\mathrm{~d}, J=7.8 \mathrm{~Hz}, 0.5 \mathrm{H}, \mathrm{H}-1 \beta), 3.98-3.05(\mathrm{~m}, 15 \mathrm{H}), 1.95(\mathrm{t}, J=5.5$ $\left.\mathrm{Hz}, 2 \mathrm{H}, 2 \times \mathrm{CH}_{2} \mathrm{SMe}\right), 1.43\left(\mathrm{~s}, 1.5 \mathrm{H}, \mathrm{CH}_{2} \mathrm{SMe}\right), 1.43(\mathrm{~s}, 1.5 \mathrm{H}$, $\left.\mathrm{CH}_{2} \mathrm{SMe}\right) ;{ }^{13} \mathrm{C}$ NMR $\left(126 \mathrm{MHz}, \mathrm{CD}_{3} \mathrm{OD}\right) \delta 159.3\left(\mathrm{C}_{\mathrm{q} \text { arom }}\right), 158.8$ $\left(\mathrm{C}_{\mathrm{q} \text { arom }}\right), 158.2\left(\mathrm{C}_{\mathrm{q} \text { arom }}\right), 158.0\left(\mathrm{C}_{\mathrm{q} \text { arom }}\right), 154.4\left(\mathrm{C}_{\mathrm{H}} \mathrm{T}_{3}\right), 154.4\left(\mathrm{C}_{\mathrm{H}}\right.$ $\left.\mathrm{T}_{3}{ }^{\prime}\right), 153.4\left(\mathrm{C}_{\mathrm{H}} 1\right), 150.8\left(\mathrm{C}_{\mathrm{H}} 7\right), 140.2\left(\mathrm{C}_{\mathrm{H}} \mathrm{T}_{5}, \mathrm{~T}_{5}{ }^{\prime \prime}\right), 139.6\left(\mathrm{C}_{\mathrm{H}} \mathrm{T}_{4}{ }^{\prime}\right)$, $139.4\left(\mathrm{C}_{\mathrm{H}} 9\right), 138.3\left(\mathrm{C}_{\mathrm{H}} 3\right), 129.9\left(\mathrm{C}_{\mathrm{H}} \mathrm{T}_{4}, \mathrm{~T}_{4}{ }^{\prime \prime}\right), 129.3\left(\mathrm{C}_{\mathrm{H}} 2\right), 128.4$ $\left(\mathrm{C}_{\mathrm{H}} 8\right), 126.3\left(\mathrm{C}_{\mathrm{H}} \mathrm{T}_{6}, \mathrm{~T}_{6}{ }^{\prime \prime}\right), 125.9\left(\mathrm{C}_{\mathrm{H}} 4\right), 125.5\left(\mathrm{C}_{\mathrm{H}} \mathrm{T}_{3}{ }^{\prime}, \mathrm{T}_{5}{ }^{\prime}\right), 125.2$ $\left(\mathrm{C}_{\mathrm{H}} 10\right), 98.3(\mathrm{C}-1 \beta), 93.9(\mathrm{C}-1 \alpha), 80.6,80.4,78.1,77.0,76.3,74.9$, 73.8, 72.8, 72.0, 71.9, 71.3, 71.2, 71.2, 68.4, 68.4, $62.5(\mathrm{C}-6 \alpha / \beta), 62.4$ $(\mathrm{C}-6 \alpha / \beta), 35.7\left(\mathrm{CH}_{2} \mathrm{SMe}\right), 35.6\left(\mathrm{CH}_{2} \mathrm{SMe}\right), 15.3\left(2 \times \mathrm{CH}_{2} \mathrm{SMe}\right)$; HRMS (ESI) $m / z[\mathrm{M}+\mathrm{H}]^{2+}$ calcd for $\mathrm{C}_{38} \mathrm{H}_{45} \mathrm{~N}_{5} \mathrm{O}_{8} \mathrm{RuS} 416.6011$, found 416.6026 . Elemental analysis calcd $(\%)$ for $[8] \mathrm{PF}_{6} \cdot 2.5 \mathrm{H}_{2} \mathrm{O}: \mathrm{C}$, 44.62; H, 4.93; N, 6.85. Found: 45.17; H, 5.16; N, 6.55.

$[R u(t p y)(b p y)(50)] P F_{6}\left([9] P F_{6}\right)$. The title compound was synthesized analogous according to the procedure described for $[1]\left(\mathrm{PF}_{6}\right)_{2}$ using $[\mathrm{Ru}(\mathrm{tpy})(\mathrm{bpy}) \mathrm{Cl})] \mathrm{Cl}(58.8 \mathrm{mg}, 0.105 \mathrm{mmol})$ and $\mathbf{H 5 0}$ (42.0 mg, 123 $\mu \mathrm{mol})$ in $\mathrm{H}_{2} \mathrm{O}(18 \mathrm{~mL})$, affording the title compound as a red solid (23.5 mg, 24.1 $\mu \mathrm{mol}, 23 \%): R_{f}=0.36(16 / 4 / 1$ acetone/water $/ 1 \mathrm{M}$ $\mathrm{HCl}) ;{ }^{1} \mathrm{H}$ NMR $\left(500 \mathrm{MHz}, \mathrm{CD}_{3} \mathrm{OD}\right) \delta 9.86(\mathrm{ddd}, J=5.6,1.5,0.7 \mathrm{~Hz}$, $1 \mathrm{H}, 1), 8.89-8.87(\mathrm{~m}, 1 \mathrm{H}, 4), 8.85\left(\mathrm{~d}, J=8.2 \mathrm{~Hz}, 2 \mathrm{H}, \mathrm{T}_{3}{ }^{\prime}, \mathrm{T}_{5}{ }^{\prime}\right), 8.69$ (dd, $\left.J=8.2,1.2 \mathrm{~Hz}, 2 \mathrm{H}, \mathrm{T}_{6}, \mathrm{~T}_{6}{ }^{\prime \prime}\right), 8.67-8.62(\mathrm{~m}, 1 \mathrm{H}, 10), 8.50-8.41$ $\left(\mathrm{m}, 2 \mathrm{H}, \mathrm{T}_{4}{ }^{\prime}, 3\right), 8.16-8.10\left(\mathrm{~m}, 3 \mathrm{H}, \mathrm{T}_{5}, \mathrm{~T}_{5}{ }^{\prime \prime}, 2\right), 7.97(\mathrm{td}, J=7.8,1.5 \mathrm{~Hz}$, $1 \mathrm{H}, 9), 7.84$ (ddd, $J=5.6,1.5,0.7 \mathrm{~Hz}, 2 \mathrm{H}, \mathrm{T}_{3}, \mathrm{~T}_{3}{ }^{\prime \prime}$ ), 7.50 (ddd, $J=7.2$, $\left.5.6,1.4 \mathrm{~Hz}, 2 \mathrm{H}, \mathrm{T}_{4}, \mathrm{~T}_{4}{ }^{\prime \prime}\right), 7.33(\mathrm{dq}, J=5.9,0.9 \mathrm{~Hz}, 1 \mathrm{H}, 7), 7.26(\mathrm{ddd}, J=$ $7.2,5.7,1.3 \mathrm{~Hz}, 1 \mathrm{H}, 8), 5.10(\mathrm{~d}, J=3.6 \mathrm{~Hz}, 0.5 \mathrm{H}, \mathrm{H}-1 \alpha), 4.50(\mathrm{~d}, J=7.6$ $\mathrm{Hz}, 0.5 \mathrm{H}, \mathrm{H}-1 \beta), 3.99-3.08(\mathrm{~m}, 15 \mathrm{H}), 1.96(\mathrm{t}, J=5.5 \mathrm{~Hz}, 2 \mathrm{H}, 2 \times$ $\left.\mathrm{CH}_{2} \mathrm{SMe}\right), 1.44$ (s, $\left.3 \mathrm{H}, 2 \times \mathrm{CH}_{2} \mathrm{SMe}\right) ;{ }^{13} \mathrm{C} \mathrm{NMR}\left(126 \mathrm{MHz}, \mathrm{CD}_{3} \mathrm{OD}\right)$ $\delta 159.3\left(\mathrm{C}_{\mathrm{q} \text { arom }}\right), 158.8\left(\mathrm{C}_{\mathrm{q}}\right.$ arom $), 158.2\left(\mathrm{C}_{\mathrm{q} \text { arom }}\right), 158.0\left(\mathrm{C}_{\mathrm{q} \text { arom }}\right)$, $154.4\left(\mathrm{C}_{\mathrm{H}} \mathrm{T}_{3}^{\prime}\right), 153.4\left(\mathrm{C}_{\mathrm{H}} 1\right), 150.8\left(\mathrm{C}_{\mathrm{H}} 7\right), 140.2\left(\mathrm{C}_{\mathrm{H}} \mathrm{T}_{5}, \mathrm{~T}_{5}{ }^{\prime \prime}\right), 139.6$ $\left(\mathrm{C}_{\mathrm{H}} \mathrm{T}_{4}{ }^{\prime}\right), 139.4\left(\mathrm{C}_{\mathrm{H}} 9\right), 138.3\left(\mathrm{C}_{\mathrm{H}} 3\right), 129.9\left(\mathrm{C}_{\mathrm{H}} \mathrm{T}_{4}, \mathrm{~T}_{4}{ }^{\prime \prime}\right), 129.3\left(\mathrm{C}_{\mathrm{H}}\right.$ 2), $128.4\left(\mathrm{C}_{\mathrm{H}} 8\right), 126.3\left(\mathrm{C}_{\mathrm{H}} \mathrm{T}_{6}, \mathrm{~T}_{6}{ }^{\prime \prime}\right), 126.0\left(\mathrm{C}_{\mathrm{H}} 4\right), 125.6\left(\mathrm{C}_{\mathrm{H}} \mathrm{T}_{3}{ }^{\prime}\right)$, $125.5\left(\mathrm{C}_{\mathrm{H}} \mathrm{T}_{5}{ }^{\prime}\right), 125.1\left(\mathrm{C}_{\mathrm{H}} 10\right), 98.2(\mathrm{C}-1 \beta), 94.0(\mathrm{C}-1 \alpha), 87.6,84.4$, 77.8, 76.1, 73.7, 73.0, 73.0, 73.0, 72.0, 72.0, 71.3, 71.3, 71.2, 71.2, 71.1, 68.4, 68.3, 62.6 (C-6 $\alpha / \beta), 62.5(\mathrm{C}-6 \alpha / \beta), 35.7\left(2 \times \mathrm{CH}_{2} \mathrm{SMe}\right), 15.4(2$ $\times \mathrm{CH}_{2} \mathrm{SMe}$ ); HRMS (ESI) $m / z[\mathrm{M}+\mathrm{H}]^{2+}$ calcd for $\mathrm{C}_{38} \mathrm{H}_{45} \mathrm{~N}_{5} \mathrm{O}_{8} \mathrm{RuS}$ 416.6011, found 416.6026. Elemental analysis calcd (\%) for [9] $\mathrm{PF}_{6}$. $2 \mathrm{H}_{2} \mathrm{O}: \mathrm{C}, 45.02 ; \mathrm{H}, 4.87$; N, 6.91. Found: C, 44.88; H, 4.59; N, 6.78.

$[R u(S-t p y)(b p y)(26)] P F_{6}\left([10] P F_{6}\right)$. A deoxygenated solution of 31 (40.0 mg, $0.0661 \mathrm{mmol})$ and $26(48.0 \mathrm{mg}, 0.140 \mathrm{mmol})$ in $\mathrm{H}_{2} \mathrm{O}(11$ $\mathrm{mL}$ ) was heated at $80{ }^{\circ} \mathrm{C}$ for $16 \mathrm{~h}$, after which it was concentrated in vacuo. The resulting residue was then purified over silica $(100 / 0 / 0$ to $100 / 95 / 5$ in acetone/water/aq $\mathrm{KPF}_{6}$ ), followed by purification over Sephadex LH-20 (MeOH) to afford the title compound as a red microcrystalline solid (18 mg, $24.4 \mu \mathrm{mol}, 37 \%): R_{f}=0.46(100 / 80 / 20$ acetone/water/aq $\left.\mathrm{KPF}_{6}\right) ;{ }^{1} \mathrm{H} \mathrm{NMR}\left(500 \mathrm{MHz}, \mathrm{CD}_{3} \mathrm{OD}\right) \delta=9.84(\mathrm{~d}, J$ $=5.9 \mathrm{~Hz}, 1 \mathrm{H}, 1), 9.03\left(\mathrm{~s}, 2 \mathrm{H}, \mathrm{T}_{3}{ }^{\prime}, \mathrm{T}_{5}{ }^{\prime}\right), 8.81(\mathrm{~d}, J=8.2 \mathrm{~Hz}, 1 \mathrm{H}, 4), 8.73$ $\left(\mathrm{d}, J=8.1 \mathrm{~Hz}, 2 \mathrm{H}, \mathrm{T}_{6}, \mathrm{~T}_{6}{ }^{\prime \prime}\right), 8.58(\mathrm{~d}, J=8.2 \mathrm{~Hz}, 1 \mathrm{H}, 10), 8.43(\mathrm{t}, J=7.9$ $\mathrm{Hz}, 1 \mathrm{H}, 3), 8.13\left(\mathrm{dt}, J=13.2,7.4 \mathrm{~Hz}, 3 \mathrm{H}, 2, \mathrm{~T}_{4}, \mathrm{~T}_{4}{ }^{\prime \prime}\right), 7.95(\mathrm{t}, J=7.7 \mathrm{~Hz}$, $1 \mathrm{H}, 9), 7.81\left(\mathrm{~d}, J=5.9 \mathrm{~Hz}, 2 \mathrm{H}, \mathrm{T}_{3}, \mathrm{~T}_{3}{ }^{\prime \prime}\right), 7.60-7.43\left(\mathrm{~m}, 2 \mathrm{H}, \mathrm{T}_{5}, \mathrm{~T}_{5}{ }^{\prime \prime}\right)$, $7.25(\mathrm{dt}, J=12.7,6.0 \mathrm{~Hz}, 2 \mathrm{H}, 8,7), 4.30(\mathrm{~d}, J=7.8 \mathrm{~Hz}, 1 \mathrm{H}, \mathrm{H}-1), 4.00$ (dd, $\left.J=10.6,5.3 \mathrm{~Hz}, 1 \mathrm{H}, \mathrm{CHH} \mathrm{OCH}{ }_{2}\right), 3.86(\mathrm{~d}, J=12.0 \mathrm{~Hz}, 1 \mathrm{H}, \mathrm{CHH}$ $\mathrm{H}-6), 3.67$ (m, 4H, CHH H-6, CHH OCH $2,2 \times \mathrm{OCH}_{2}$ ), 3.57 (dd, $J=$ $\left.5.7,3.4 \mathrm{~Hz}, 2 \mathrm{H}, \mathrm{OCH}_{2}\right), 3.48\left(\mathrm{dd}, J=5.8,3.4 \mathrm{~Hz}, 2 \mathrm{H}, \mathrm{OCH}_{2}\right), 3.44(\mathrm{t}, J$ $\left.=5.5 \mathrm{~Hz}, 2 \mathrm{H}, \mathrm{OCH}_{2}\right), 3.41-3.36(\mathrm{~m}, 1 \mathrm{H}, \mathrm{H}-3), 3.29(\mathrm{~m}, 2 \mathrm{H}, \mathrm{H}-4, \mathrm{H}-$ 5), $3.14(\mathrm{t}, J=8.5 \mathrm{~Hz}, 1 \mathrm{H}, \mathrm{H}-2), 1.91\left(\mathrm{t}, J=5.5 \mathrm{~Hz}, 2 \mathrm{H}, \mathrm{CH}_{2} \mathrm{SMe}\right), 1.41$ (s, 3H, $\left.\mathrm{CH}_{2} \mathrm{SMe}\right) ;{ }^{13} \mathrm{C} \mathrm{NMR}\left(126 \mathrm{MHz}, \mathrm{CD}_{3} \mathrm{OD}\right) \delta 159.2\left(\mathrm{C}_{\mathrm{q} \text { arom }}\right)$, $158.7\left(\mathrm{C}_{\mathrm{q} \text { arom }}\right), 157.9\left(\mathrm{C}_{\mathrm{q} \text { arom }}\right), 157.7\left(\mathrm{C}_{\mathrm{q}}\right.$ arom $), 154.8\left(\mathrm{C}_{\mathrm{q} \text { arom }}\right), 154.2$ $\left(\mathrm{C}_{\mathrm{H}} \mathrm{T}_{3}, \mathrm{~T}_{3}{ }^{\prime \prime}\right), 153.2\left(\mathrm{C}_{\mathrm{H}} 1\right), 150.6\left(\mathrm{C}_{\mathrm{H}} 7\right), 140.4\left(\mathrm{C}_{\mathrm{H}} \mathrm{T}_{4}, \mathrm{~T}_{4}{ }^{\prime \prime}\right), 139.8$ $\left(\mathrm{C}_{\mathrm{H}} 3\right), 139.6\left(\mathrm{C}_{\mathrm{H}} 9\right), 130.2\left(\mathrm{C}_{\mathrm{H}} \mathrm{T}_{5}, \mathrm{~T}_{5}{ }^{\prime \prime}\right), 129.3\left(\mathrm{C}_{\mathrm{H}} 8\right)$ 128.5 $\left(\mathrm{C}_{\mathrm{H}} 2\right)$, $126.7\left(\mathrm{C}_{\mathrm{H}} \mathrm{T}_{6}, \mathrm{~T}_{6}{ }^{\prime \prime}\right), 125.9\left(\mathrm{C}_{\mathrm{H}} 4\right), 125.1\left(\mathrm{C}_{\mathrm{H}} 10\right), 121.7\left(\mathrm{CH} \mathrm{T}_{3}{ }^{\prime}, \mathrm{T}_{5}{ }^{\prime}\right)$, 104.2 (C-1), 77.8 (C-3, C-5), 74.9 (C-2), 71.4 (C-5), $71.1\left(\mathrm{OCH}_{2}\right)$, $71.0\left(\mathrm{OCH}_{2}\right), 69.7\left(\mathrm{OCH}_{2}\right), 68.0\left(\mathrm{OCH}_{2}\right), 62.5(\mathrm{C}-6), 35.2$ $\left(\mathrm{CH}_{2} \mathrm{SMe}\right), 15.2\left(\mathrm{CH}_{2} \mathrm{SMe}\right)$; HRMS (ESI) $\mathrm{m} / z[\mathrm{M}]^{+}$calcd for $\mathrm{C}_{38} \mathrm{H}_{44} \mathrm{~N}_{5} \mathrm{O}_{11} \mathrm{RuS}_{2}$ 912.1517, found 912.1543. Elemental analysis calcd (\%) for $[10] \mathrm{PF}_{6} \cdot 0.5 \mathrm{KPF}_{6} \cdot 5 \mathrm{H}_{2} \mathrm{O}: \mathrm{C}, 36.84 ; \mathrm{H}, 4.39 ; \mathrm{N}, 5.65$. Found: 36.83; H, 4.40; N, 5.36 .

$\Delta / \Lambda-[R u(t p y)(b p y)(28)]\left(P F_{6}\right)_{2}\left([11] C l_{2}\right) .\left[\mathrm{Ru}\left(\mathrm{bpy}_{2}\right) \mathrm{Cl}_{2}\right](73.0 \mathrm{mg}$, $0.151 \mathrm{mmol})$ and $28(46.0 \mathrm{mg}, 0.146 \mathrm{mmol})$ were dissolved in deoxygenated $\mathrm{H}_{2} \mathrm{O}(10 \mathrm{~mL})$, and this mixture was heated at $80^{\circ} \mathrm{C}$ for $16 \mathrm{~h}$, after which the mixture was concentrated in vacuo. Purification by Sephadex LH-20 (MeOH) afforded the title compound as an inseparable mixture of diastereomers $(69.0 \mathrm{mg}, 0.0864 \mathrm{mmol}, 59 \%)$ : $R_{f}=0.28(16 / 4 / 1$ acetone/water $/ 1 \mathrm{M} \mathrm{HCl}) ;{ }^{1} \mathrm{H} \mathrm{NMR}(500 \mathrm{MHz}$, $\left.\mathrm{CD}_{3} \mathrm{OD}\right) \delta 10.02(\mathrm{dd}, J=5.7,1.4 \mathrm{~Hz}, 1 \mathrm{H}), 9.86(\mathrm{dd}, J=5.7,1.4 \mathrm{~Hz}$, $1 \mathrm{H}), 9.50(\mathrm{dd}, J=5.7,1.4 \mathrm{~Hz}, 1 \mathrm{H}), 9.42(\mathrm{dd}, J=5.7,1.3 \mathrm{~Hz}, 1 \mathrm{H}), 8.81$ $(\mathrm{d}, J=8.2 \mathrm{~Hz}, 2 \mathrm{H}), 8.79-8.76(\mathrm{~m}, 2 \mathrm{H}), 8.69-8.62(\mathrm{~m}, 4 \mathrm{H}), 8.45-8.36$ $(\mathrm{m}, 4 \mathrm{H}), 8.12(\mathrm{tt}, J=8.0,1.8 \mathrm{~Hz}, 4 \mathrm{H}), 8.06(\mathrm{dddd}, J=13.5,7.3,5.6,1.4$ $\mathrm{Hz}, 5 \mathrm{H}), 7.63(\mathrm{td}, J=5.7,1.4 \mathrm{~Hz}, 2 \mathrm{H}), 7.57$ (ddd, $J=7.5,5.7,1.4 \mathrm{~Hz}$, $2 \mathrm{H}), 7.49-7.42(\mathrm{~m}, 4 \mathrm{H}), 4.65(\mathrm{~d}, J=7.8 \mathrm{~Hz}, 1 \mathrm{H}), 4.58(\mathrm{~d}, J=7.8 \mathrm{~Hz}$, $1 \mathrm{H}), 3.92$ (ddd, $J=19.8,11.8,1.9 \mathrm{~Hz}, 2 \mathrm{H}), 3.78-3.70(\mathrm{~m}, 1 \mathrm{H}), 3.62$ $(\mathrm{dd}, J=11.9,6.4 \mathrm{~Hz}, 1 \mathrm{H}), 3.50-3.35(\mathrm{~m}, 10 \mathrm{H}), 3.30(\mathrm{t}, J=8.2 \mathrm{~Hz}, 1 \mathrm{H})$, $3.27-3.20(\mathrm{~m}, 2 \mathrm{H}), 3.13(\mathrm{dd}, J=14.0,6.4 \mathrm{~Hz}, 1 \mathrm{H}), 3.02(\mathrm{dd}, J=13.9$, $7.1 \mathrm{~Hz}, 1 \mathrm{H}), 2.92(\mathrm{dd}, J=13.1,2.1 \mathrm{~Hz}, 1 \mathrm{H}), 2.80(\mathrm{dd}, J=13.1,1.7 \mathrm{~Hz}$, $1 \mathrm{H}), 1.53(\mathrm{~s}, 3 \mathrm{H}), 1.50(\mathrm{~s}, 3 \mathrm{H}), 1.25(\mathrm{~s}, 3 \mathrm{H}), 1.23(\mathrm{~s}, 3 \mathrm{H}) ;{ }^{13} \mathrm{C} \mathrm{NMR}$ $\left(126 \mathrm{MHz}, \mathrm{CD}_{3} \mathrm{OD}\right) \delta 159.1,159.1,159.0,158.9,158.1,158.0,157.9$, $155.4,155.0,154.9,154.8,152.0,152.0,151.9,151.9,140.3,140.2$, 
$130.8,130.0,129.9,129.5,129.3,129.0,129.0,128.9,126.2,126.1$, 126.0, 125.6, 125.6, 125.5, 125.4, 104.2, 103.6, 78.4, 78.3, 78.3, 78.2, 75.3, 75.3, 75.2, 71.6, 71.6, 62.7, 40.5, 38.6, 38.4, 37.4, 18.5, 18. 1, 16.1, 16.0; HRMS (ESI) $m / z[\mathrm{M}]^{2+}$ calcd for $\mathrm{C}_{31} \mathrm{H}_{38} \mathrm{~N}_{4} \mathrm{O}_{6} \mathrm{RuS}_{2}$ 364.0633, found 364.0646. Elemental analysis calcd (\%) for $[11] \mathrm{Cl}_{2} \cdot 3 \mathrm{H}_{2} \mathrm{O}: \mathrm{C}$, 43.66; H, 5.20; N, 6.57. Found: 43.34; H, 5.35; N, 6.29.

\section{ASSOCIATED CONTENT}

\section{(5) Supporting Information}

The Supporting Information is available free of charge on the ACS Publications website at DOI: 10.1021/acs.joc.8b01342.

${ }^{1} \mathrm{H}$ and ${ }^{13} \mathrm{C}$ spectra for $13,15,18,19,21-28,30-32$, 34-36, H37, 38, H40, 41-45, H46, 49, H50, [1]$\left(\mathrm{PF}_{6}\right)_{2}-[\mathbf{5}]\left(\mathrm{PF}_{6}\right)_{2},[\mathbf{6}] \mathrm{PF}_{6}-[\mathbf{1 0}] \mathrm{PF}_{6}$, and $[\mathbf{1 1}] \mathrm{Cl}_{2}(\mathrm{PDF})$

\section{AUTHOR INFORMATION}

\section{Corresponding Authors}

*(S.B.) E-mail: bonnet@chem.leidenuniv.nl.

*(L.N.L.) E-mail: 1.n.lameijer@rug.nl.

\section{ORCID $\odot$}

Lucien N. Lameijer: 0000-0003-2841-4742

Stefan van der Vorm: 0000-0002-4047-9373

Sylvestre Bonnet: 0000-0002-5810-3657

\section{Notes}

The authors declare no competing financial interest.

\section{ACKNOWLEDGMENTS}

This work was supported by the Dutch Organization for Scientific Research (NWO-CW) via a VIDI grant to S.B. The European Research Council is kindly acknowledged for a Starting Grant to S.B. Dr. Wouter F.J. Hogendorf is greatly acknowledged for providing scientific input. Professor Dr. Lies Bouwman and Anne-Geert Volbeda are kindly acknowledged for scientific discussion. Corjan van de Griend is kindly acknowledged for melting point measurements.

\section{REFERENCES}

(1) Schleifer, K. H.; Kandler, O. Peptidoglycan Types of Bacterial Cell-Walls and Their Taxonomic Implications. Bacteriol Rev. 1972, 36, 407.

(2) Sychantha, D.; Little, D. J.; Chapman, R. N.; Boons, G. J.; Robinson, H.; Howell, P. L.; Clarke, A. J. PatB1 is an Oacetyltransferase that decorates secondary cell wall polysaccharides. Nat. Chem. Biol. 2017, 14, 79.

(3) Caffall, K. H.; Mohnen, D. The structure, function, and biosynthesis of plant cell wall pectic polysaccharides. Carbohydr. Res. 2009, 344, 1879.

(4) Merzendorfer, H.; Zimoch, L. Chitin metabolism in insects: structure, function and regulation of chitin synthases and chitinases. J. Exp. Biol. 2003, 206, 4393.

(5) Brandley, B. K.; Schnaar, R. L. Cell-surface carbohydrates in cell recognition and response. J. Leukocyte Biol. 1986, 40, 97.

(6) Watson, J. D.; Crick, F. H. Molecular structure of nucleic acids; a structure for deoxyribose nucleic acid. Nature 1953, 171, 737.

(7) Zong, C.; Venot, A.; Li, X.; Lu, W.; Xiao, W.; Wilkes, J. L.; Salanga, C. L.; Handel, T. M.; Wang, L.; Wolfert, M. A.; Boons, G. J. Heparan Sulfate Microarray Reveals That Heparan Sulfate-Protein Binding Exhibits Different Ligand Requirements. J. Am. Chem. Soc. 2017, 139, 9534.

(8) Walvoort, M. T.; Testa, C.; Eilam, R.; Aharoni, R.; Nuti, F.; Rossi, G.; Real-Fernandez, F.; Lanzillo, R.; Brescia Morra, V.; Lolli, F.; Rovero, P.; Imperiali, B.; Papini, A. M. Antibodies from multiple sclerosis patients preferentially recognize hyperglucosylated adhesin of nontypeable Haemophilus influenzae. Sci. Rep. 2016, 6, 39430.
(9) Tornroth-Horsefield, S.; Neutze, R. Opening and closing the metabolite gate. Proc. Natl. Acad. Sci. U. S. A. 2008, 105, 19565.

(10) Vander Heiden, M. G.; Cantley, L. C.; Thompson, C. B. Understanding the Warburg effect: the metabolic requirements of cell proliferation. Science 2009, 324, 1029.

(11) Szablewski, L. Expression of glucose transporters in cancers. Biochim. Biophys. Acta, Rev. Cancer 2013, 1835, 164.

(12) Fowler, J. S.; Ido, T. Initial and subsequent approach for the synthesis of 18FDG. Semin. Nucl. Med. 2002, 32, 6.

(13) Calvaresi, E. C.; Hergenrother, P. J. Glucose conjugation for the specific targeting and treatment of cancer. Chem. Sci. 2013, 4, 2319.

(14) Patra, M.; Awuah, S. G.; Lippard, S. J. Chemical Approach to Positional Isomers of Glucose-Platinum Conjugates Reveals Specific Cancer Targeting through Glucose-Transporter-Mediated Uptake in Vitro and in Vivo. J. Am. Chem. Soc. 2016, 138, 12541.

(15) Patra, M.; Johnstone, T. C.; Suntharalingam, K.; Lippard, S. J. A Potent Glucose-Platinum Conjugate Exploits Glucose Transporters and Preferentially Accumulates in Cancer Cells. Angew. Chem., Int. Ed. 2016, 55, 2550.

(16) Petrig, J.; Schibli, R.; Dumas, C.; Alberto, R.; Schubiger, P. A. Derivatization of glucose and 2-deoxyglucose for transition metal complexation: substitution reactions with organometallic $99 \mathrm{mTc}$ and Re precursors and fundamental NMR investigations. Chem. - Eur. J. 2001, 7, 1868.

(17) Lameijer, L. N.; Brevé, T. G.; van Rixel, V. H. S.; Askes, S. H. C.; Siegler, M. A.; Bonnet, S. Effects of the Bidentate Ligand on the Photophysical Properties, Cellular Uptake, and (Photo)cytotoxicity of Glycoconjugates Based on the $[\mathrm{Ru}(\mathrm{tpy})(\mathrm{NN})(\mathrm{L})] 2+$ Scaffold. Chem. Eur. J. 2018, 24, 2709.

(18) Lameijer, L. N.; Hopkins, S. L.; Brevé, T. G.; Askes, S. H. C.; Bonnet, S. d- Versus l-Glucose Conjugation: Mitochondrial Targeting of a Light-Activated Dual-Mode-of-Action Ruthenium-Based Anticancer Prodrug. Chem. - Eur. J. 2016, 22, 18484.

(19) Cuello-Garibo, J.-A.; James, C. C.; Siegler, M. A.; Bonnet, S. Ruthenium-based PACT compounds based on an N,S non-toxic ligand: a delicate balance between photoactivation and thermal stability. Chemistry Squared 2017, 1, 2.

(20) Cuello-Garibo, J.-A.; Meijer, M. S.; Bonnet, S. To cage or to be caged? The cytotoxic species in ruthenium-based photoactivated chemotherapy is not always the metal. Chem. Commun. 2017, 53, 6768.

(21) Goldbach, R. E.; Rodriguez-Garcia, I.; Lenthe, J. H. v.; Siegler, M. A.; Bonnet, S. N-Acetylmethionine and Biotin as Photocleavable Protective Groups for Ruthenium Polypyridyl Complexes. Chem. - Eur. J. 2011, 17, 9924.

(22) Kulishkin, N. T.; Mashkina, A. V. Deactivation of rhodium and palladium catalysts by sulfur compounds. React. Kinet. Catal. Lett. 1991, 45,41 .

(23) Hermann, J. C.; Chen, Y.; Wartchow, C.; Menke, J.; Gao, L.; Gleason, S. K.; Haynes, N. E.; Scott, N.; Petersen, A.; Gabriel, S.; Vu, B.; George, K. M.; Narayanan, A.; Li, S. H.; Qian, H.; Beatini, N.; Niu, L.; Gan, Q. F. Metal impurities cause false positives in high-throughput screening campaigns. ACS Med. Chem. Lett. 2013, 4, 197.

(24) van der Vorm, S.; Hansen, T.; Overkleeft, H. S.; van der Marel, G. A.; Codee, J. D. C. The influence of acceptor nucleophilicity on the glycosylation reaction mechanism. Chem. Sci. 2017, 8, 1867.

(25) Davis, B. G.; Maughan, M. A. T.; Green, M. P.; Ullman, A.; Jones, J. B. Glycomethanethiosulfonates: powerful reagents for protein glycosylation. Tetrahedron: Asymmetry 2000, 11, 245.

(26) Valerio, S.; Iadonisi, A.; Adinolfi, M.; Ravida, A. Novel approaches for the synthesis and activation of thio- and selenoglycoside donors. J. Org. Chem. 2007, 72, 6097.

(27) Fraser-Reid, B.; Wu, Z.; Udodong, U. E.; Ottosson, H. Armed/ disarmed effects in glycosyl donors: rationalization and sidetracking. J. Org. Chem. 1990, 55, 6068.

(28) Yang, Z.; Lin, W.; Yu, B. Rearrangement of sugar 1,2-orthoesters to glycosidic products: a mechanistic implication. Carbohydr. Res. 2000, 329, 879.

(29) Park, J.; Um, J. I.; Jo, A.; Lee, J.; Jung, D. W.; Williams, D. R.; Park, S. B. Impact of molecular charge on GLUT-specific cellular 
uptake of glucose bioprobes and in vivo application of the glucose bioprobe, GB2-Cy3. Chem. Commun. 2014, 50, 9251.

(30) Machan, C. W.; Adelhardt, M.; Sarjeant, A. A.; Stern, C. L.; Sutter, J.; Meyer, K.; Mirkin, C. A. One-pot synthesis of an Fe(II) bisterpyridine complex with allosterically regulated electronic properties. J. Am. Chem. Soc. 2012, 134, 16921.

(31) Dumas, C.; Schibli, R.; Schubiger, P. A. Versatile routes to C-2and C-6-functionalized glucose derivatives of iminodiacetic acid. J. Org. Chem. 2003, 68, 512.

(32) Li, Y.; Manickam, G.; Ghoshal, A.; Subramaniam, P. More Efficient Palladium Catalyst for Hydrogenolysis of Benzyl Groups. Synth. Commun. 2006, 36, 925.

(33) Grue-Sørensen, G.; Kelstrup, E.; Kjær, A.; Madsen, J. Ø. Diastereospecific, enzymically catalysed transmethylation from $S$ methyl-L-methionine toL-homocysteine, a naturally occurring process. J. Chem. Soc., Perkin Trans. 1 1984, 1091.

(34) Miao, Y.; Rousseau, C.; Mortreux, A.; Martin, P.; Zinck, P. Access to new carbohydrate-functionalized polylactides via organocatalyzed ring-opening polymerization. Polymer 2011, 52, 5018.

(35) Gervay, J.; Danishefsky, S. A stereospecific route to 2deoxy-.beta.-glycosides. J. Org. Chem. 1991, 56, 5448.

(36) Halcomb, R. L.; Danishefsky, S. J. On the direct epoxidation of glycals: application of a reiterative strategy for the synthesis of.beta.linked oligosaccharides. J. Am. Chem. Soc. 1989, 111, 6661.

(37) Volbeda, A. G.; Kistemaker, H. A.; Overkleeft, H. S.; van der Marel, G. A.; Filippov, D. V.; Codee, J. D. Chemoselective Cleavage of p-Methoxybenzyl and 2-Naphthylmethyl Ethers Using a Catalytic Amount of $\mathrm{HCl}$ in Hexafluoro-2-propanol. J. Org. Chem. 2015, 80, 8796.

(38) Doi, J. T.; Luehr, G. W. Thioether protection via selectively cleavable sulfonium salts. Tetrahedron Lett. 1985, 26, 6143.

(39) Hu, F.; Chen, Z.; Zhang, L.; Shen, Y.; Wei, L.; Min, W. Vibrational Imaging of Glucose Uptake Activity in Live Cells and Tissues by Stimulated Raman Scattering. Angew. Chem., Int. Ed. 2015, $54,9821$.

(40) Xue, X.; Yin, Z.; Meng, X.; Li, Z. A carbohydrate-based approach for the total synthesis of $(-)$-dinemasone $B,(+)$-4a-epi-dinemasone $B$, (-)-7-epi-dinemasone B, and (+)-4a,7-Di-epi-dinemasone B. J. Org. Chem. 2013, 78, 9354.

(41) Shing, T. K. M.; Zhong, Y.-L. Ring-selective synthesis of Oheterocycles from acyclic 3-O-allyl-monosaccharides via intramolecular nitrone-alkene cycloaddition. Tetrahedron 2001, 57, 1573.

(42) Kaji, E.; Lichtenthaler, F. W.; Osa, Y.; Takahashi, K.; Zen, S. A Practical Synthesis of Mannosaminyl- $\beta(1 \rightarrow 4)$-glucosyl- $\alpha(1 \rightarrow 2)$-rhamnose, the Trisaccharide Repeating Unit of aStreptococcus pneumoniaeCapsular Polysaccharide. Bull. Chem. Soc. Jpn. 1995, 68, 2401.

(43) Morin, C.; Ogier, L. Synthesis of 4-O- and 6-O-(2'-iodoethyl)-dglucose. Carbohydr. Res. 1998, 310, 277.

(44) Wark, T. A.; Stephan, D. W. Early metal thiolato species as metalloligands in the formation of early/late heterobimetallic complexes: syntheses and molecular structures of $\mathrm{Cp} 2 \mathrm{Ti}(\mathrm{SMe}) 2$, $\mathrm{Cp} 2 \mathrm{~V}(\mathrm{SMe}) 2$, (Cp2Ti(.mu.-SMe)2)2Ni and (Ni(.mu.-SMe)2)6. Organometallics 1989, 8, 2836.

(45) Muhlhausen, U.; Schirrmacher, R.; Piel, M.; Lecher, B.; Briegert, M.; Piee-Staffa, A.; Kaina, B.; Rosch, F. Synthesis of 131I-labeled glucose-conjugated inhibitors of O6-methylguanine-DNA methyltransferase (MGMT) and comparison with nonconjugated inhibitors as potential tools for in vivo MGMT imaging. J. Med. Chem. 2006, 49, 263.

(46) Wang, Q.; Day, P.; Griffiths, J. P.; Nie, H.; Wallis, J. D. Synthetic strategies for preparing BEDT-TTF derivatives functionalised with metal ion binding groups. New J. Chem. 2006, 30, 1790.

\section{NOTE ADDED AFTER ISSUE PUBLICATION}

Due to a production error, the corresponding author details for the first author were inadvertently omitted in the version that published on November 2, 2018. The authorship has been corrected and reposted on November 5, 2018. 